\title{
Near Source Recording of the Depth of Burial Experiment at Shagan River, Kazakhstan: Data Report
}

\author{
W.S. Phillips \\ D.C. Pearson \\ C.L. Edwards \\ D.F. Baker \\ M.D. Denny
}

July 1998

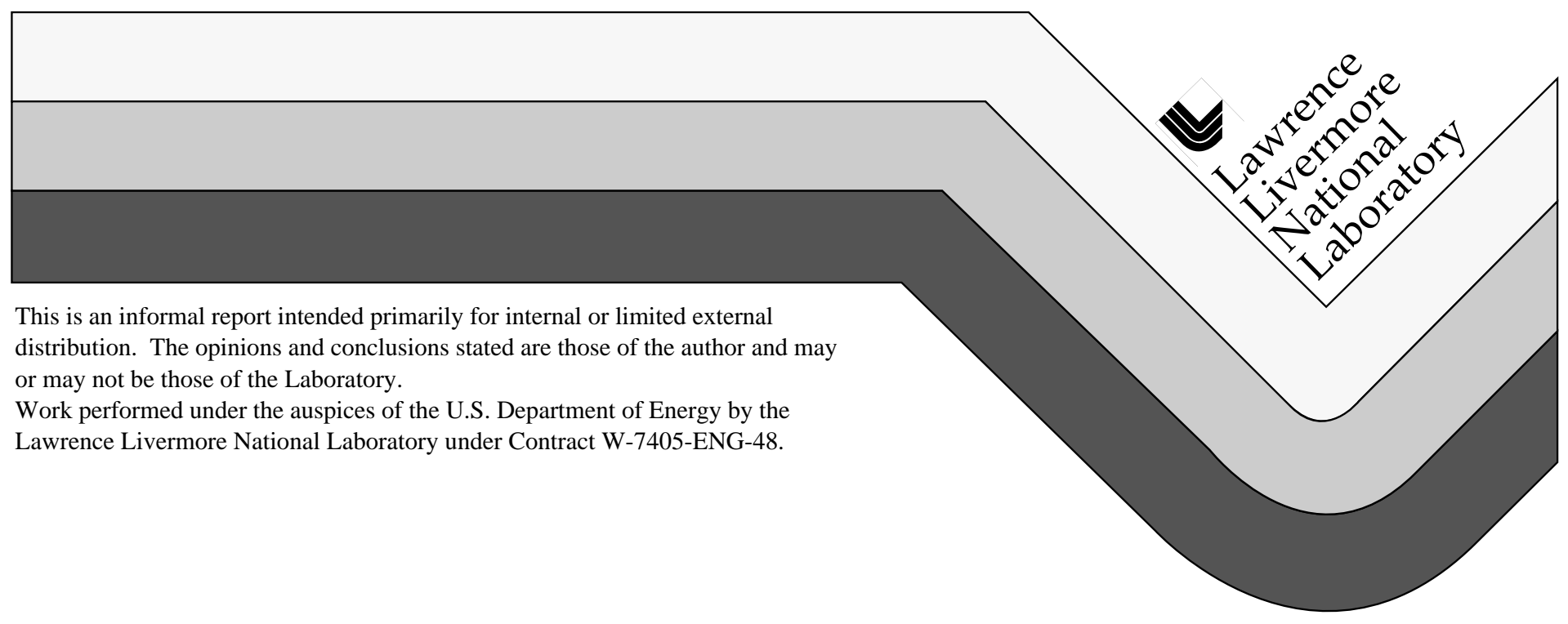




\section{DISCLAIMER}

This document was prepared as an account of work sponsored by an agency of the United States Government. Neither the United States Government nor the University of California nor any of their employees, makes any warranty, express or implied, or assumes any legal liability or responsibility for the accuracy, completeness, or usefulness of any information, apparatus, product, or process disclosed, or represents that its use would not infringe privately owned rights. Reference herein to any specific commercial product, process, or service by trade name, trademark, manufacturer, or otherwise, does not necessarily constitute or imply its endorsement, recommendation, or favoring by the United States Government or the University of California. The views and opinions of authors expressed herein do not necessarily state or reflect those of the United States Government or the University of California, and shall not be used for advertising or product endorsement purposes.

This report has been reproduced directly from the best available copy.

Available to DOE and DOE contractors from the Office of Scientific and Technical Information P.O. Box 62, Oak Ridge, TN 37831

Prices available from (423) 576-8401

Available to the public from the National Technical Information Service

U.S. Department of Commerce 5285 Port Royal Rd. Springfield, VA 22161 


\section{NEAR SOURCE RECORDING \\ OF THE DEPTH OF BURIAL EXPERIMENT \\ AT SHAGAN RIVER, KAZAKHSTAN: \\ DATA REPORT}

The LANL CTBT Seismic Field Experimentation Team

Authors:

W.S. Phillips ${ }^{1}$, D.C. Pearson ${ }^{1}$, C.L. Edwards ${ }^{1}$, D.F. Baker ${ }^{1}$ and M.D. Denny ${ }^{2}$

${ }^{1}$ Los Alamos National Laboratory, ${ }^{2}$ Lawrence Livermore National Laboratory,

Sponsored by US Department of Energy

Office of Nonproliferation and National Security

Office of Research and Development

Contract No. W-7405-ENG-36
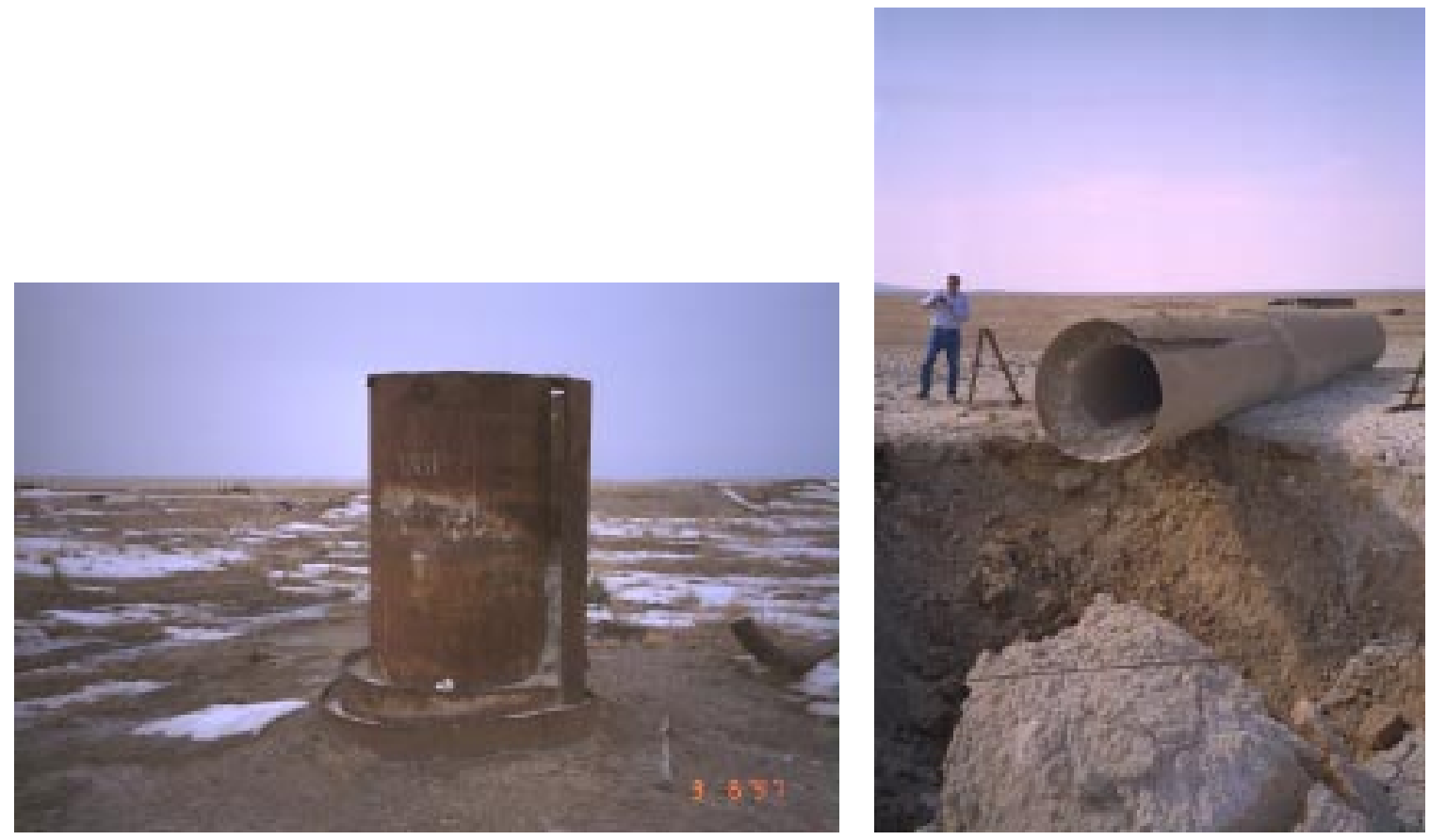

July, 1998 



\section{SUMMARY}

The seismic field experimentation team at Los Alamos National Laboratory collaborated with Lawrence Livermore, the Defense Special Weapons Agency and the National Nuclear Center of the Republic of Kazakhstan to record the Source Depth of Burial Experiment during the summer of 1997. A series of three 25 ton explosions at depths of 50, 300 and 550 meters along with associated 50 to $100 \mathrm{~kg}$ Green's function explosions and a 5 ton proof of concept explosion were instrumented at near source $(0.1$ to $20 \mathrm{~km})$ and regional distances (100 to $1100 \mathrm{~km}$ ) using portable seismic data acquisition equipment. Los Alamos was responsible for the nearsource deployment. These data represent the first U.S. recordings of seismic data on the former Soviet Union's Semipalatinsk nuclear test site.

The main objective of the experiment was to test whether effects of source depth can help to discriminate between underground nuclear explosions (deep) and large industrial explosions (shallow) using observations at regional distance ranges. The close-in records help to separate the effects of source and path on the regional signals. A secondary objective was to help calibrate the Kazakhstan seismic network.

Near-source records show the $50 \mathrm{~m}$ deep explosion generated higher amplitude surface waves than did either of the deeper explosions. Impulsive P-wave arrivals dominated the traces from the 300 and 550 meter deep explosions. Amplitudes from the 5 ton explosion were an order of magnitude smaller than the 25 ton explosions, twice as small as expected, perhaps due to a near-source geology effect. Empirical Green's function results for the 25 ton shots show increasing corner frequency with depth, consistent with the MuellerMurphy source model which predicts a decreasing elastic cavity radius, thus an increasing corner frequency with depth. A larger elastic radius is also consistent with the high amplitudes measured for the shallow explosion. 


\section{INTRODUCTION}

The newly formed Republic of Kazakhstan has declared itself to be a non-nuclear state and the US is providing technical and financial support to aid in the decommissioning of the test facilities (tunnels and boreholes) through the Defense Special Weapons Agency (DSWA). The decommissioning of a series of Shagan River boreholes in the summer of 1997 provided the opportunity to perform the Source Depth of Burial Experiment. A map showing the location of the Shagan River test site can be found in Figure 1.

The properties of geological materials change quickly near the earth's surface and if effects of these materials allow us to discriminate between shallow (near-surface) and deep (1-km) explosions we may be able to develop techniques to discriminate between large industrial blasts and an underground nuclear test. Large mine blasts rarely occur at great depths because of the potential of irreversible damage to mine infrastructure.

Large explosions of known position and initiation time are useful for calibrating traveltimes and amplitude response along paths to regional seismic stations. Near Shagan River, permanent stations include the Kazakhstan seismic network stations at Makanchi (MAK), Kurchatov (KUR) and Aktyubinsk (AKT). MAK has been designated a primary station of the International Monitoring System (IMS), while KUR and AKT have been designated auxiliary stations. 
A final objective is to provide a model for cooperation amongst nations that can lead to calibration experiments for the benefit of all. Such work is formally encouraged in the Comprehensive Test Ban Treaty (CTBT) under the heading of confidence building measures. Extensive, world-wide calibration will be critical for monitoring small seismic events using regionally recorded data.

Recording seismic data close to the explosions is an important part of regional calibration. Although close-in data will not be available on a routine basis, what we learn about source details may be important to later studies based on regional data alone. Because the effects of attenuation or scattering (the path effect) will not be as apparent in the close-in records, they will help to separate out the effects of source and path in the regional data. For example, Yang et al. (1998) develop models of an induced mine collapse that are very different from accepted models using close-in data recorded at White Pine, Michigan. A second, and very important objective is to confirm the initiation time of the source in an independent manner. This will be critical to calibrating travel times to IMS stations for purposes of accurately locating events in the region. Thirdly, close-in stations may also record aftershocks which might be important indicators of source location and type in an On Site Inspection (OSI) situation (Phillips et al., 1997).

In the following, we will describe data collection procedures and present preliminary results from the near-source field deployment at Shagan River. The explosions included a 5 ton proof of concept 
shot, five, 50 to $100 \mathrm{~kg}$, Green's function shots and three, 25 ton, depth of burial shots, set at $50 \mathrm{~m}, 300 \mathrm{~m}$ and $550 \mathrm{~m}$ (Table 1, Figures 2 and 3$)$.

\section{NEAR-SOURCE DATA COLLECTION}

The National Nuclear Center (NNC) of Kazakhstan prepared seismometer vaults for the Shagan River experiments by augering 1 $\mathrm{m}$ diameter, $1.5 \mathrm{~m}$ deep holes and filling with 4 inches of concrete. After deploying instruments, the holes were covered and dirt was shoveled on top. This provided thermal stability for the instruments as well as some level of security.

The Los Alamos team deployed L4-3D, $1 \mathrm{~Hz}$ seismometers and data acquisition equipment in the vaults (Figure 4). Satellite-based (GPS) clocks were used for timing. GPS was also used to determine station locations. Digitization rate was set at $500 \mathrm{~Hz}$ and stations were operated in event triggered mode. A map of the station distribution is shown in Figures 2 and 3, and coordinates are included in Table 2.

\section{SHOTS}

A proof-of-concept, 5 ton shot was fired in hole 1389, July 13, to test the deployment and detonation performance of the explosive, in excess of $600 \mathrm{~m}$ beneath the water table. Depth to the water table was $30 \mathrm{~m}$ maximum for these holes. The 5 ton shot was initiated in meta-sedimentary materials of unknown type, while later shots were 
performed in a more uniform, shale or granitic rock (Table 1). A flaked TNT (Granulatol) explosive available from Russia was used at Shagan River. Near-source geophysical or Green's function shots, 50 to $100 \mathrm{~kg}$, were fired prior to each 25 ton shot, including a shot at the position of the larger shot. The 25 ton shots were fired in holes 1311 (August 3, depth $50 \mathrm{~m}$ ), 1381 (August 31, depth $300 \mathrm{~m}$ ) and 1349 (September 28, depth $550 \mathrm{~m}$ ). A useful compilation of explosive tests and shot descriptions can be found in the NNC Final Technical Report (1997). We include recording details for each shot and temporary station in Table 3 .

\section{RESULTS}

We show vertical, radial and transverse component record sections from each of the 25 ton shots in Appendices A and B. The seismograms are scaled to maximum amplitude. The most apparent characteristic of these data are the large surface wave amplitudes generated by the shallow shot, as expected by theory for fundamental modes. The shallow shot also generated higher amplitude body waves and was the only one of the three 25 ton shots to be detected and located by the Prototype International Data Center (Figure 5).

The P-wave moves out at apparent velocities between 5.2 and 5.6 $\mathrm{km} / \mathrm{s}$. Velocity seems to be a strong function of azimuth in this area (Figure 6), with slower paths crossing into more deformed regions, while faster paths remain inside granitic regions. We also observe air 
waves that move out at velocities of $340 \mathrm{~m} / \mathrm{s}$ for the Green's function shots. These waves were presumably generated by the surface portion of the primacord used to initiate the shots. Air waves should have been generated by the larger shots, but cannot be observed in the higher amplitude coda.

We show spectra of signal and noise in Appendix C. Signal spectra were calculated from the initial $0.5 \mathrm{~s}$ of the $\mathrm{P}$ wave, while noise spectra were taken from the $0.5 \mathrm{~s}$ prior to the $\mathrm{P}$ wave. Most of the variability in signal amplitudes seen in these plots result from distance effects. Large signal to noise is observed up to $200 \mathrm{~Hz}$ for many recordings, while the shallow shots and the more distant Green's function recordings generate signal up to $100 \mathrm{~Hz}$. Some noise peaks can be observed at 60 and $90 \mathrm{~Hz}$.

We show three-component body wave amplitudes in the band 8 to $16 \mathrm{~Hz}$ versus slant range in Figure 7. These results further indicate the strength of body waves generated by the shallow shot. The 5 ton shot was an order of magnitude smaller than the others, perhaps a factor of two smaller than expected. This possibly results from the more complicated geology in which the shot was initiated (Figure 3). We also show three-component surface wave amplitudes in the band 1 to $2 \mathrm{~Hz}$ versus slant range in Figure 8. Again, we see the larger amplitudes generated by the shallow shot, especially on the horizontal components. In both body and surface wave plots, the 300 $\mathrm{m}$ shot seems to generate the smallest amplitudes, further 
demonstrating that local source conditions may have as much or more influence than source depth for the deeper shots.

After correcting for source size by dividing by the yield, we measure an apparent Q of 116 (bounds 80-220) using RMS P wave signal in the band 10-20 $\mathrm{Hz}$ (Figure 9). If the low amplitude 5 ton data are ignored, the apparent $\mathrm{Q}$ becomes 160. Amplitude residuals obtained after correction for $\mathrm{Q}$ and inverse distance geometrical spreading are strongly dependent on the shot (Figure 10). This could result from a poor yield correction, including incomplete detonation, or near-shot geological effects on the source such as pressure and rock strength influence on elastic cavity radius, or on the near-source path, such as well as scattering, focusing and attenuation.

\section{DISCUSSION AND FUTURE WORK}

To further study the seismic source, signals from the small shots can be used to deconvolve path and site effects from signals of the 25 ton shots. We summarize preliminary results by plotting the corner frequency of the 25 ton shots versus depth of burial in Figure 11. Corner frequencies are inversely related to the radius of the surface over which seismic motions approach linear, elastic behavior. Corner frequencies are $100 \mathrm{~Hz}$ for the shallow shot and increase to $250 \mathrm{~Hz}$ for the deepest shot, indicating elastic radii that decrease with depth, consistent with increase in pressure and rock strength with depth, as predicted by the Mueller-Murphy explosion source model. 
Effort is currently underway to characterize the Shagan River seismic structure in three dimensions using $R g$ surface wave data generated by the 25 ton explosions. We hope to understand the effects of nearsource structure on regional waveforms with this approach.

The DSWA-DOE-NNC collaboration will continue in the summer of 1998 with a 100 ton calibration explosion at tunnel 214 in the Degelen Mountain massif. The explosion will be fully tamped and is to be followed by an untamped 100 ton explosion in another drift of tunnel 214 in 1999. Near source and regional seismic instrumentation will be augmented with CORRTEX and shock measurements within the explosive and out to $45 \mathrm{~m}$ range. The deployment will include infrasound sensors at near-source and regional distances. We also expect a 25 ton, shallow $(50 \mathrm{~m})$ shot in granitic rock to more directly compare results with the 1997 Depth of Burial shots; however, only regional recording is anticipated.

\section{ACKNOWLEDGMENTS}

We thank Luke Kluchko of DSWA, responsible for contract monitoring during the Test Hole Closure experiments, for his support and expertise. Lew Glenn (LLNL) developed the Depth of Burial Experiment concept. Nadezhda Belyashova (NNC) provided much needed field support.

\section{REFERENCES}

National Nuclear Center, Republic of Kazakhstan, Three experimental test hole closures at the Balapan test field, Final Report, Contract DSWA-0094/1, Item 0009, 108 pp, 1997. 
Yang, X., B.W. Stump and W.S. Phillips, Source mechanism of an explosively induced mine collapse, Bull. Seism. Soc. Am., 88, 843-854, 1998.

Phillips, W.S., D.C. Pearson, C.L. Edwards and B.W. Stump, Microseismicity induced by a controlled, mine collapse at White Pine, Michigan, Int. J. Rock Mech. Min. Sci, 34, no. 3-4, paper no. 00246, 1997.

For further information or inquiries about obtaining data, please contact:

W. Scott Phillips

MS C335

Los Alamos National Laboratory

Los Alamos, New Mexico 87545

wsp@lanl.gov 
TABLE 1. 1997 SHAGAN RIVER SHOTS

\begin{tabular}{lcccccccll} 
Month & $\underline{\text { Day }}$ & $\underline{\text { Time }}$ & $\underline{\text { Hole }}$ & $\underline{\text { Latitude }}$ & $\underline{\text { Longitude }}$ & $\underline{\text { Depth }}$ & $\underline{\text { Yield }}$ & \multicolumn{1}{c}{ Geology } \\
JUL & 06 & $09: 32: 42.911^{*}$ & 1381 & 49.8837 & 78.8147 & $500 \mathrm{~m}$ & $50 \mathrm{~kg}$ & Granosyenite \\
JUL & 06 & $12: 44: 08.411^{*}$ & 1381 & 49.8837 & 78.8147 & $300 \mathrm{~m}$ & $50 \mathrm{~kg}$ & Granosyenite \\
JUL & 07 & $07: 27: 42.575^{*}$ & 1311 & 49.9412 & 78.7860 & $204 \mathrm{~m}$ & $92 \mathrm{~kg}$ & Shale \\
JUL & 07 & $07: 56: 50.872^{*}$ & 1311 & 49.9412 & 78.7860 & $50 \mathrm{~m}$ & $92 \mathrm{~kg}$ & Shale \\
JUL & 07 & $11: 40: 52.740^{*}$ & 1349 & 49.8794 & 78.8493 & $585 \mathrm{~m}$ & $107 \mathrm{~kg}$ & Granite \\
JUL & 13 & $08: 11: 04.304$ & 1389 & 49.8790 & 78.7600 & $630 \mathrm{~m}$ & $5 \mathrm{t}$ & NA \\
AUG & 03 & $08: 07: 20.040$ & 1311 & 49.9412 & 78.7860 & $50 \mathrm{~m}$ & $25 \mathrm{t}$ & Shale \\
AUG & 31 & $07: 08: 39.179$ & 1381 & 49.8837 & 78.8147 & $300 \mathrm{~m}$ & $25 \mathrm{t}$ & Granosyenite \\
SEP & 28 & $07: 30: 15.126$ & 1349 & 49.8794 & 78.8493 & $550 \mathrm{~m}$ & 25 & t & Granosyenite
\end{tabular}

* Origin times for Green's function shots derived from traveltimes from 25 ton shots.

TABLE 2. SHAGAN RIVER TEMPORARY STATIONS

\begin{tabular}{|c|c|c|}
\hline$\underline{\text { Station }}$ & $\underline{\text { Latitude }}$ & Longitude \\
\hline 2 & 49.8636 & 78.8701 \\
\hline 3 & 49.8874 & 78.9087 \\
\hline 4 & 49.8766 & 78.7636 \\
\hline 6 & 49.8217 & 78.7531 \\
\hline 7 & 49.8526 & 78.9841 \\
\hline 8 & 49.9777 & 78.7590 \\
\hline 9 & 49.9719 & 78.9587 \\
\hline
\end{tabular}


TABLE 3. SHAGAN RIVER SHOTS AND STATIONS

\begin{tabular}{|c|c|c|c|c|c|c|c|c|c|}
\hline \multicolumn{2}{|c|}{$\underline{\text { Date }}$} & Hole & $\frac{\text { Depth }}{\mathrm{m}}$ & $\underline{\text { Yield }}$ & $\underline{\text { Station }}$ & $\underline{D A S}$ & $\underline{\text { Sensor }}$ & $\frac{\text { Distance }}{\mathrm{km}}$ & $\frac{\text { Azimuth }}{\circ}$ \\
\hline JUL & 06 & 1381 & 500 & $50 \mathrm{~kg}$ & $\begin{array}{l}2 \\
3 \\
6\end{array}$ & $\begin{array}{l}0470 \\
0510 \\
0405\end{array}$ & $\begin{array}{l}625 \\
627 \\
621\end{array}$ & $\begin{array}{l}4.6 \\
6.8 \\
8.2\end{array}$ & $\begin{array}{r}119 \\
86 \\
213\end{array}$ \\
\hline JUL & 06 & 1381 & 300 & $50 \mathrm{~kg}$ & $\begin{array}{l}2 \\
3 \\
6 \\
8\end{array}$ & $\begin{array}{l}0470 \\
0510 \\
0405 \\
0509\end{array}$ & $\begin{array}{lll}6 & 2 & 5 \\
6 & 2 & 7 \\
6 & 2 & 1 \\
6 & 2 & 0\end{array}$ & $\begin{array}{r}4.6 \\
6.8 \\
8.2 \\
11.2\end{array}$ & $\begin{array}{r}119 \\
86 \\
213 \\
339\end{array}$ \\
\hline JUL & 07 & 1311 & 204 & $92 \mathrm{~kg}$ & $\begin{array}{l}6 \\
7 \\
8\end{array}$ & $\begin{array}{l}0405 \\
0409 \\
0509\end{array}$ & $\begin{array}{lll}6 & 2 & 1 \\
6 & 2 & 2 \\
6 & 2 & 0\end{array}$ & $\begin{array}{r}13.5 \\
17.3 \\
4.5\end{array}$ & $\begin{array}{l}190 \\
125 \\
335\end{array}$ \\
\hline JUL & 07 & 1311 & 50 & $92 \mathrm{~kg}$ & $\begin{array}{l}7 \\
8\end{array}$ & $\begin{array}{l}0409 \\
0509\end{array}$ & $\begin{array}{l}622 \\
620\end{array}$ & $\begin{array}{r}17.3 \\
4.5\end{array}$ & $\begin{array}{l}125 \\
335\end{array}$ \\
\hline JUL & 07 & 1349 & 585 & $107 \mathrm{~kg}$ & $\begin{array}{l}7 \\
8\end{array}$ & $\begin{array}{l}0409 \\
0509\end{array}$ & $\begin{array}{l}622 \\
620\end{array}$ & $\begin{array}{l}10.1 \\
12.7\end{array}$ & $\begin{array}{l}107 \\
329\end{array}$ \\
\hline JUL & 13 & 1389 & 630 & $5 \mathrm{t}$ & $\begin{array}{l}2 \\
3 \\
4 \\
6 \\
7 \\
8 \\
9\end{array}$ & $\begin{array}{l}0459 \\
0510 \\
0473 \\
0405 \\
0409 \\
0509 \\
0414\end{array}$ & $\begin{array}{lll}6 & 2 & 5 \\
6 & 2 & 7 \\
6 & 1 & 9 \\
6 & 2 & 1 \\
6 & 2 & 2 \\
6 & 2 & 0 \\
6 & 2 & 3\end{array}$ & $\begin{array}{r}8.0 \\
10.7 \\
0.4 \\
6.4 \\
16.4 \\
11.0 \\
17.6\end{array}$ & $\begin{array}{r}102 \\
85 \\
136 \\
184 \\
100 \\
0 \\
54\end{array}$ \\
\hline AUG & 03 & 1311 & 50 & $25 \mathrm{t}$ & $\begin{array}{l}2 \\
3 \\
4 \\
6 \\
7 \\
8 \\
9\end{array}$ & $\begin{array}{l}0459 \\
0510 \\
0473 \\
0405 \\
0409 \\
0509 \\
0414\end{array}$ & 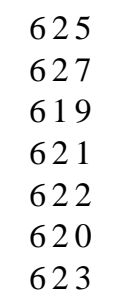 & $\begin{array}{r}10.5 \\
10.7 \\
7.4 \\
13.5 \\
17.3 \\
4.5 \\
12.9\end{array}$ & $\begin{array}{r}145 \\
124 \\
193 \\
190 \\
125 \\
335 \\
75\end{array}$ \\
\hline AUG & 31 & 1381 & 300 & $25 \mathrm{t}$ & $\begin{array}{l}2 \\
3 \\
4 \\
6 \\
7 \\
8 \\
9\end{array}$ & $\begin{array}{l}0459 \\
0510 \\
0473 \\
0405 \\
0409 \\
0509 \\
0414\end{array}$ & $\begin{array}{l}625 \\
6227 \\
6119 \\
6221 \\
6222 \\
620 \\
6223\end{array}$ & $\begin{array}{r}4.6 \\
6.8 \\
3.8 \\
8.2 \\
12.7 \\
11.2 \\
14.3\end{array}$ & $\begin{array}{r}119 \\
86 \\
258 \\
213 \\
106 \\
339 \\
46\end{array}$ \\
\hline SEP & 28 & 1349 & 550 & $25 \mathrm{t}$ & $\begin{array}{l}2 \\
3 \\
6 \\
7 \\
8 \\
9\end{array}$ & $\begin{array}{l}0459 \\
0510 \\
0405 \\
0409 \\
0470 \\
0414\end{array}$ & 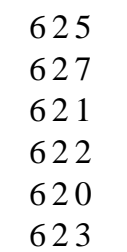 & $\begin{array}{r}2.3 \\
4.4 \\
9.4 \\
10.1 \\
12.7 \\
12.9\end{array}$ & $\begin{array}{r}140 \\
78 \\
227 \\
107 \\
329 \\
37\end{array}$ \\
\hline
\end{tabular}




\section{FIGURE CAPTIONS}

Figure 1. Map of Kazakhstan region showing permanent seismic stations (triangles) and nuclear test sites (circles).

Figure 2. Map of Shagan River test site showing temporary seismic stations (triangles) and shot holes (circles). Resolution 30 arc second topography is shown for reference. The Shagan River flows in the east-west depression in the center of the map.

Figure 3. Map of Shagan River test site showing temporary seismic stations (triangles) and shot holes (circles). A geology map is shown for reference. The lighter formations are granite and granosyenites while the layered formations are metamorphosed sediments. Small differences may be observed between hole locations measured by GPS (dark red) and those included in the geological map (light red). This is due to a combination of measurement error and superposition of different map projections.

Figure 4. Typical deployment including L4-3D seismometer, recording equipment, clock and power supply at Shagan River.

Figure 5. Location of the $50 \mathrm{~m}, 25$ ton shot in hole 1311 as determined by the International Monitoring System. The large circle represents the Shagan River test site and the dot represents the estimated location along with elliptical error limits.

Figure 6. Apparent P-wave velocity measured from 5 and 25 ton shots at Shagan River, superposed on the geology map from Figure 3. Colored lines represent apparent velocity for shot-station pairs as given by the color bar.

Figure 7. P-wave amplitudes in the band 16 to $32 \mathrm{~Hz}$ versus slant range for 5 and 25 ton shots at Shagan River. Lines represent least squares fits to the data. Colors represent different shots as noted in the legend.

Figure 8. Surface-wave amplitudes in the band 1 to $2 \mathrm{~Hz}$ versus slant? range for 5 and 25 ton shots at Shagan River. Lines represent 
least squares fits to the data. Colors represent different shots as noted in the legend.

Figure 9. RMS P-wave amplitude, 10-20 Hz, normalized by yield, versus range for 5 and 25 tone shots at Shagan River. The line represents a best fit $\mathrm{Q}$ of 216 with a spreading rate of 1/range.

Figure 10. RMS P-wave amplitude residuals from Figure 9 superposed on the geology map from Figure 3. Colored lines represent residuals for shot-station pairs as given by the color bar.

Figure 11. Corner frequency of the 25 ton shots measured using the Green's functions recordings versus shot depth. The prediction of the Mueller-Murphy model is also shown. 


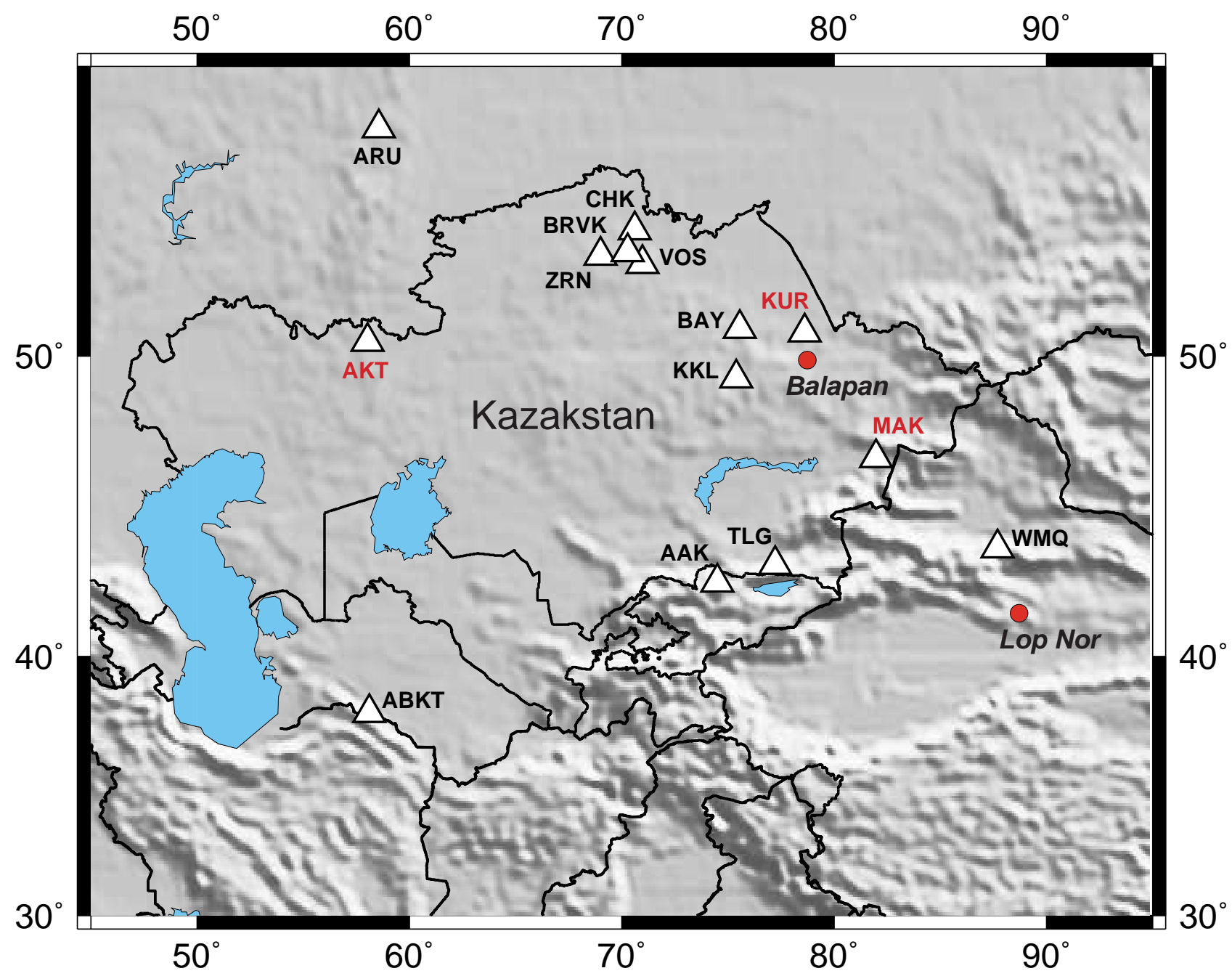




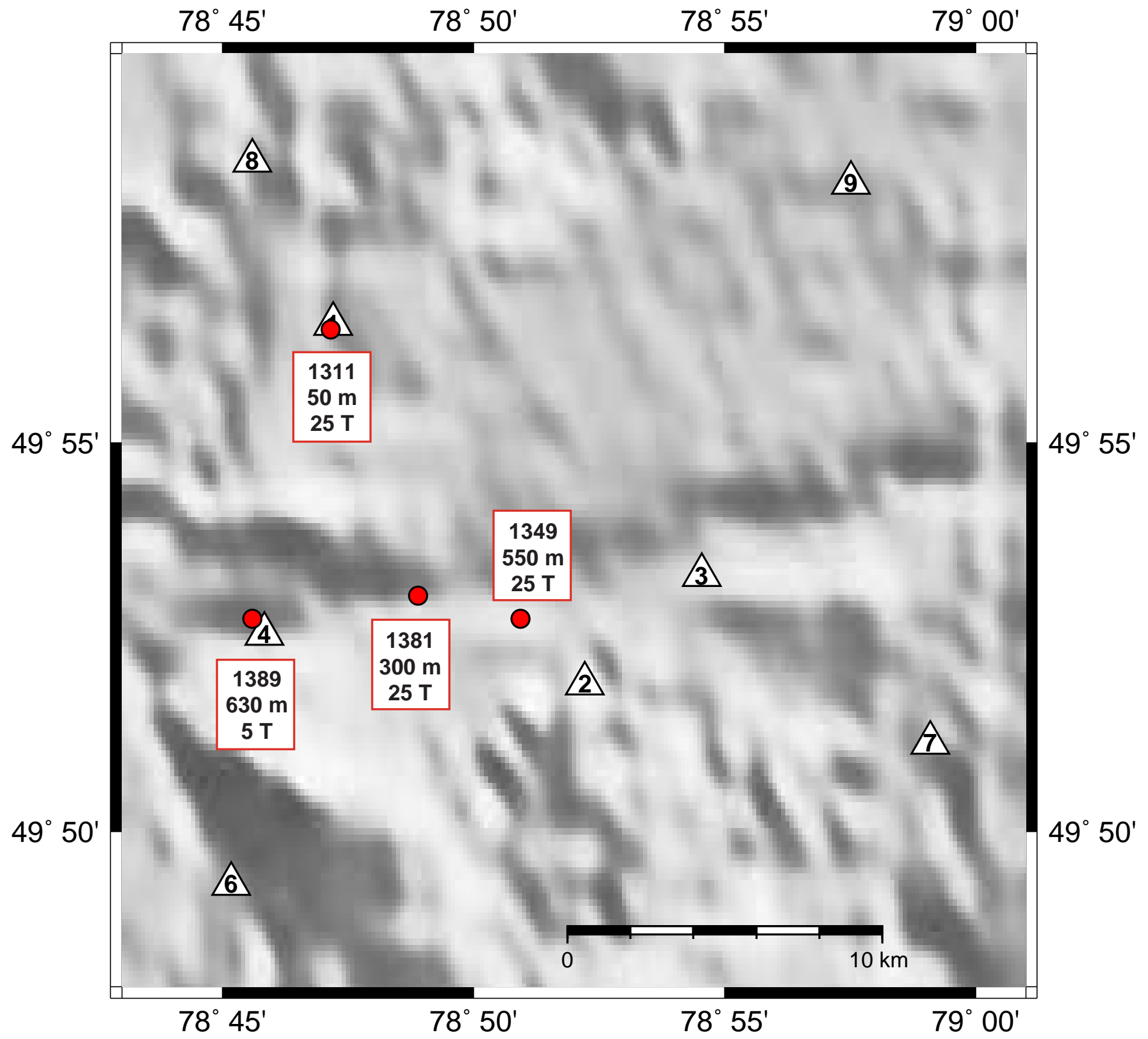

Figure 2 


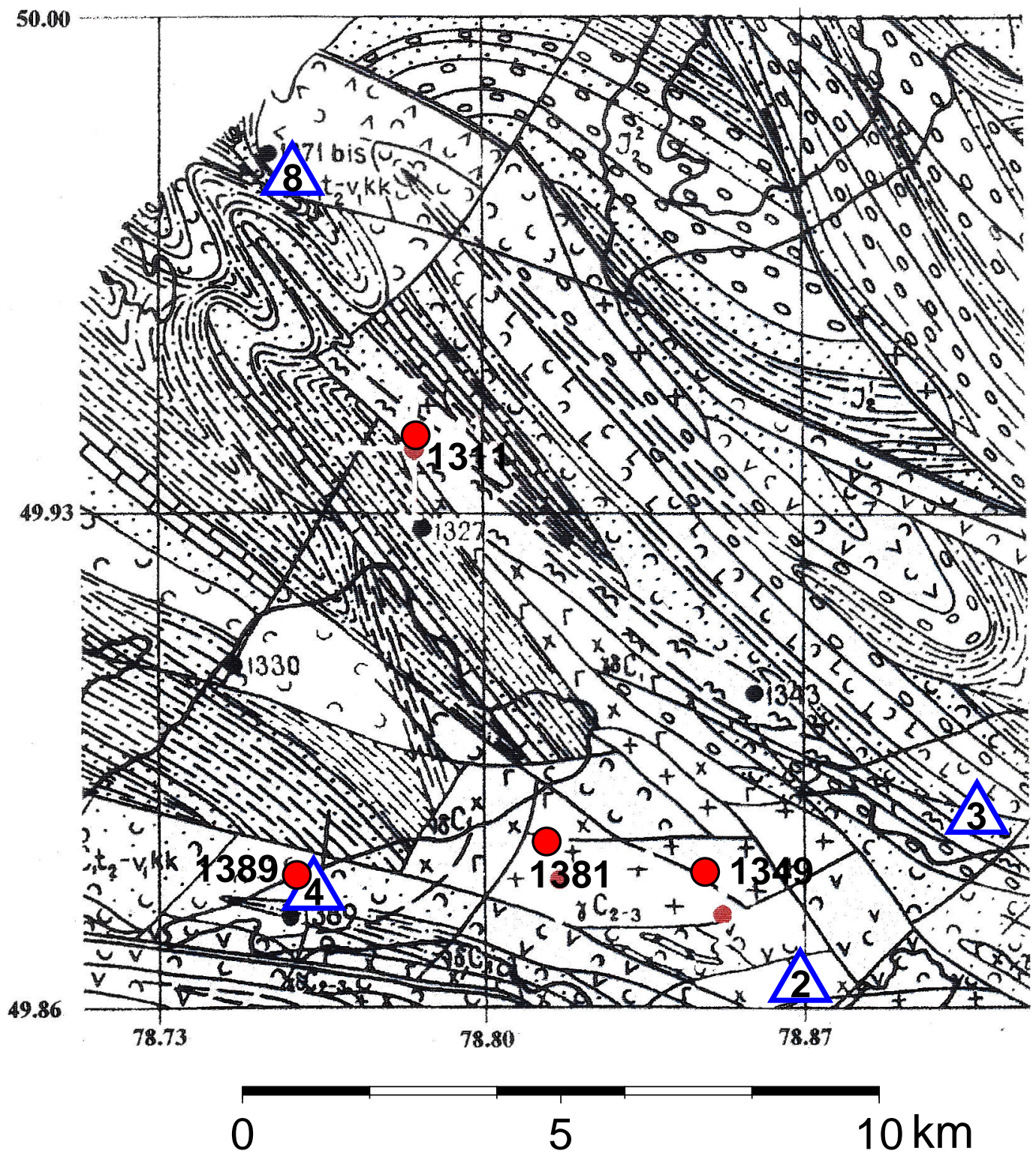

$\hat{\theta}$

6

Figure 3 


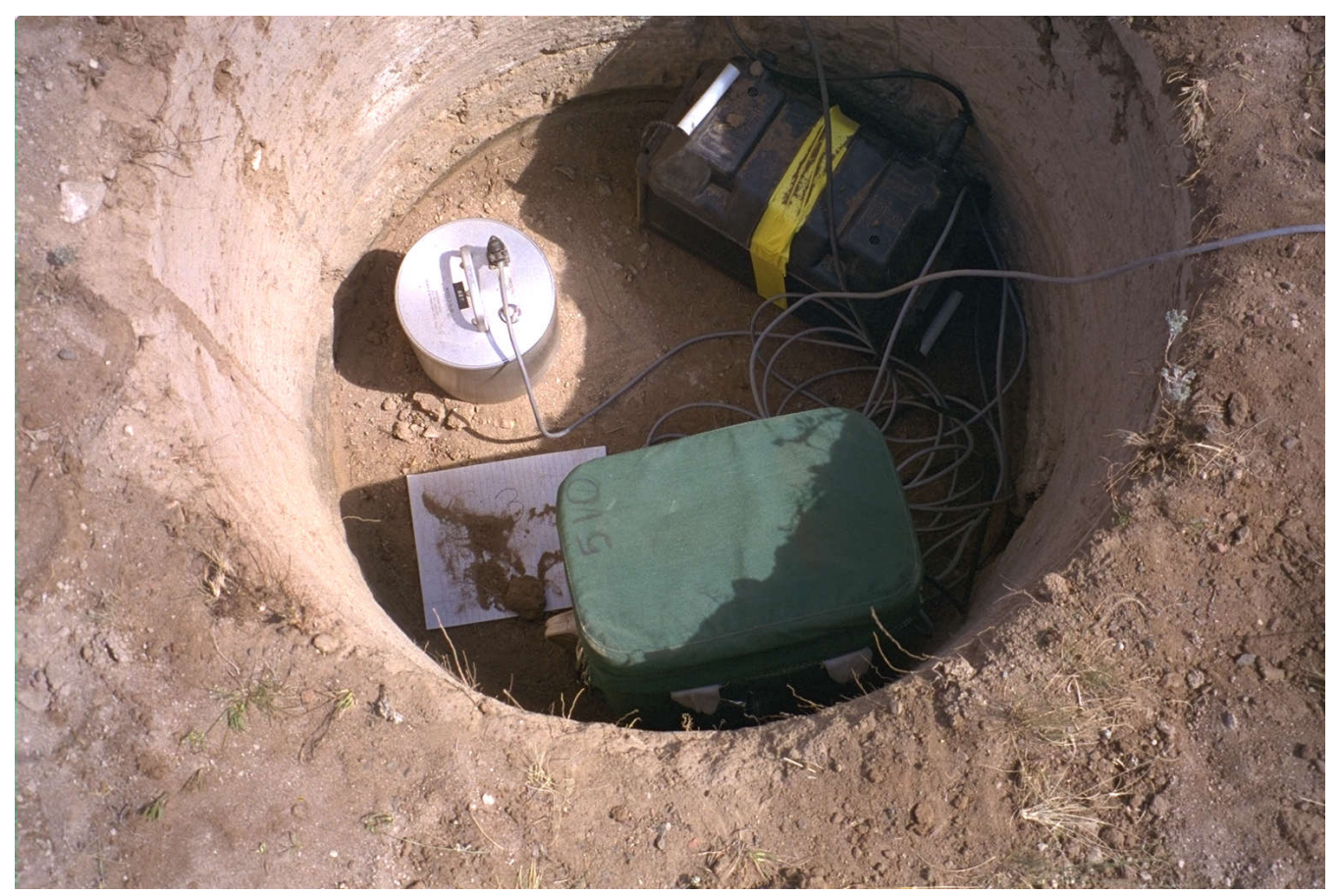

Figure 4 


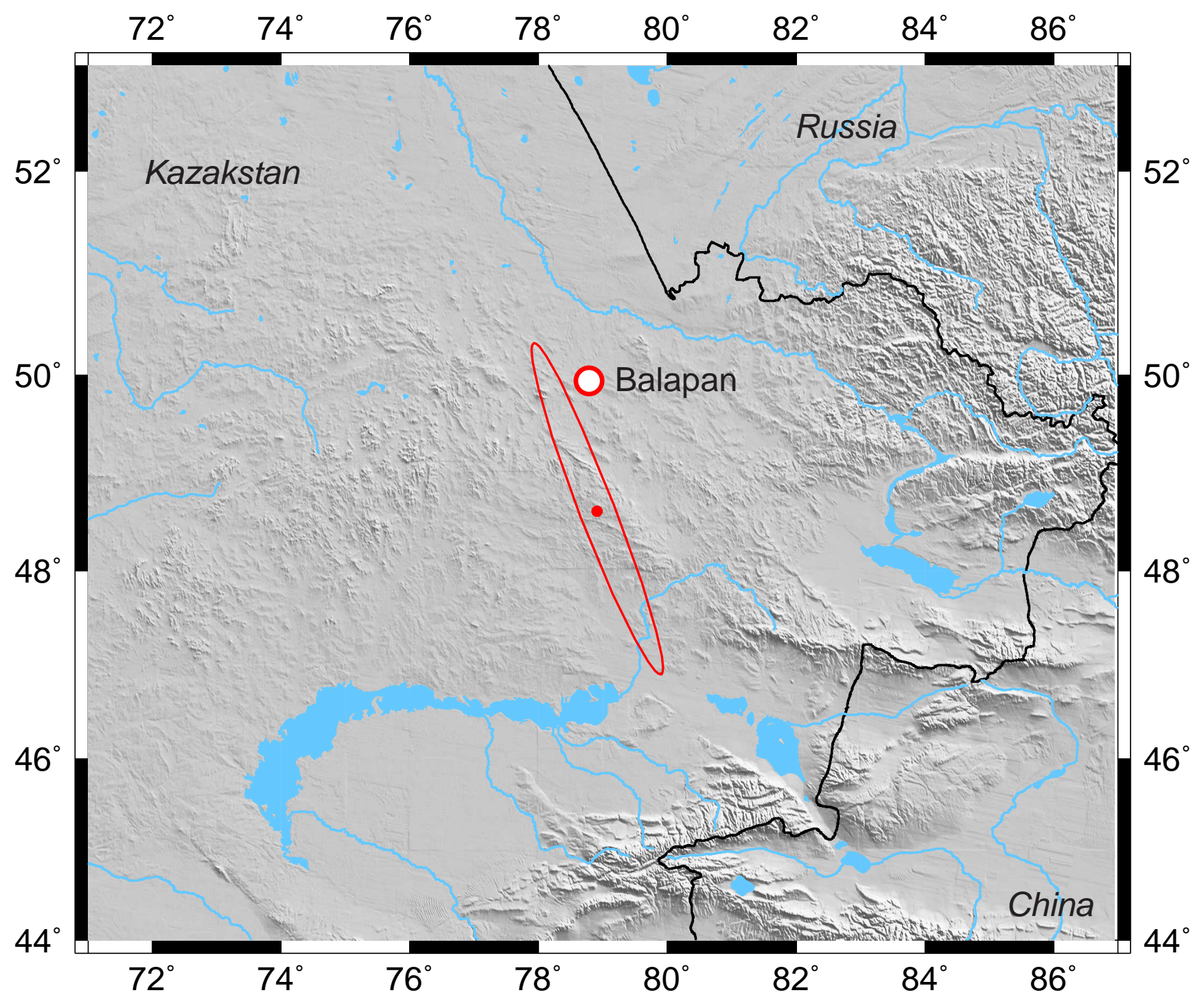

Figure 5 


\section{Apparent P Velocity, Balapan}

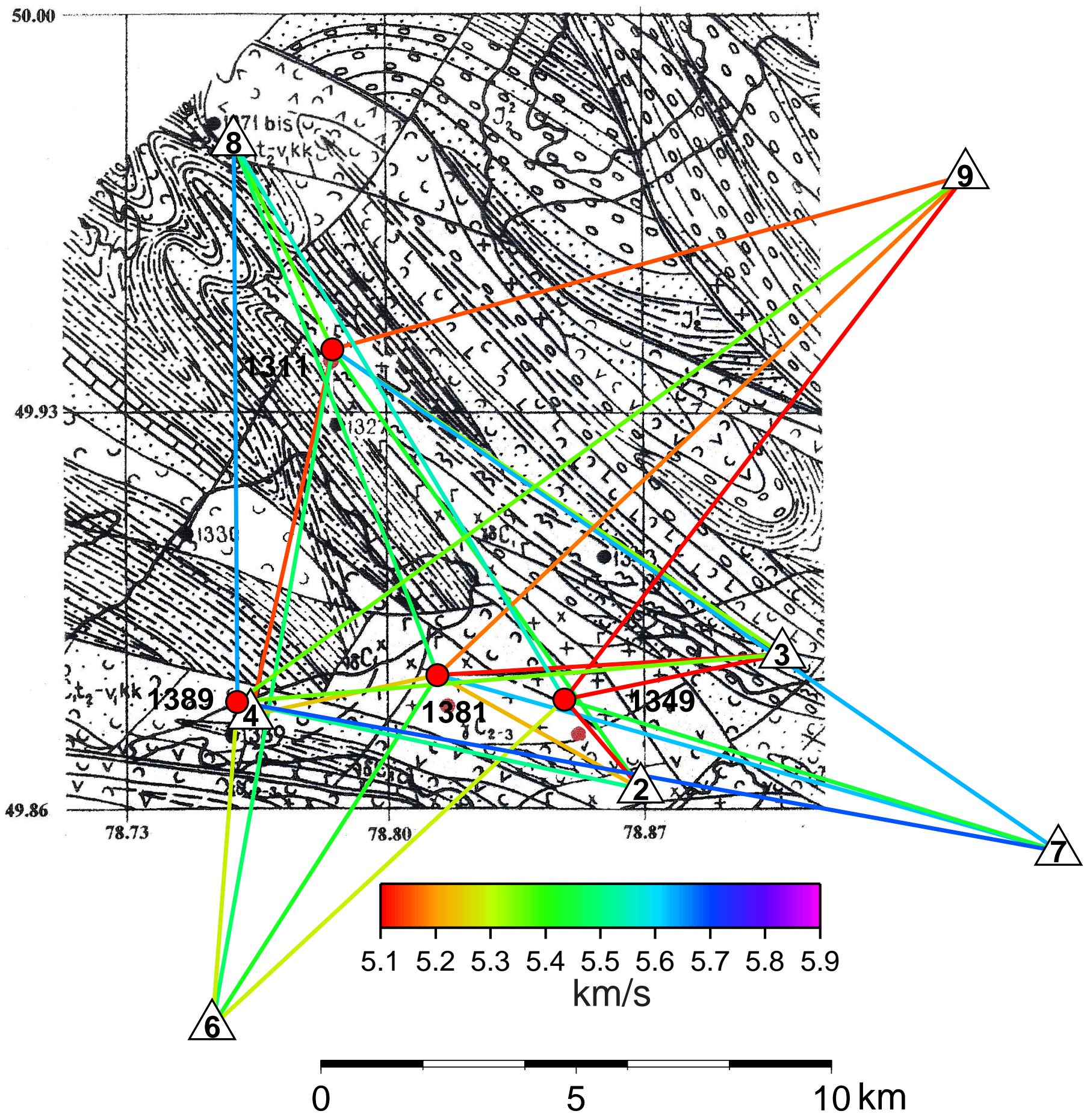



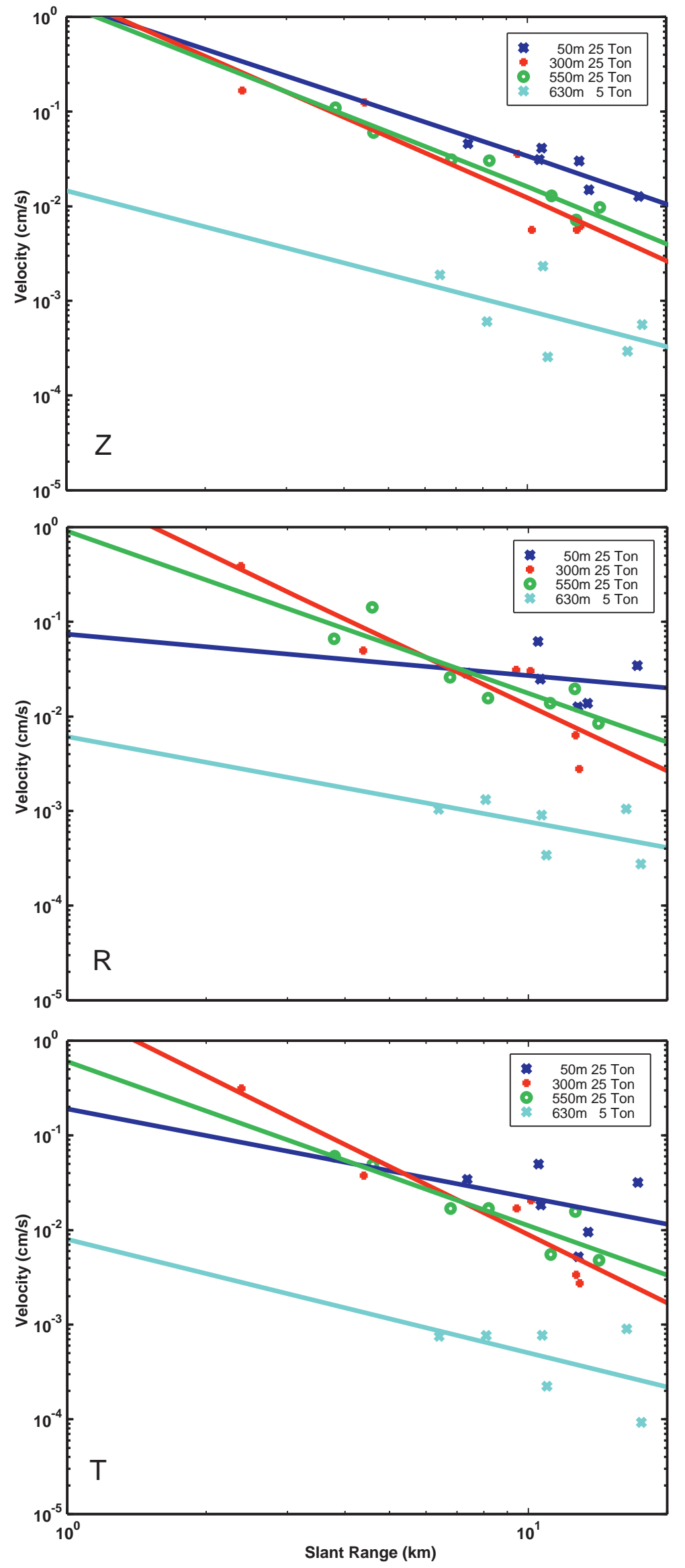

Figure 7 

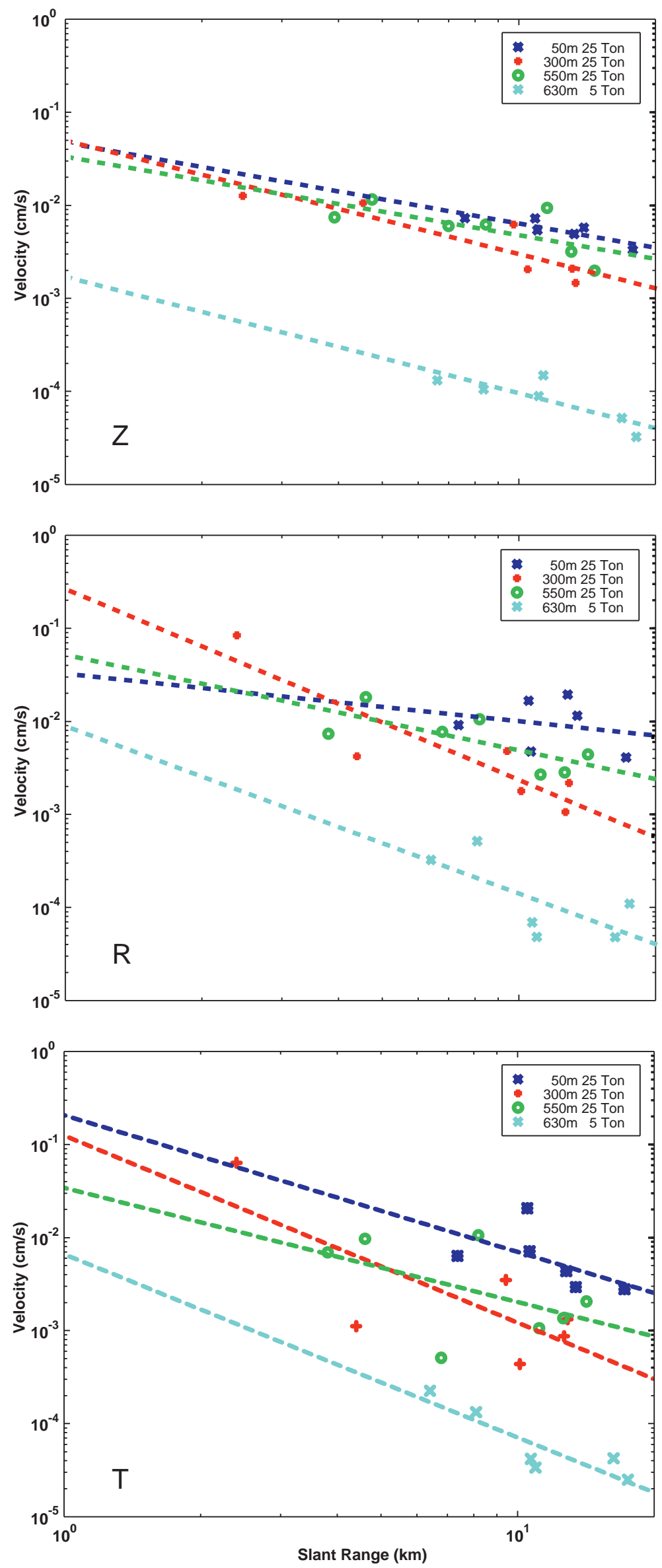

Figure 8 


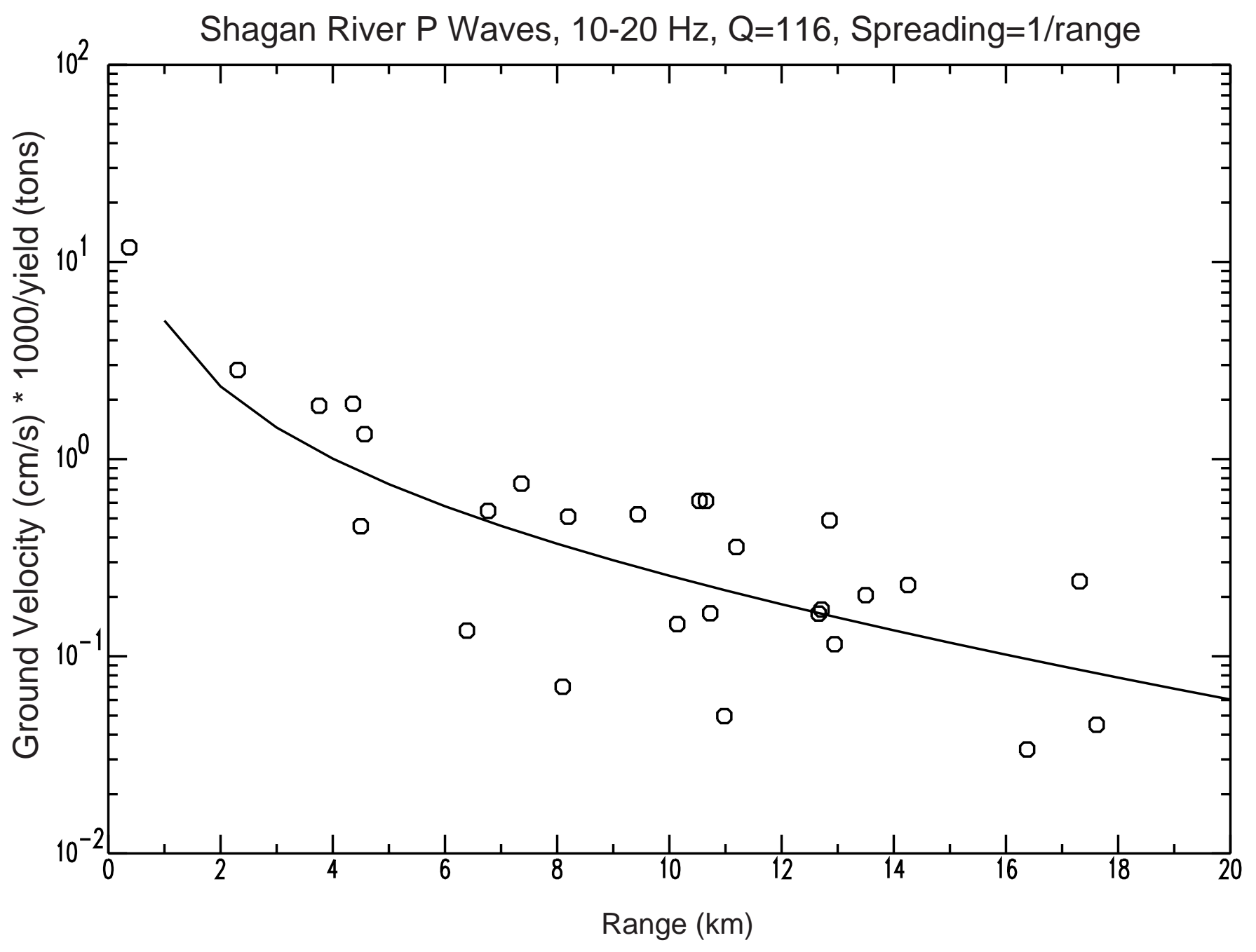

Figure 9 


\section{P Wave, $\log _{10}$ Amplitude Residuals, 10-20 Hz, Balapan}

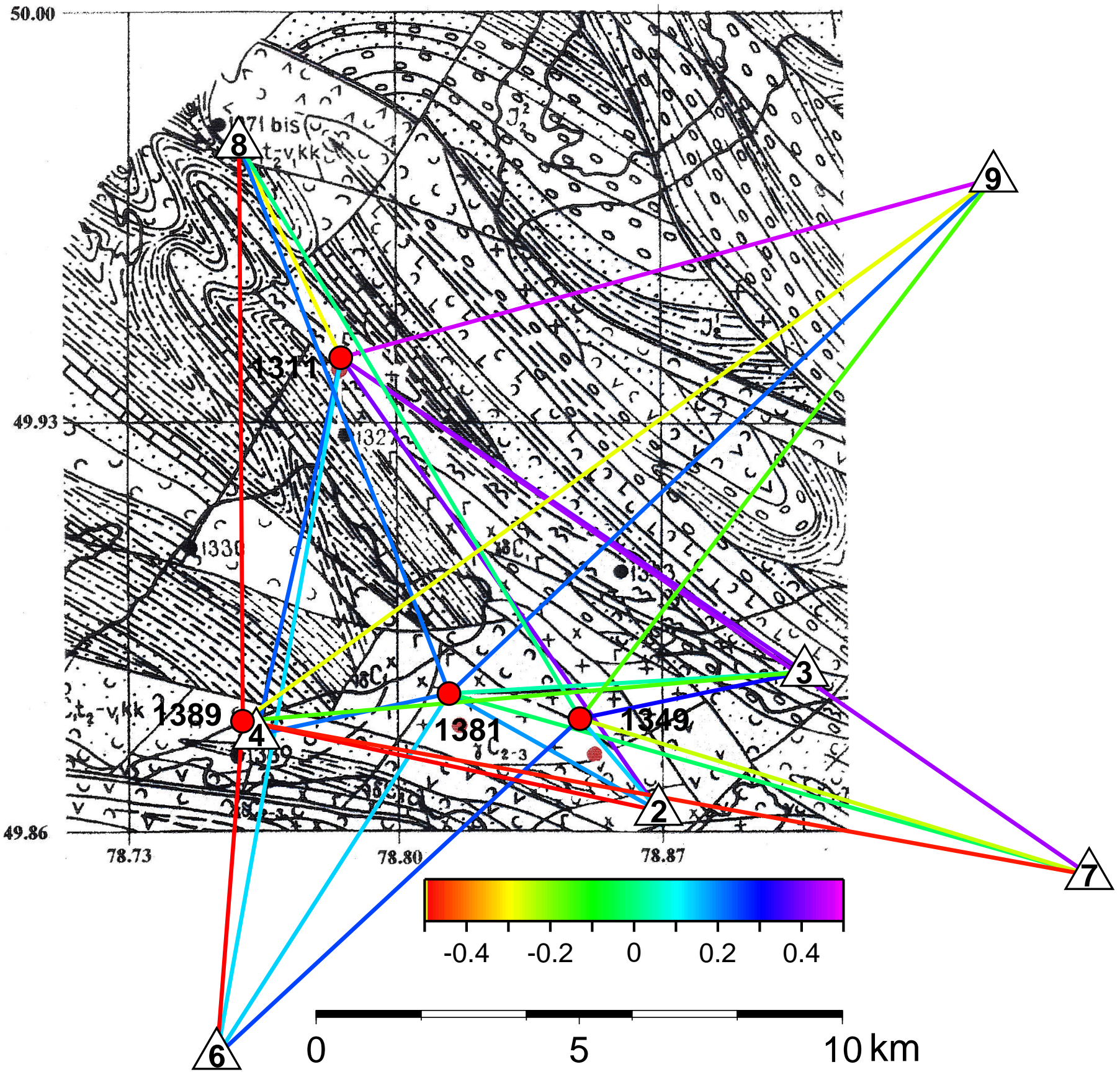




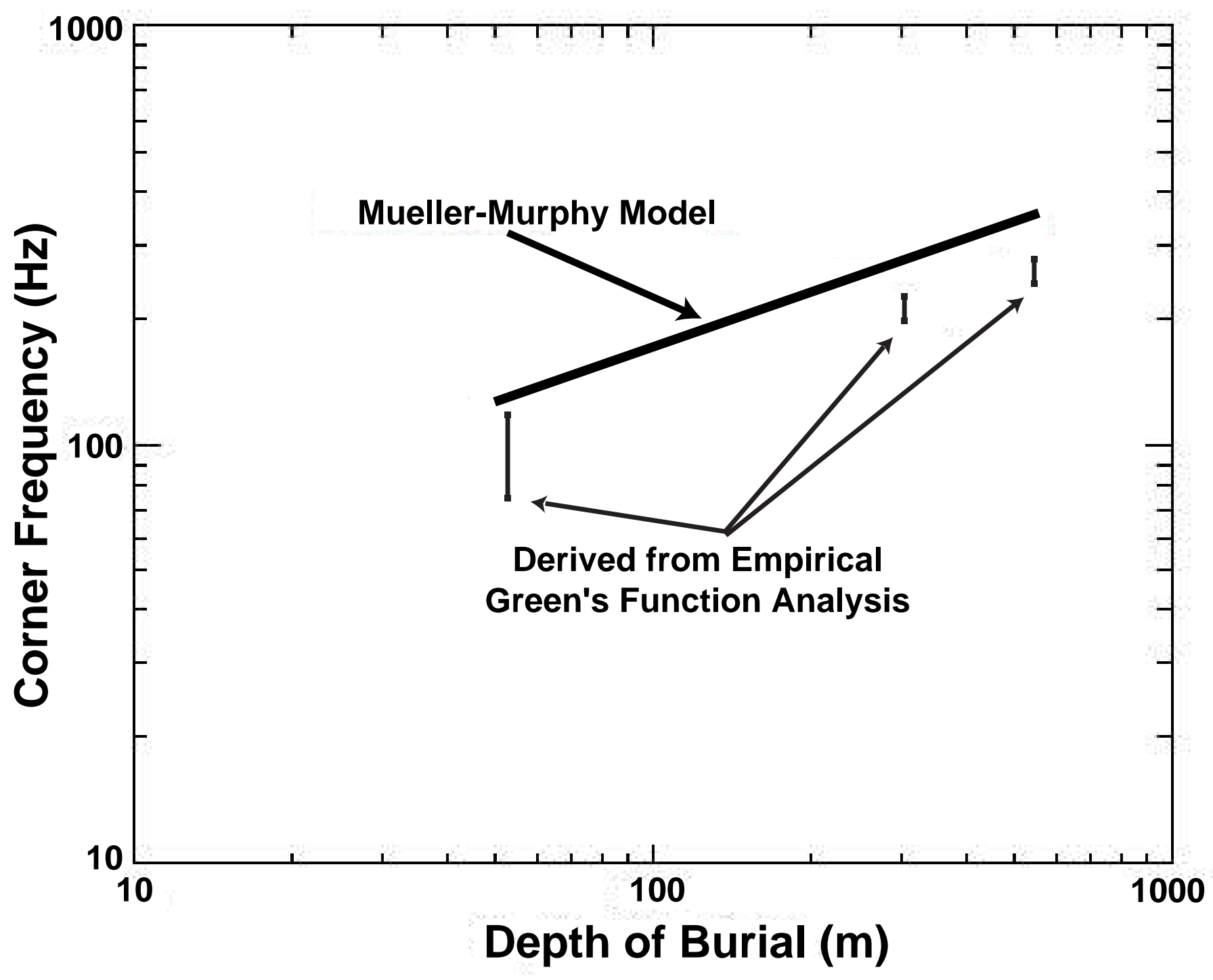

Figure 11 
Appendix A

Record section plots for vertical, radial and transverse components of 5 ton, 25 ton and Green's function shots recorded at Shagan River in 1997. No velocity correction has been applied. Zero times correspond to the shot origin times. Origin times for the Green's function shots have been estimated using traveltimes of 25 ton shots. Shot to station azimuth is given at the end of each trace. Hole ID, depth, yield and component of motion are listed at the bottom of each shot. 


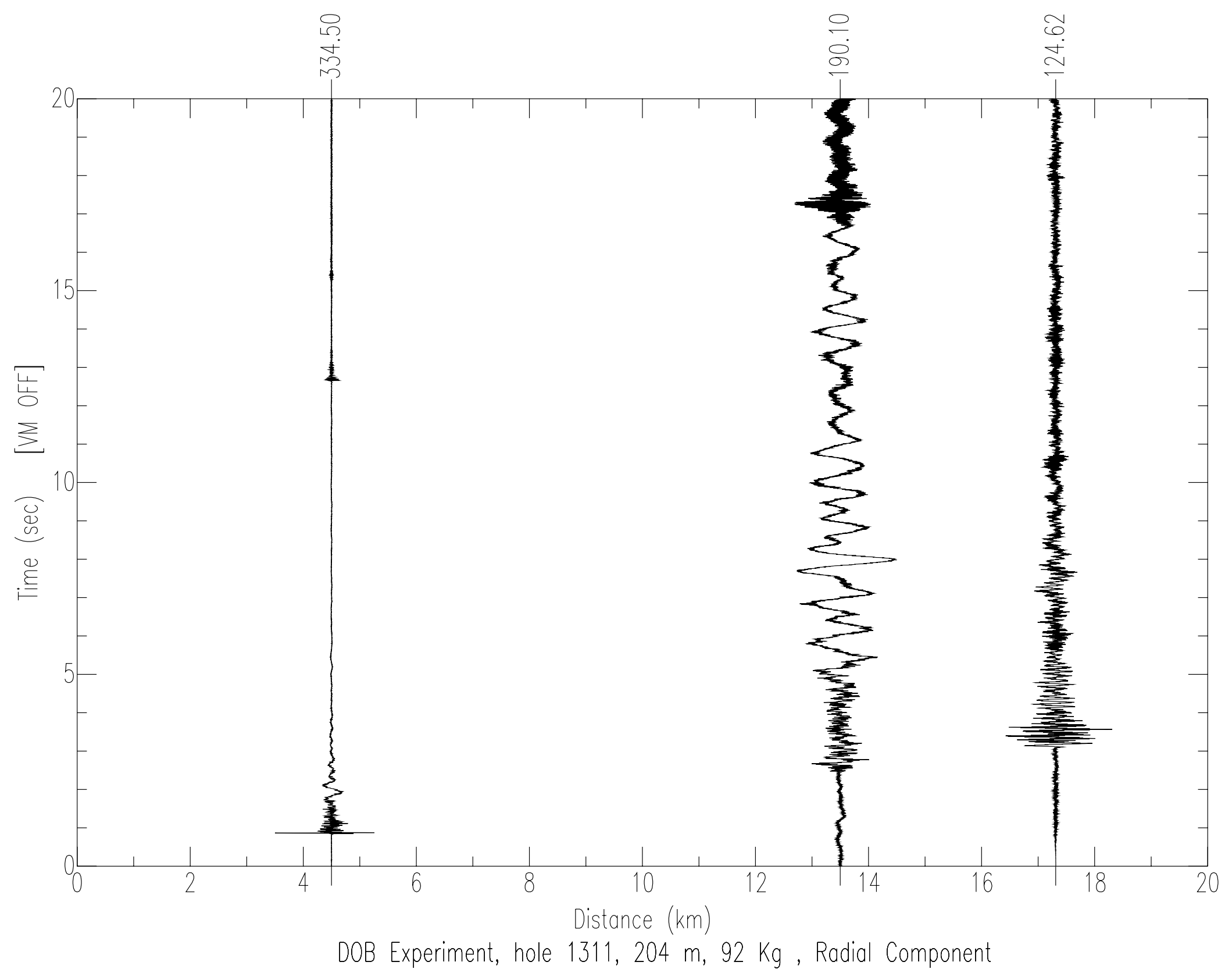




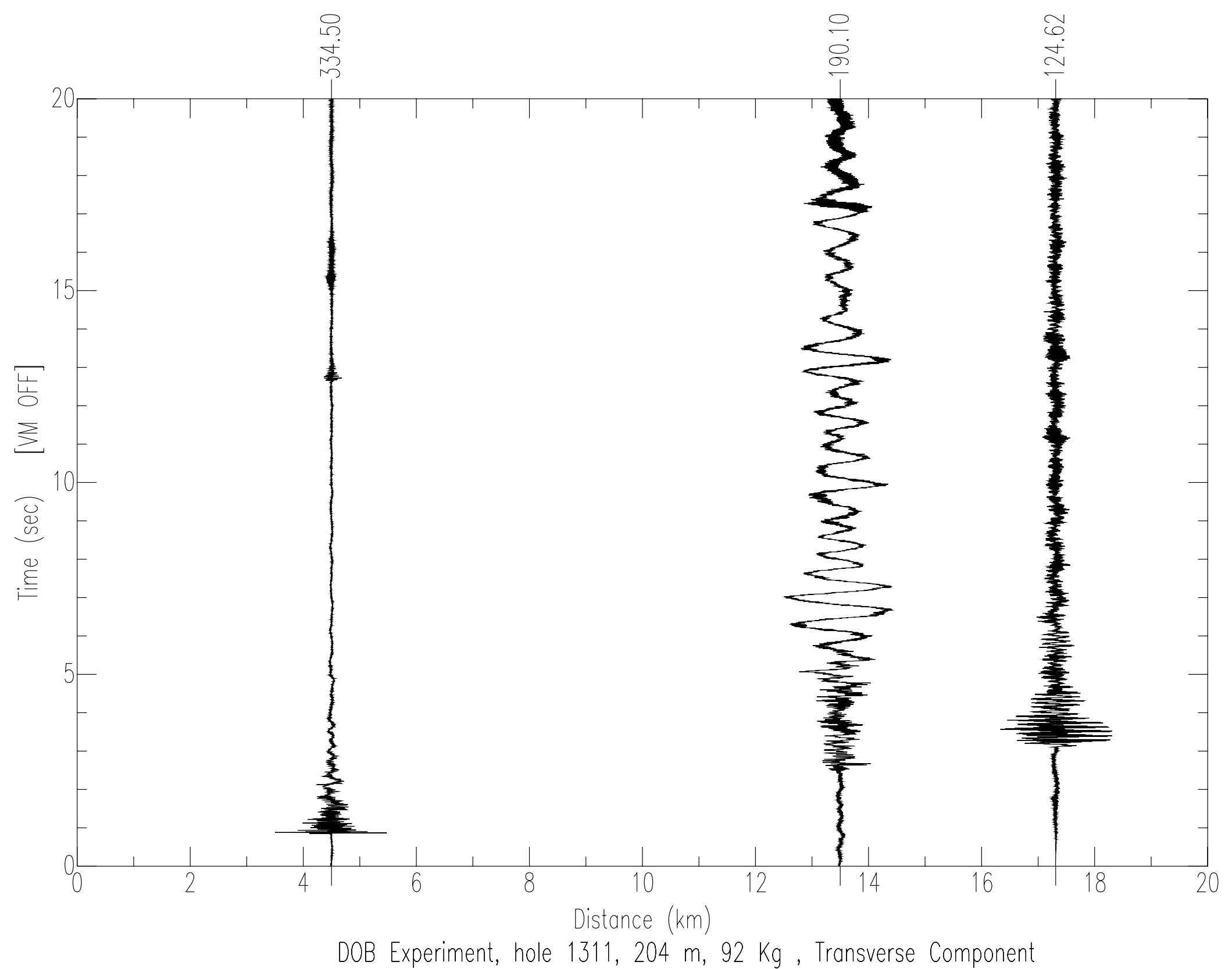




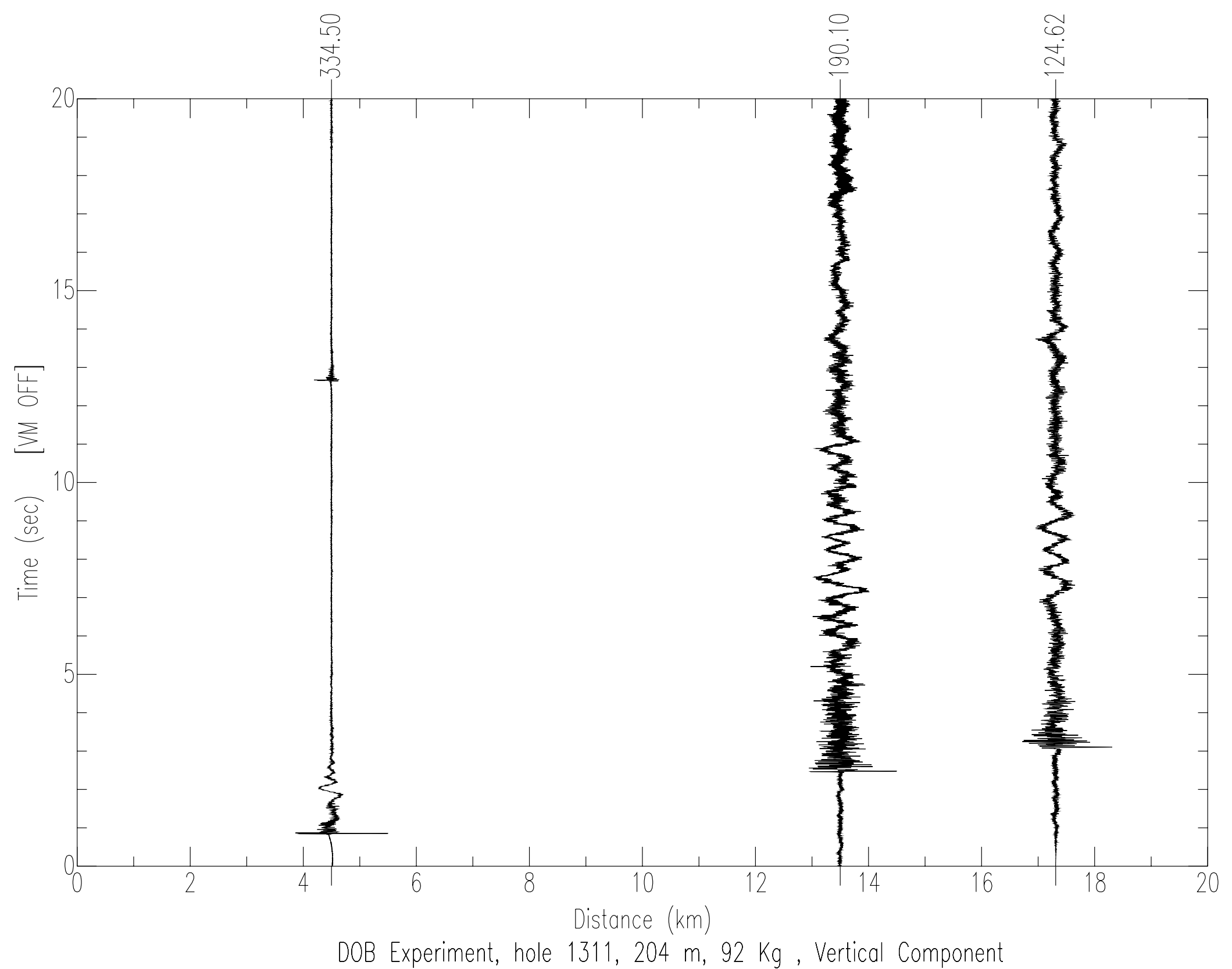




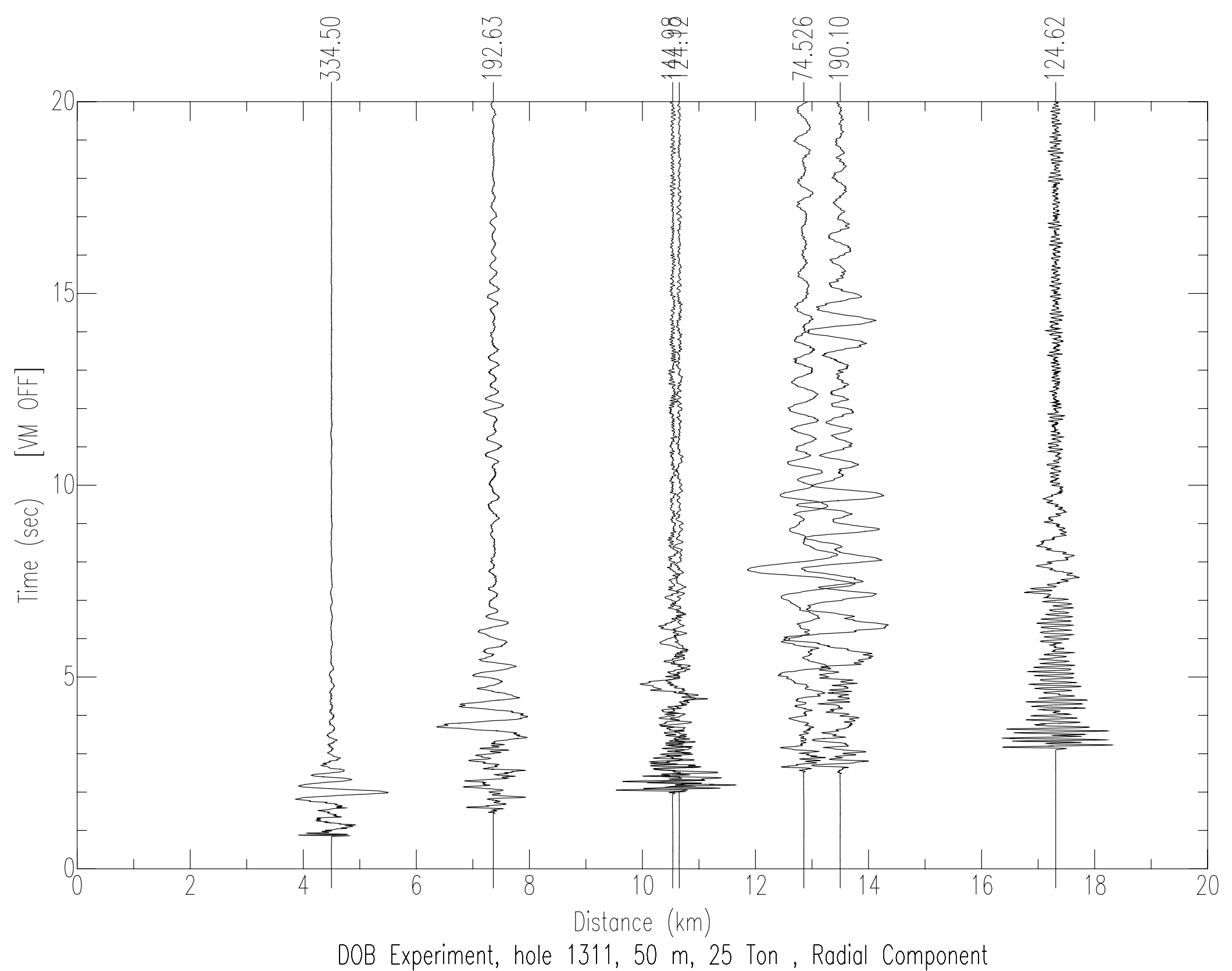




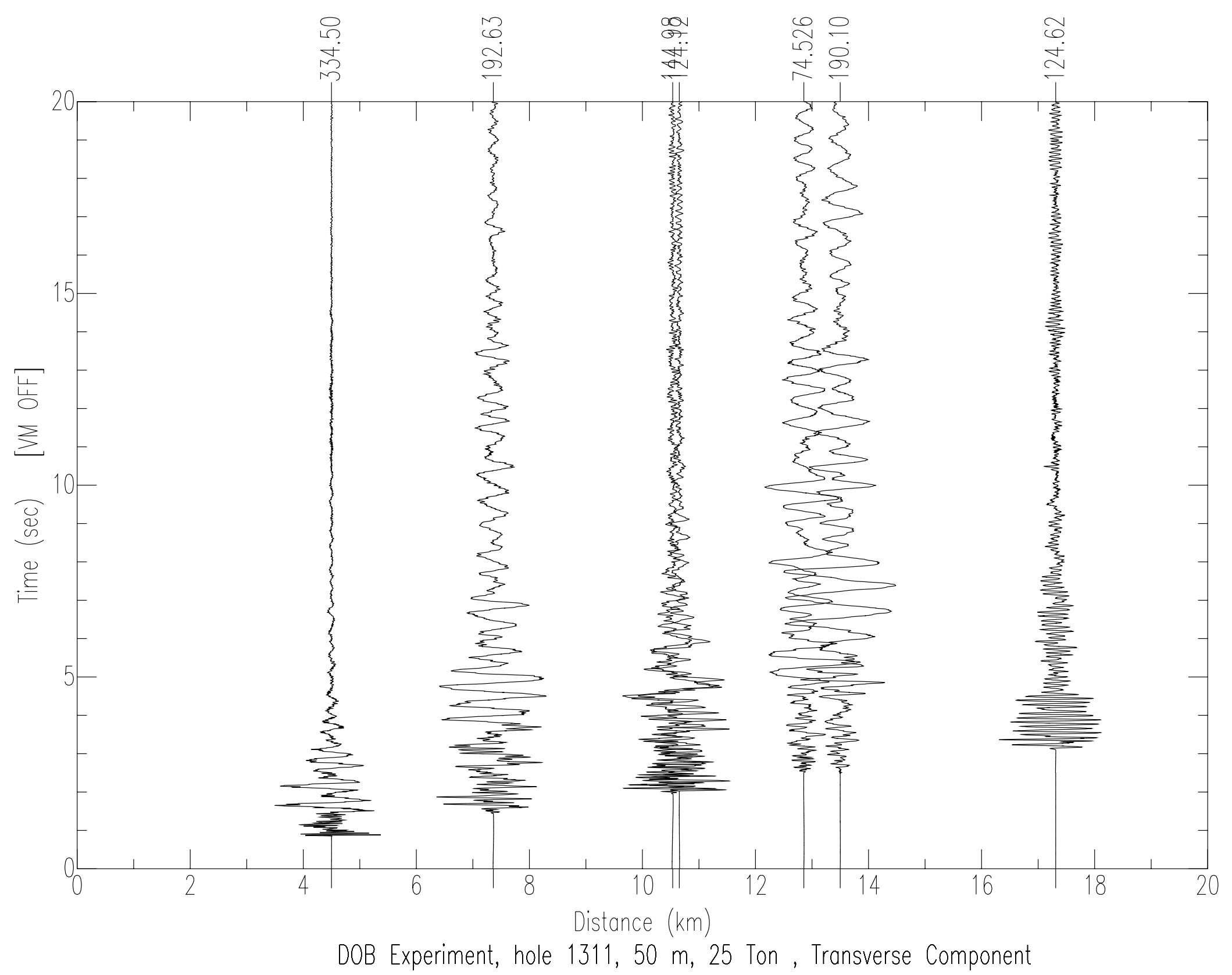




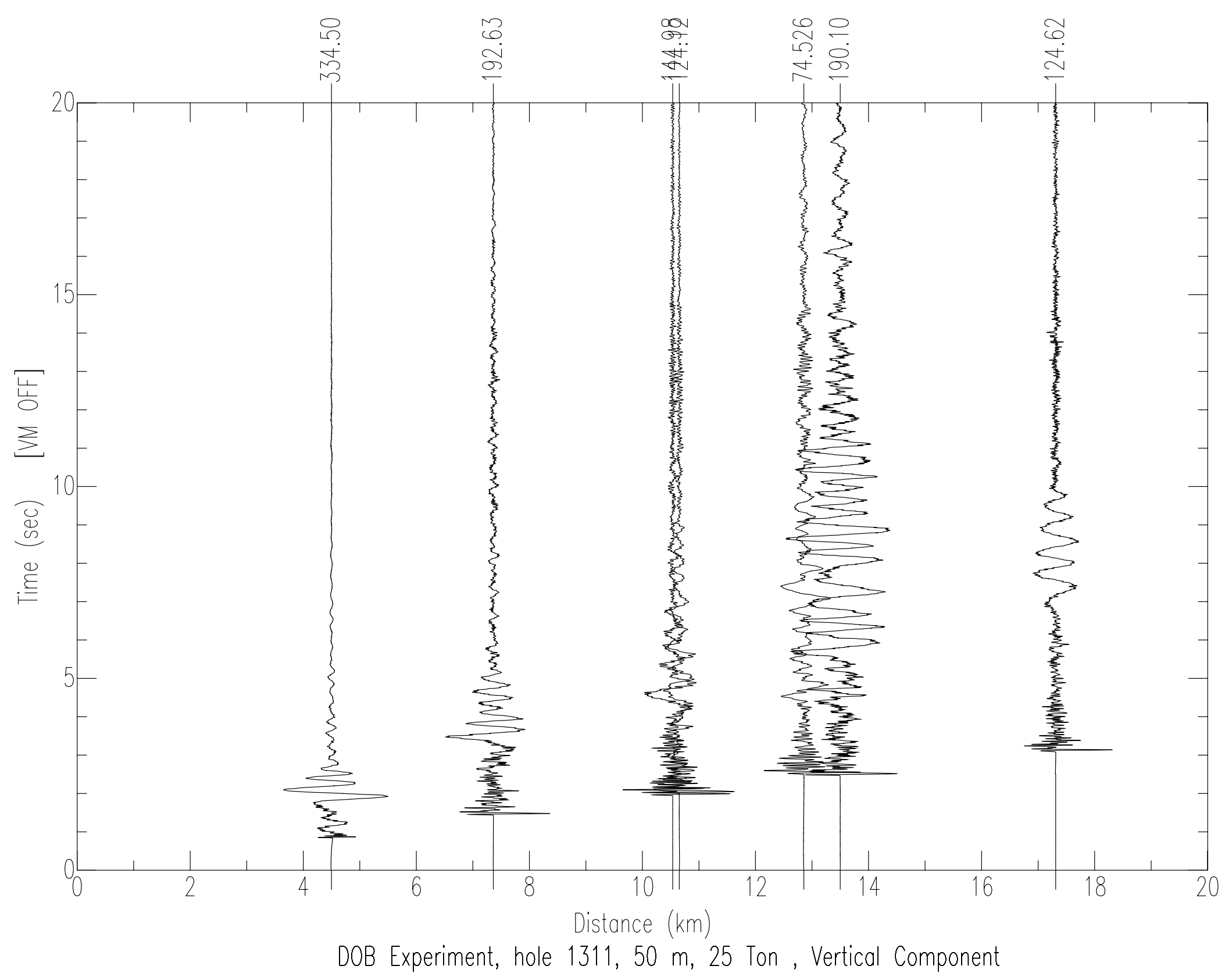




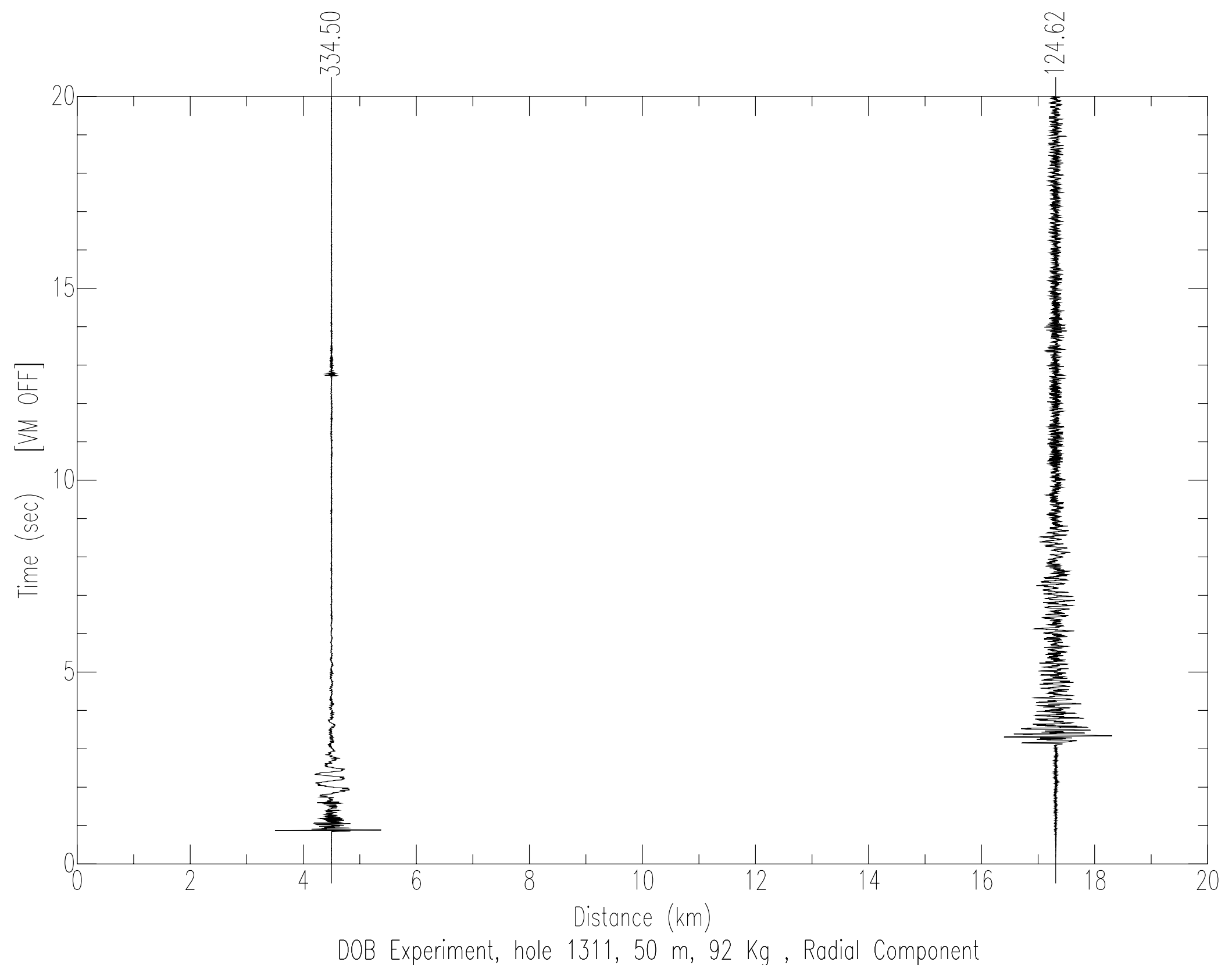




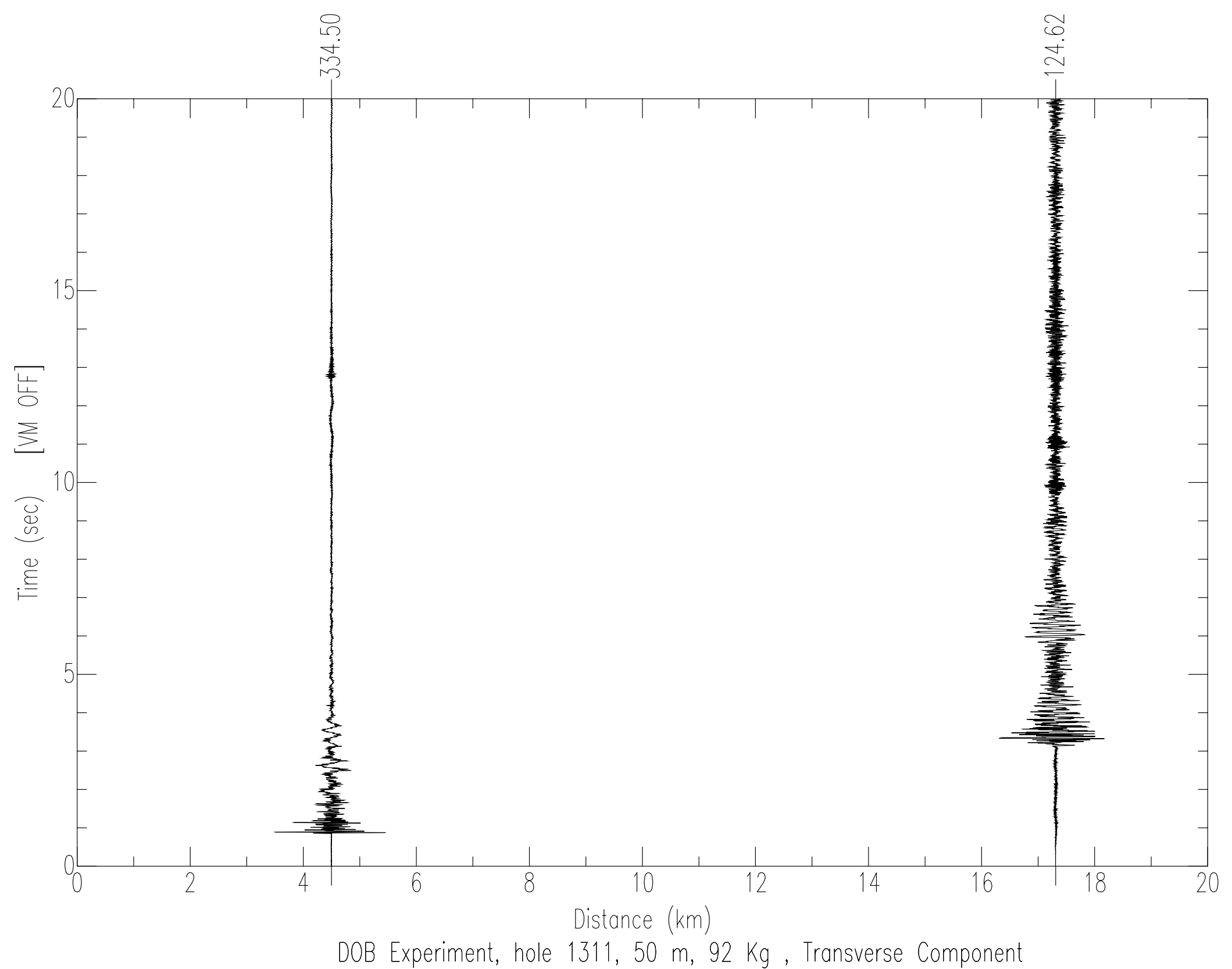




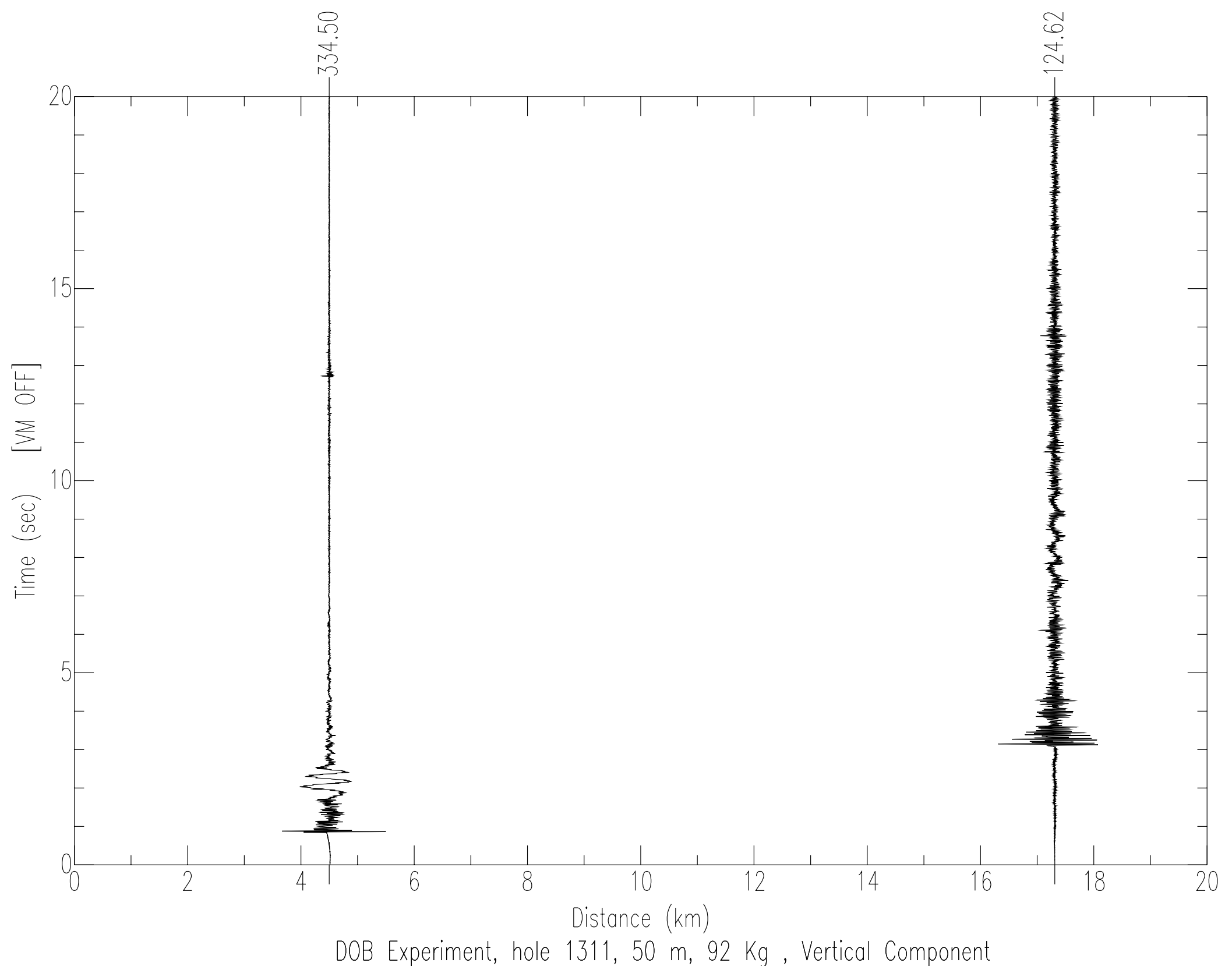




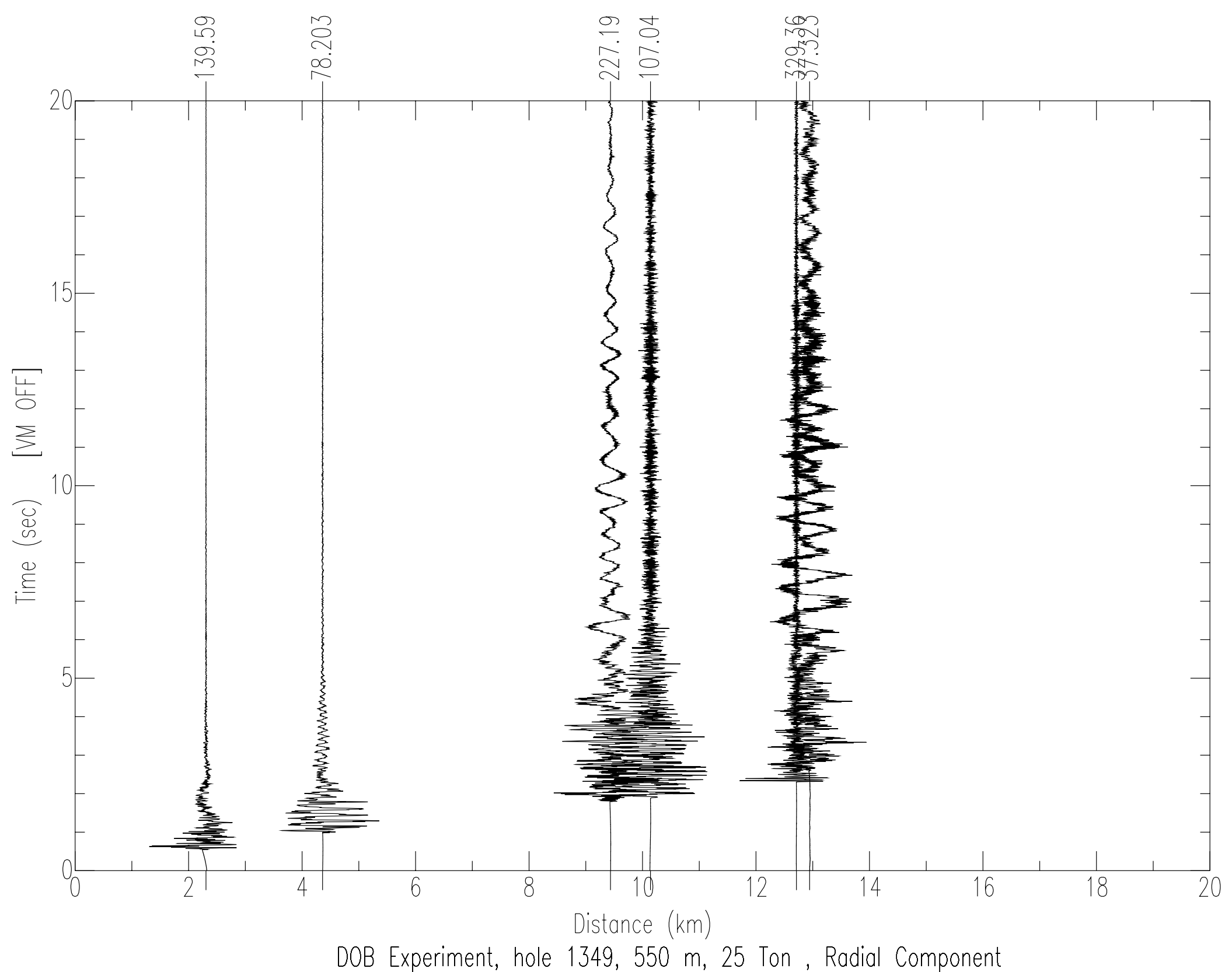




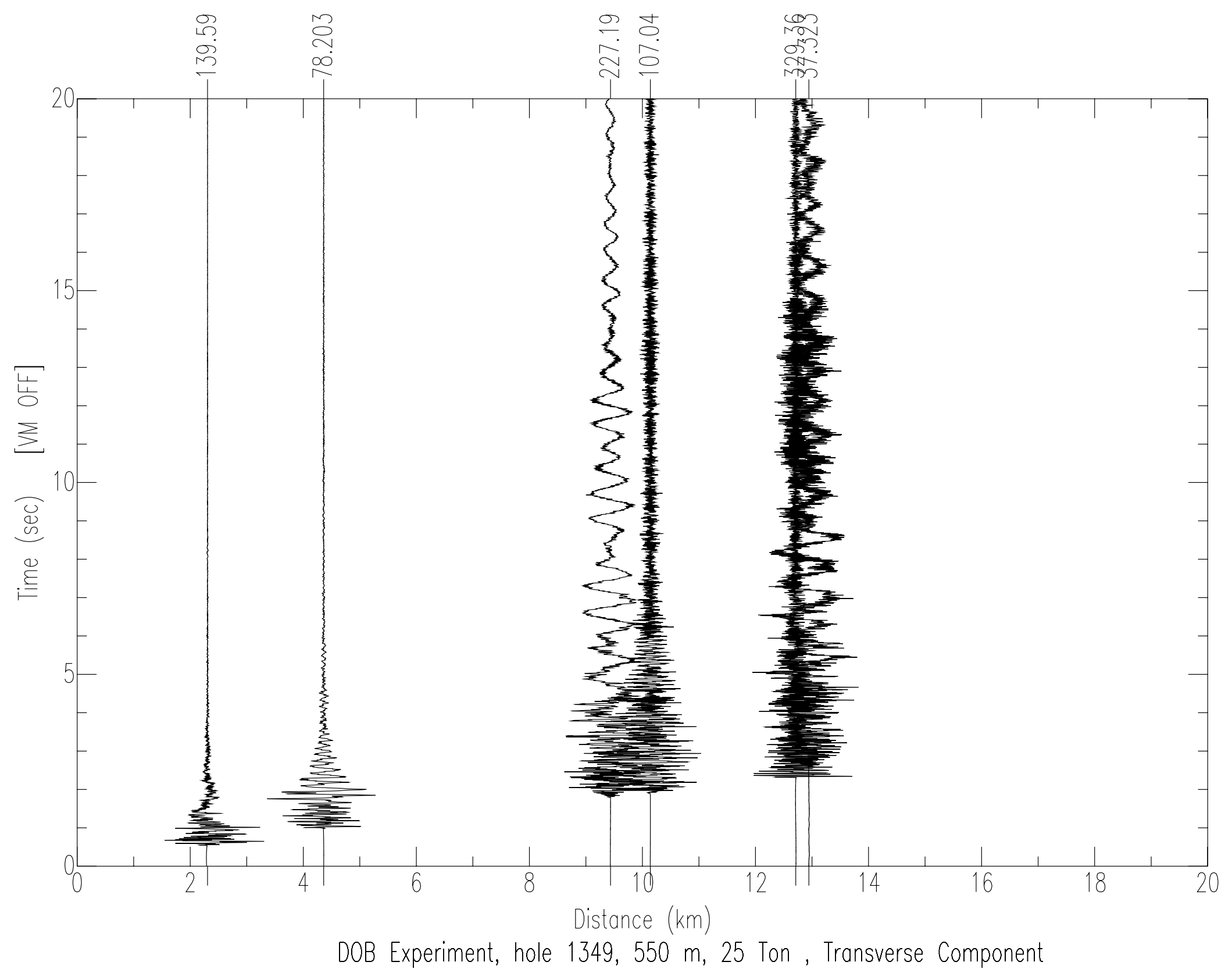




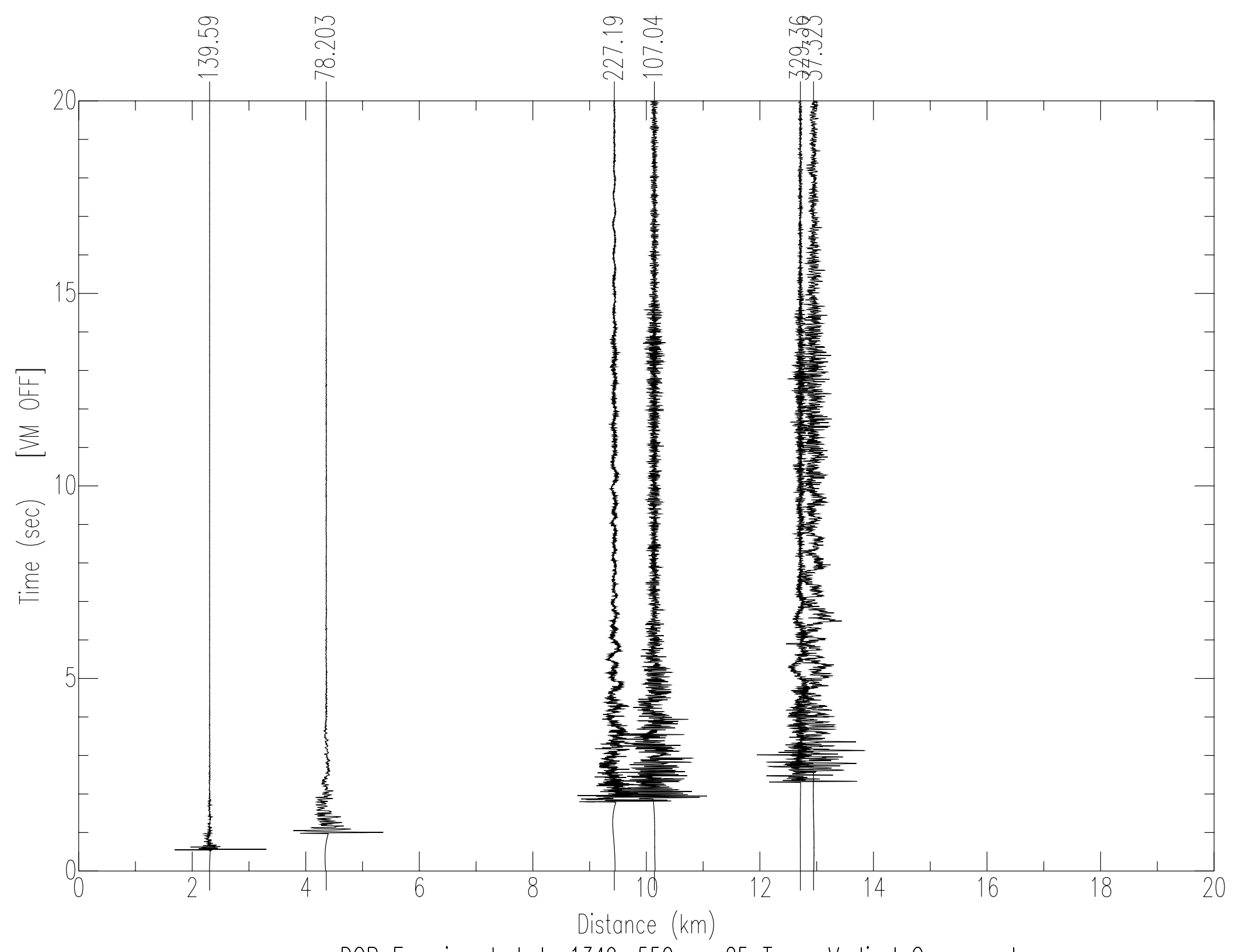

DOB Experiment, hole 1349, 550 m, 25 Ton, Vertical Component 


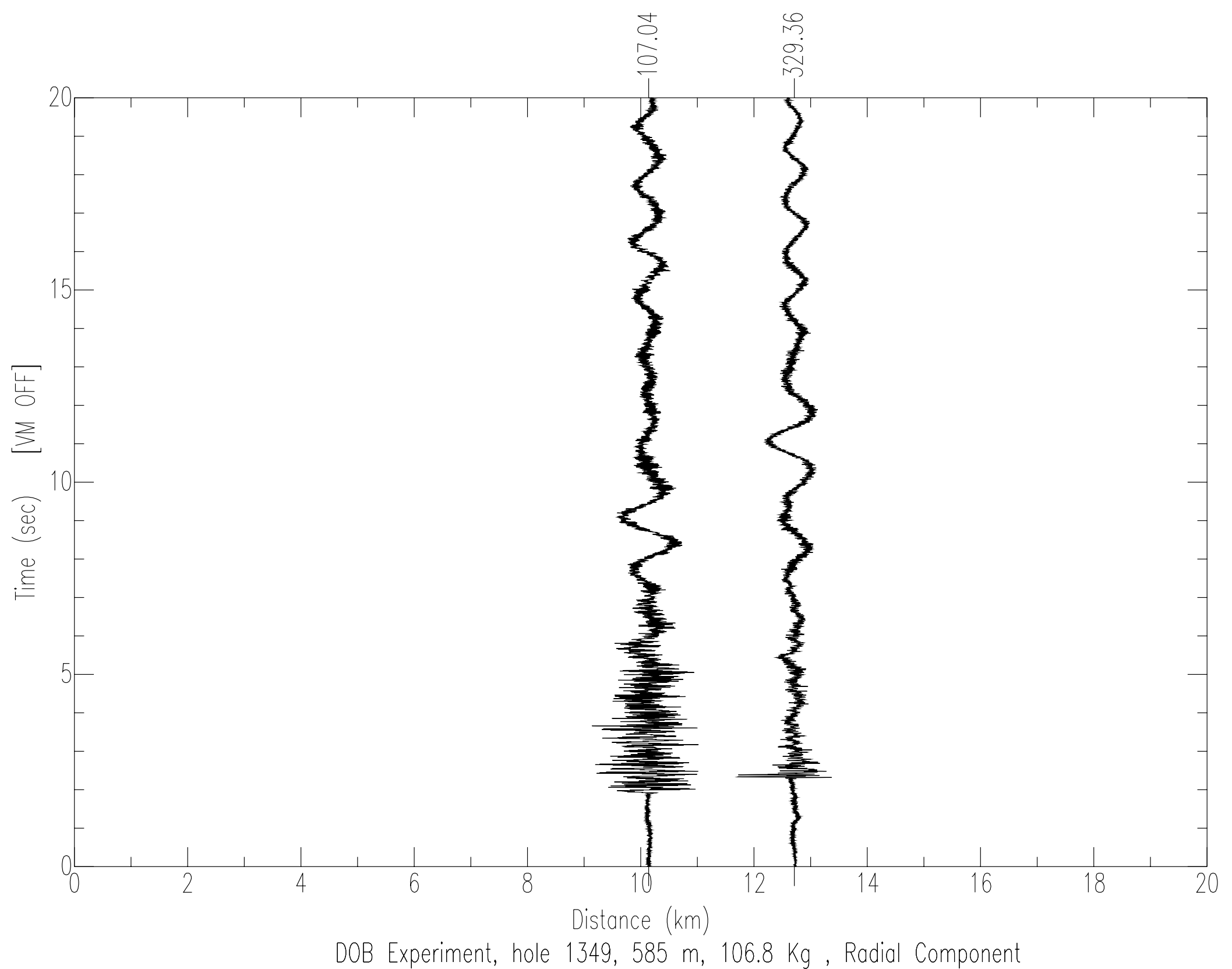




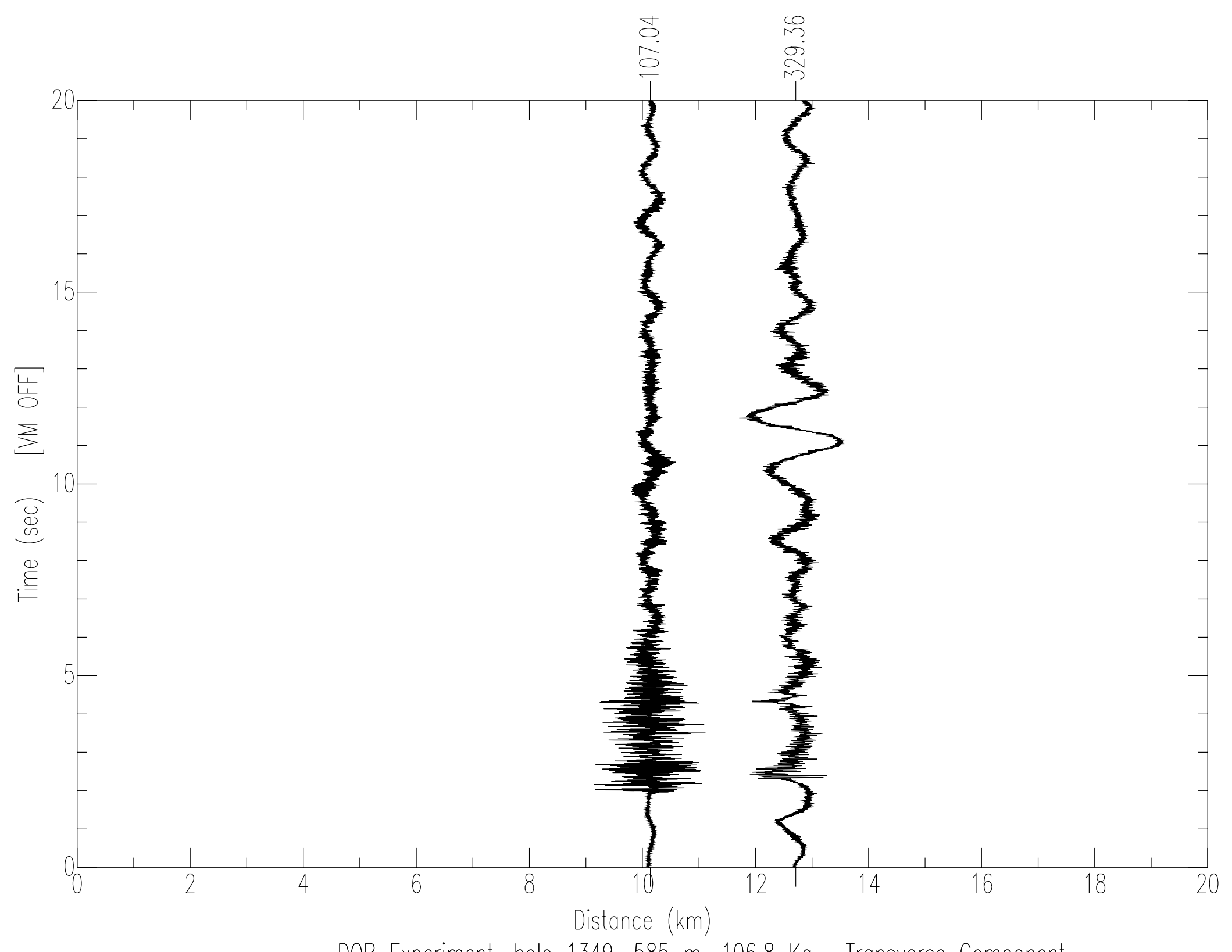

DOB Experiment, hole 1349, 585 m, $106.8 \mathrm{Kg}$, Transverse Component 


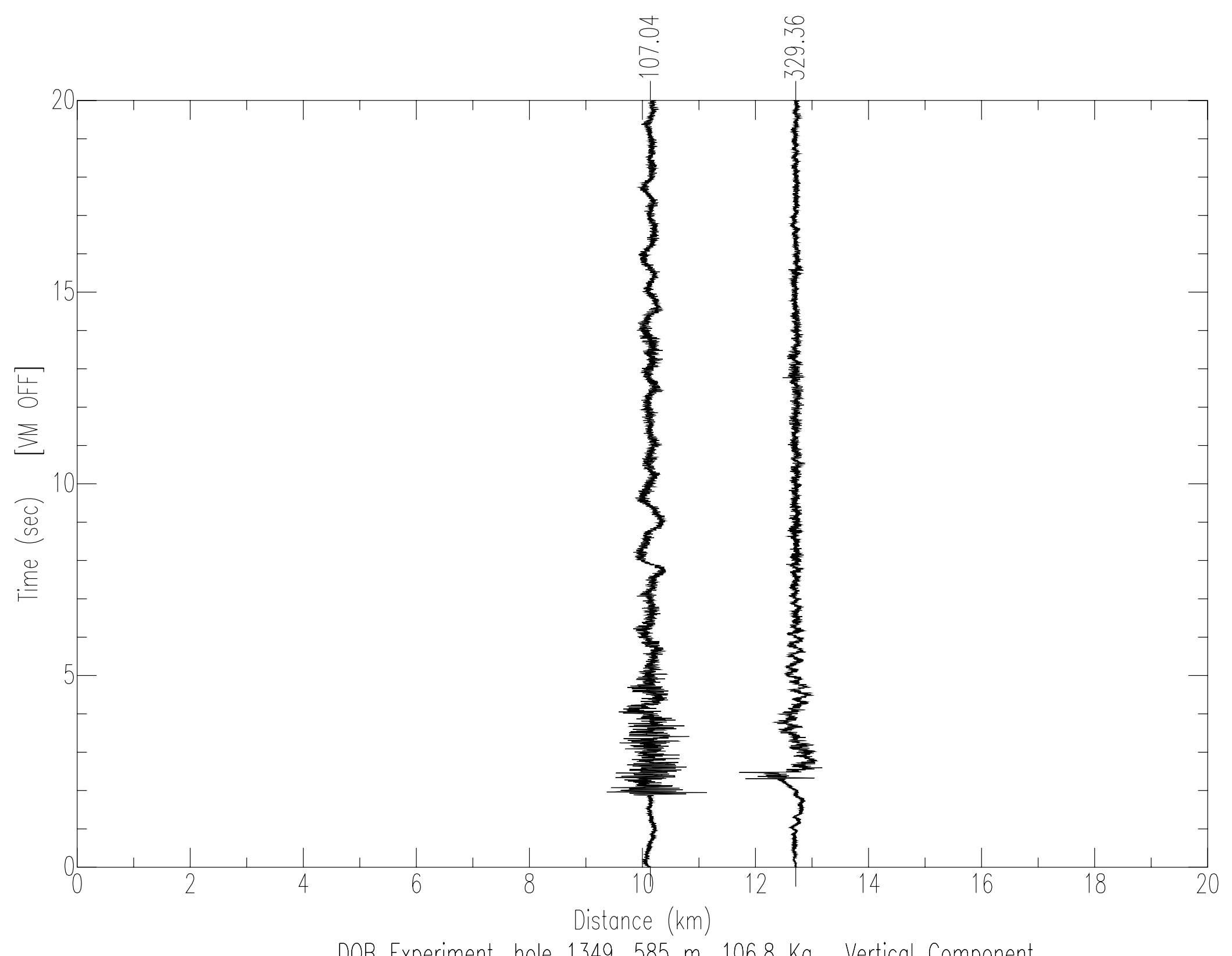

DOB Experiment, hole 1349, $585 \mathrm{~m}, 106.8 \mathrm{Kg}$, Vertical Component 


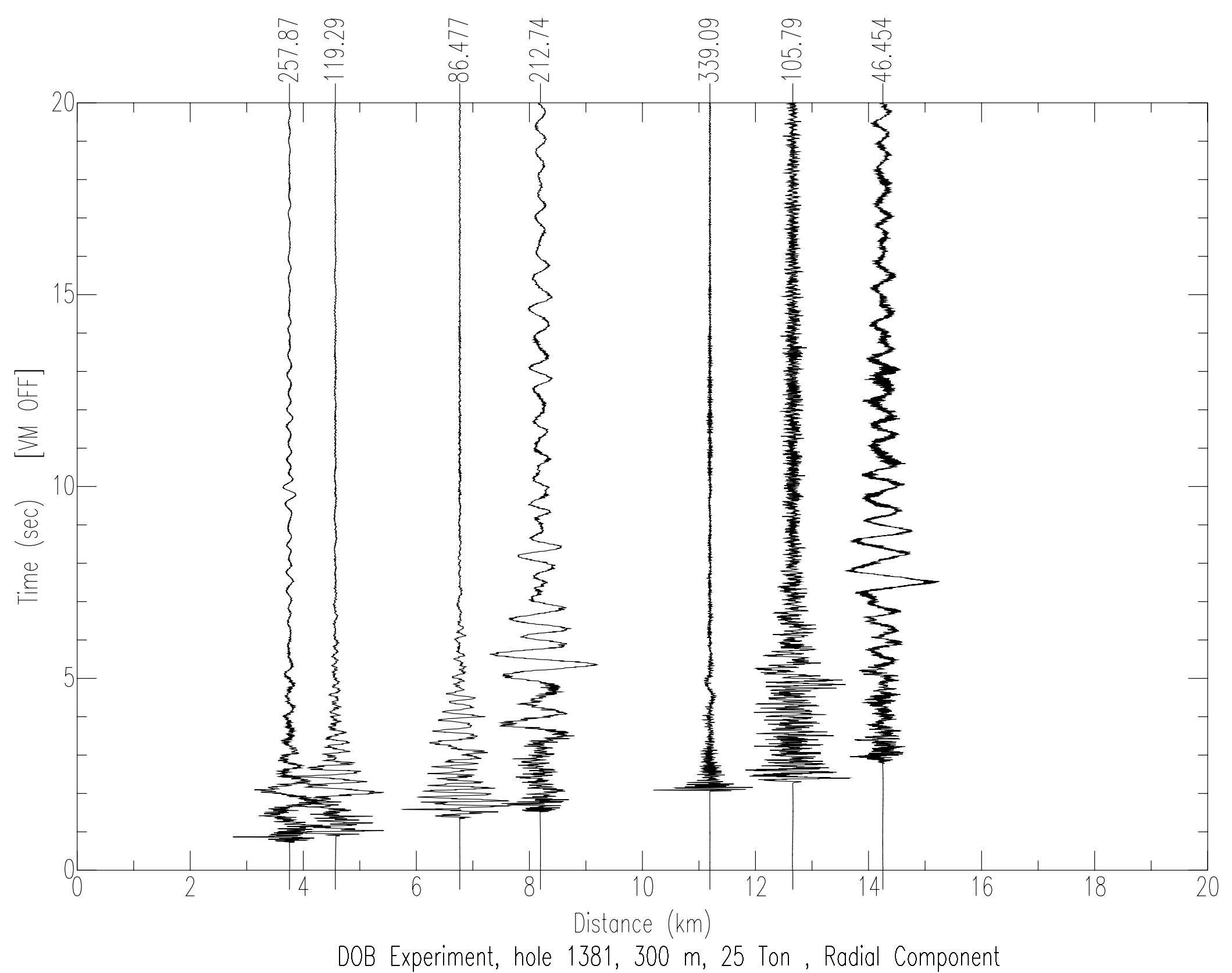




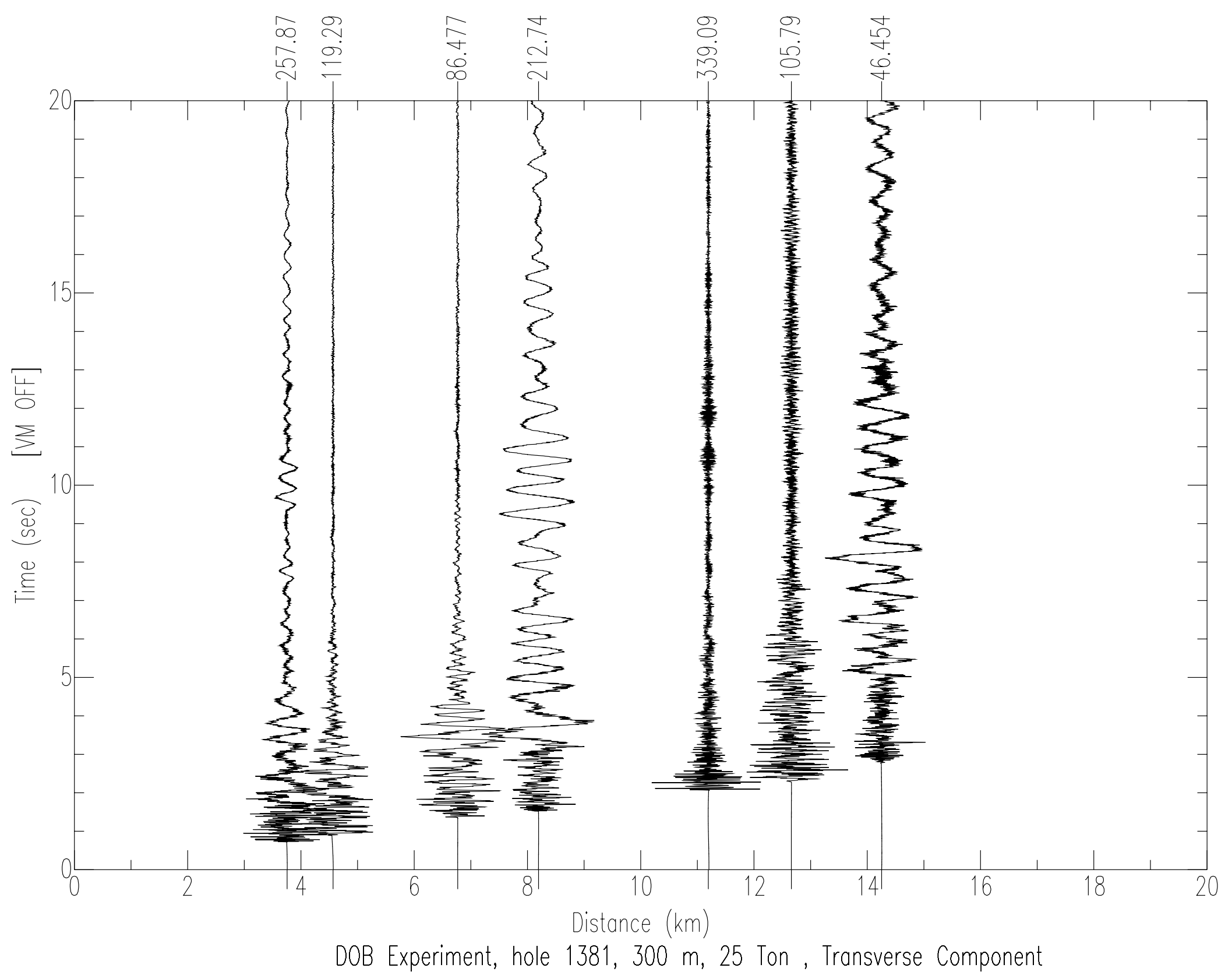




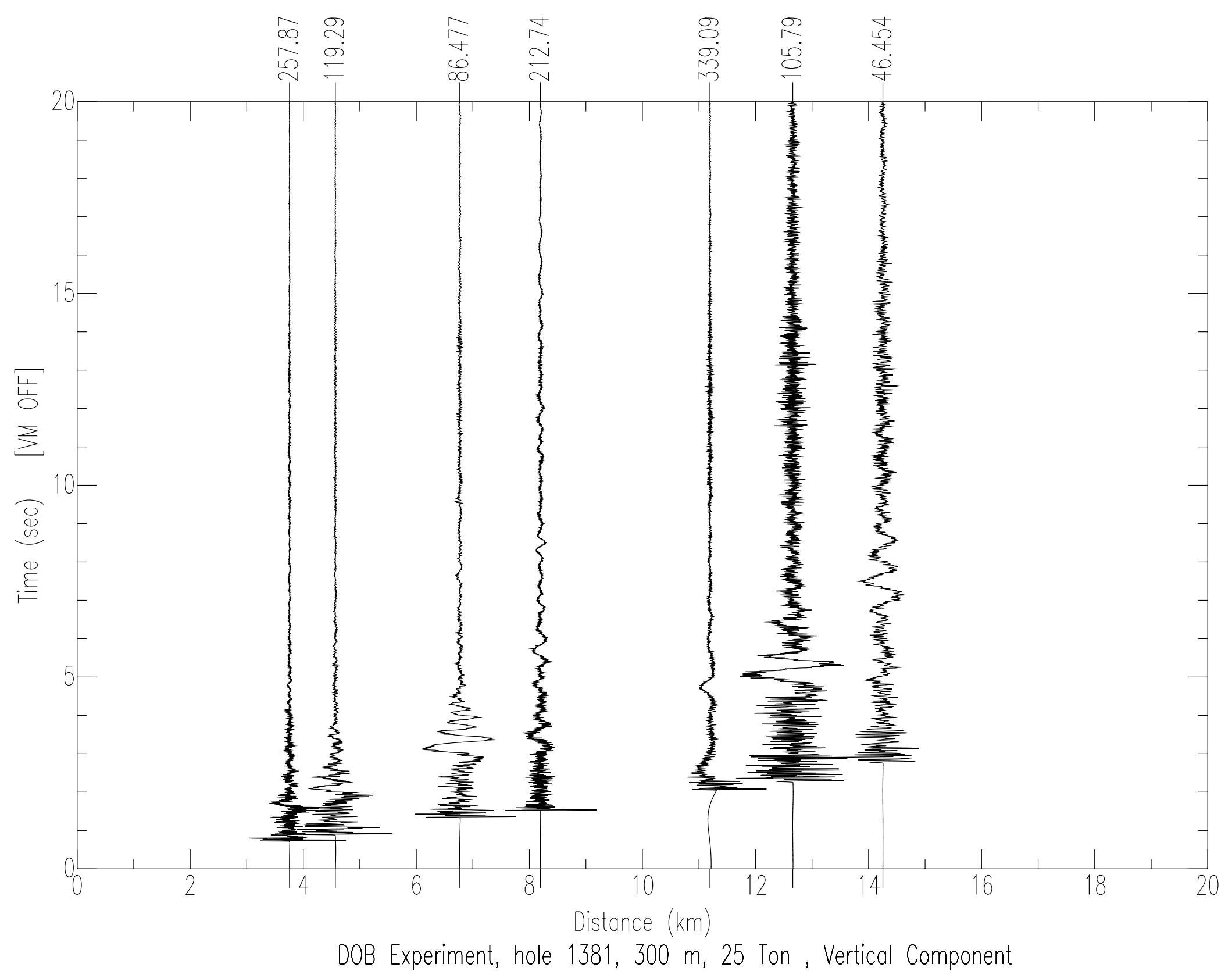




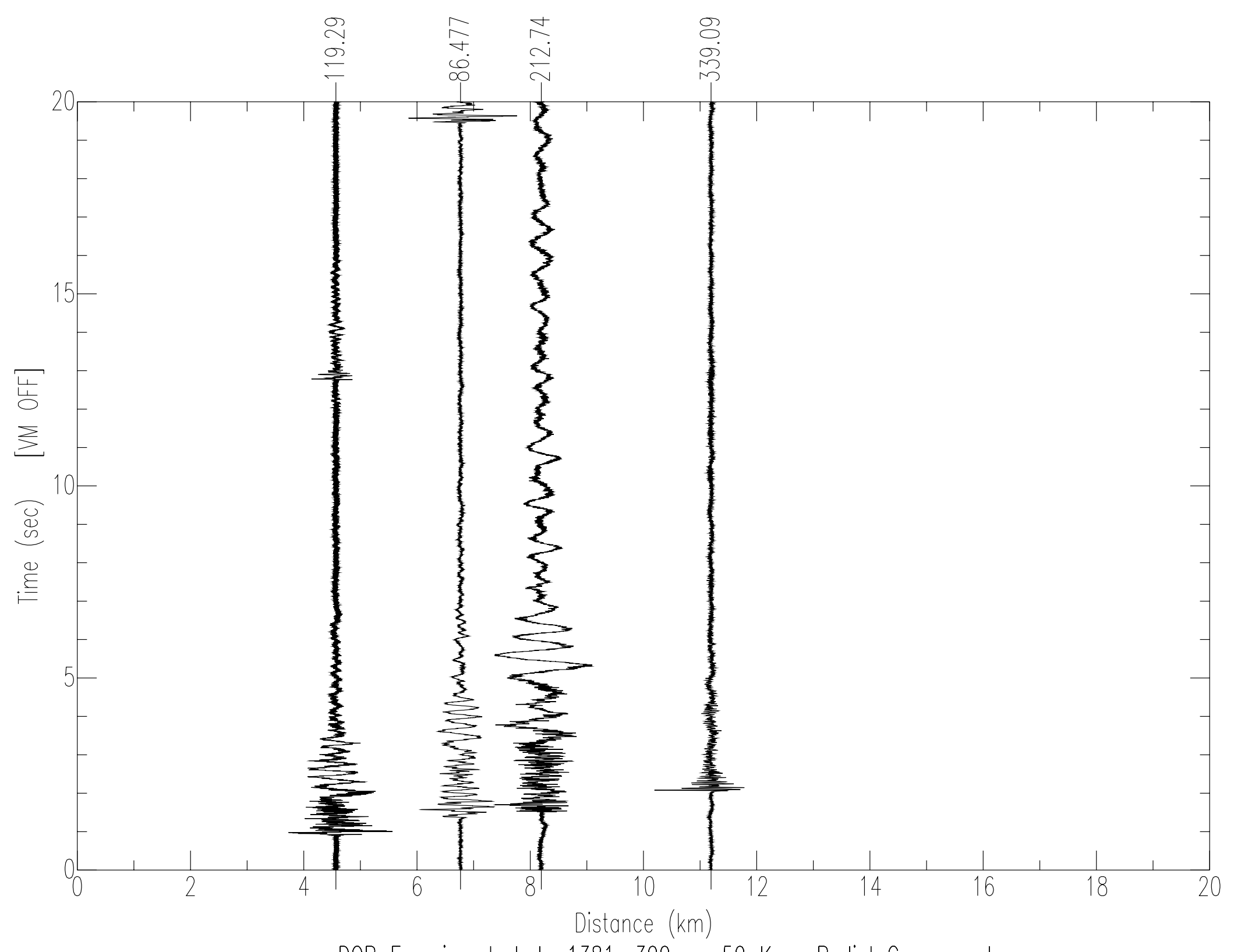

DOB Experiment, hole 1381, $300 \mathrm{~m}, 50 \mathrm{~kg}$, Radial Component 


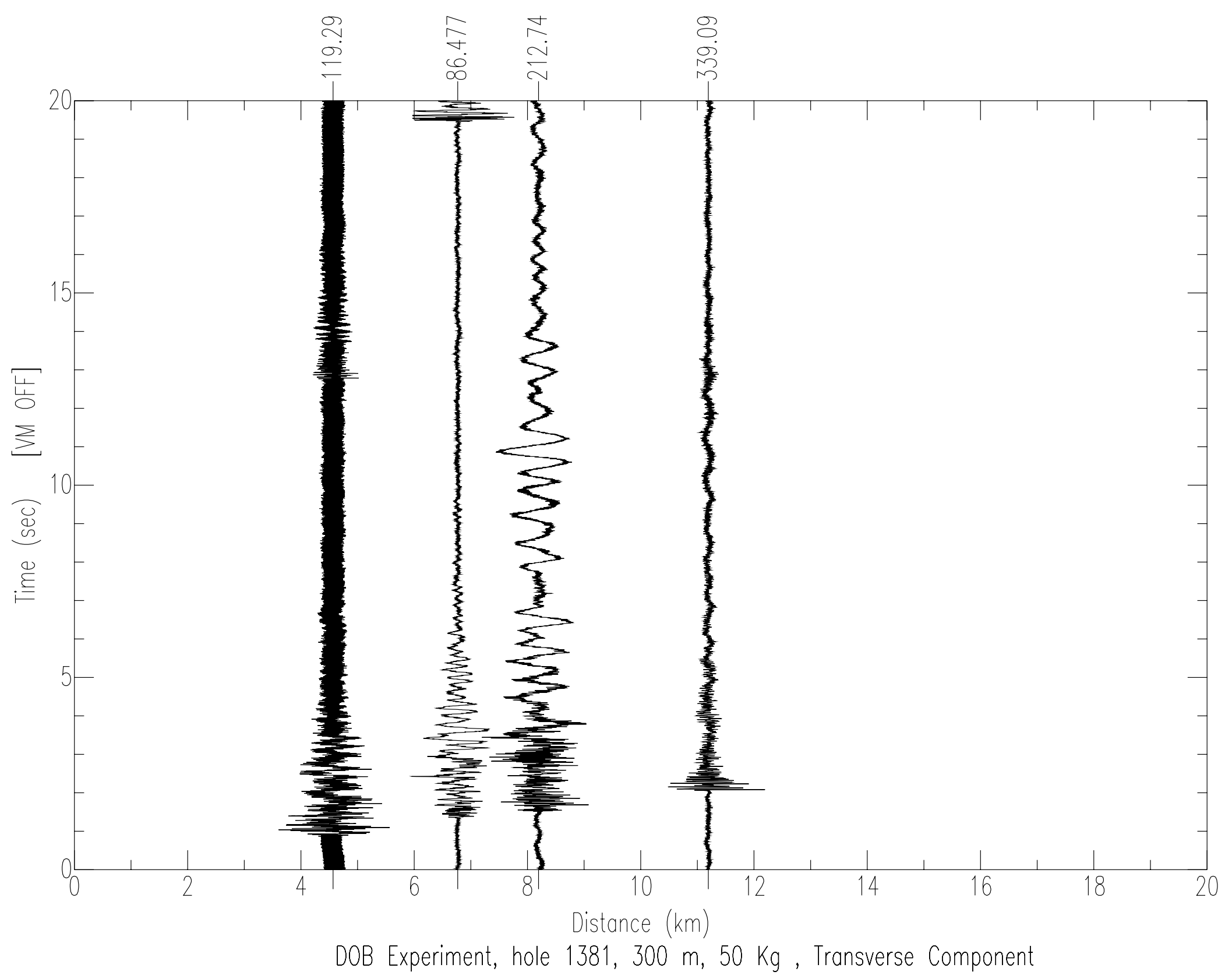




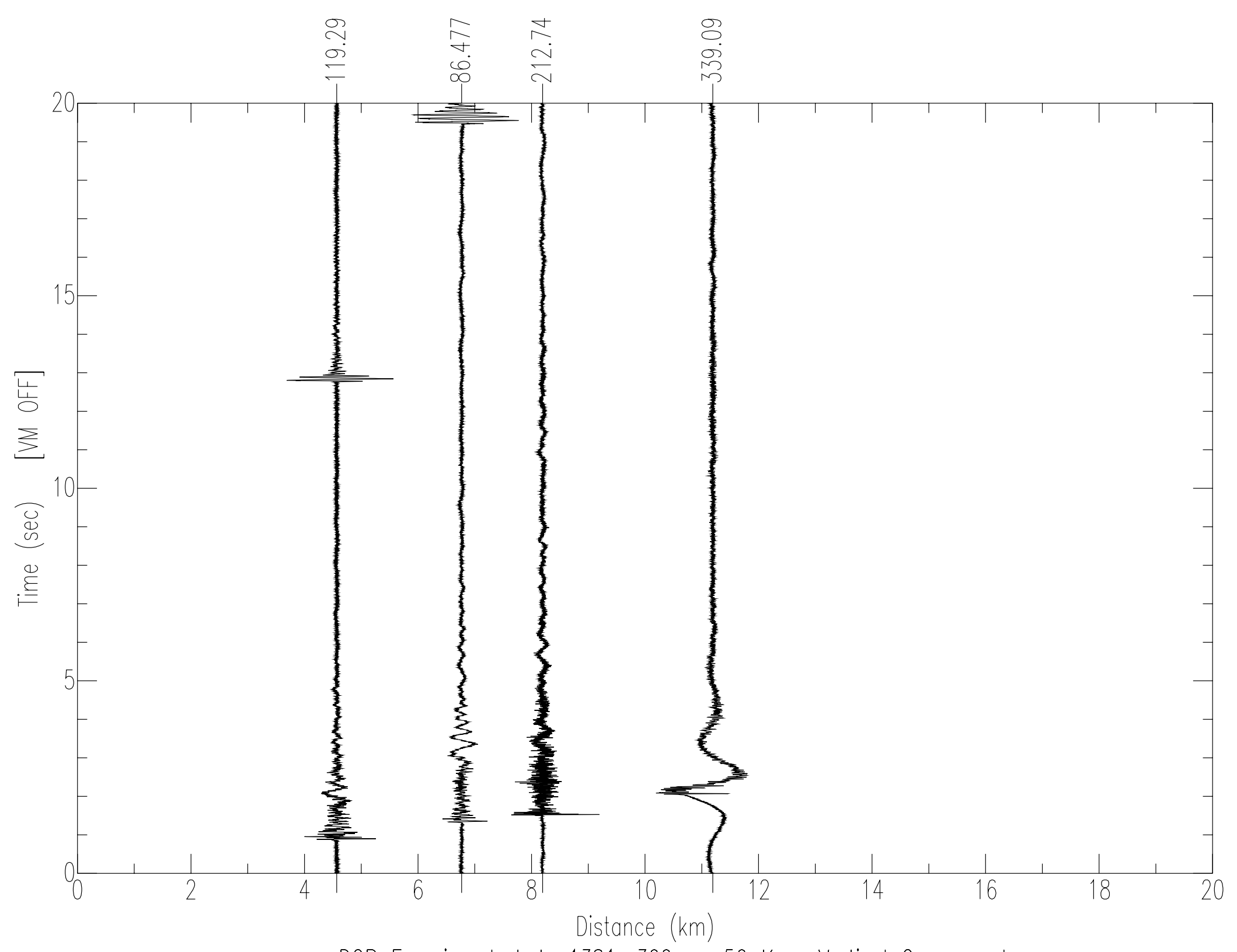

DOB Experiment, hole 1381, $300 \mathrm{~m}, 50 \mathrm{Kg}$, Vertical Component 


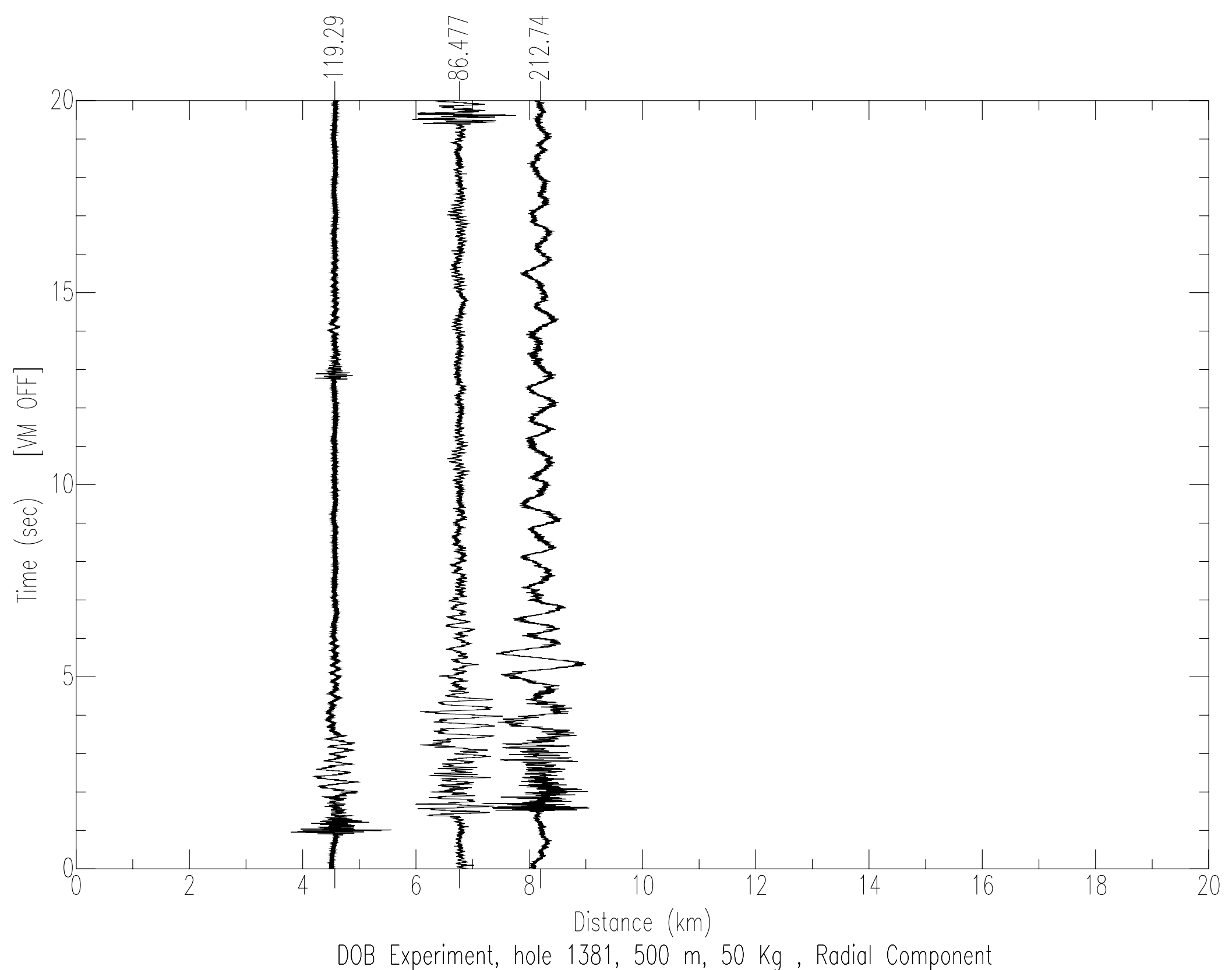




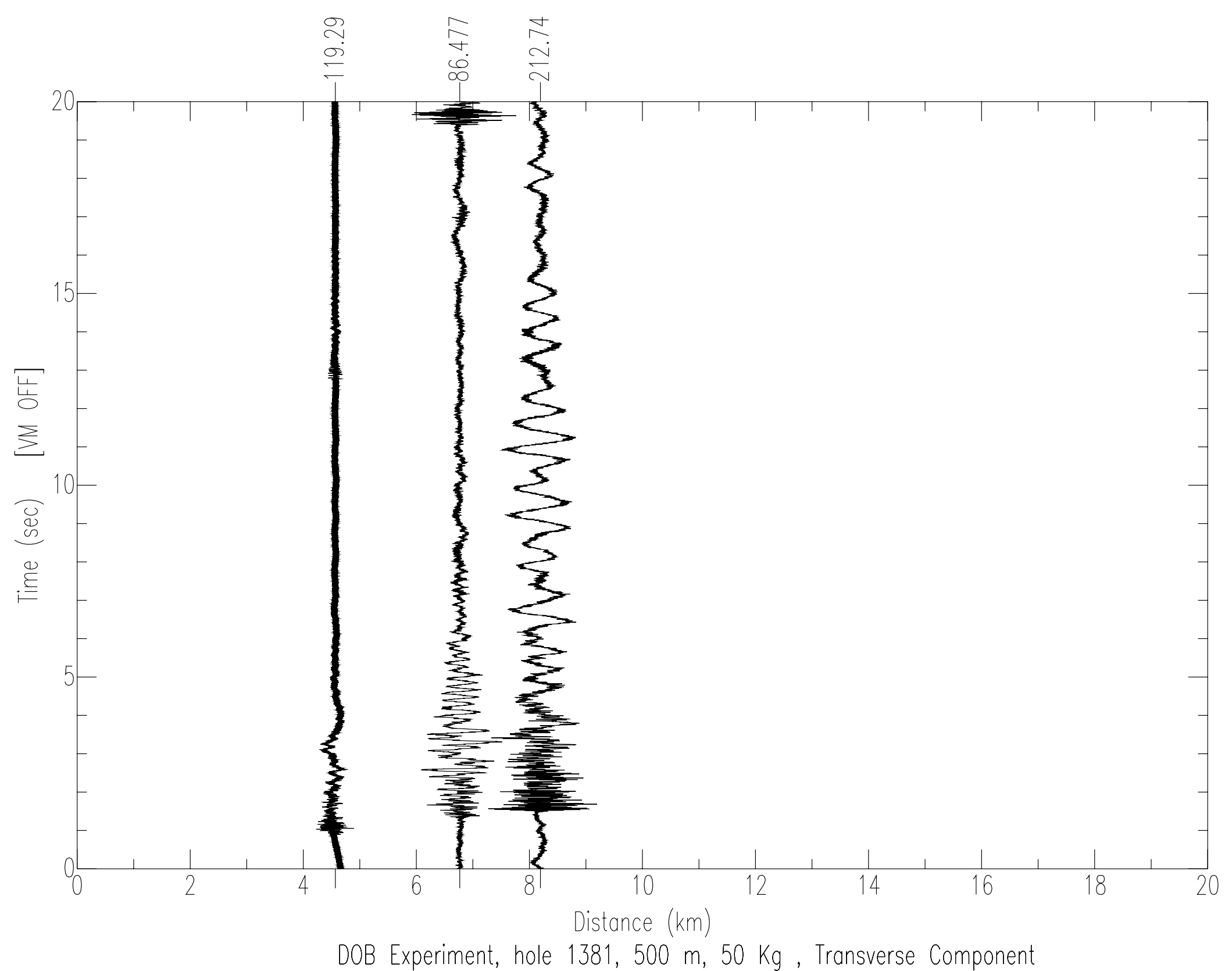




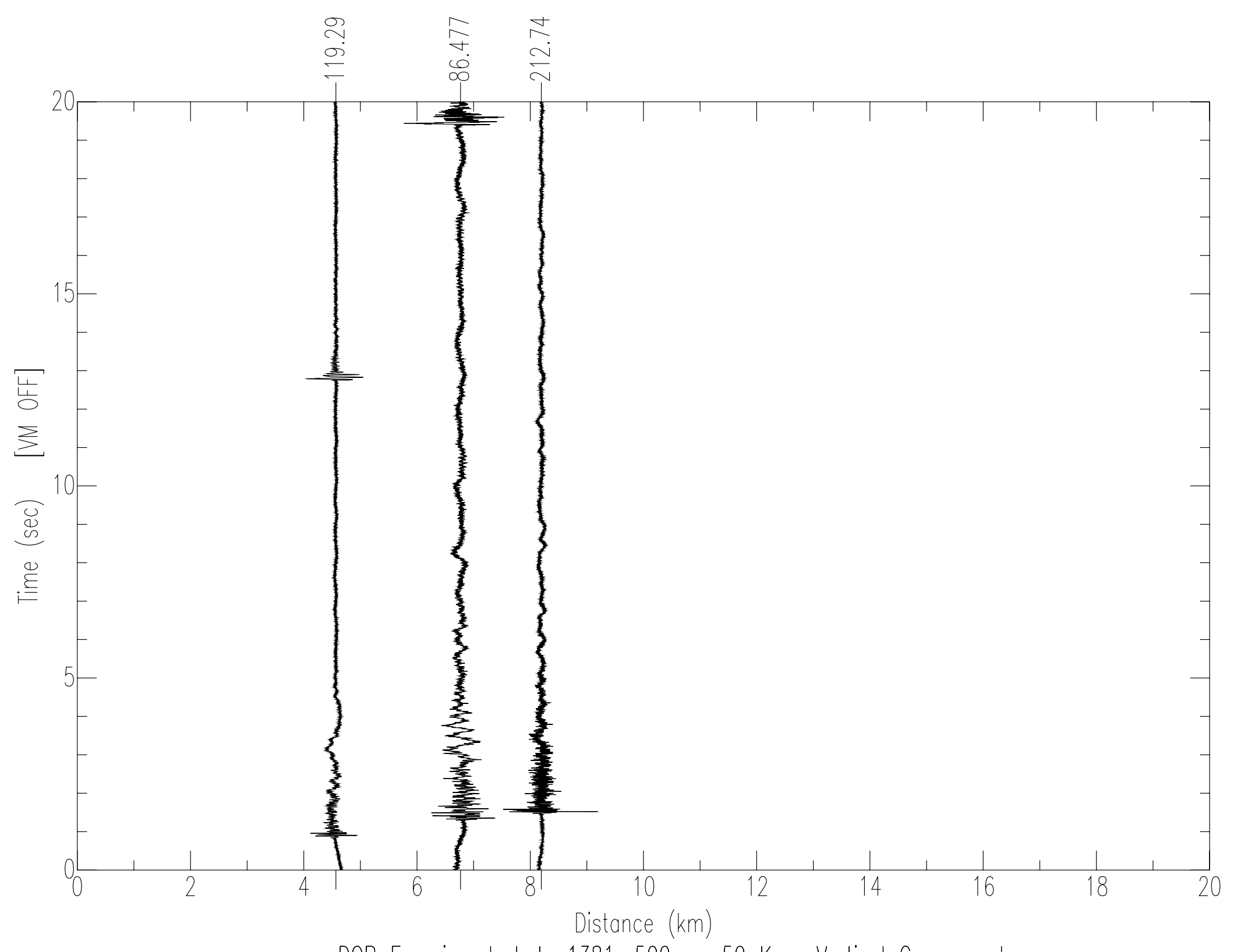

DOB Experiment, hole 1381, $500 \mathrm{~m}, 50 \mathrm{Kg}$, Vertical Component 


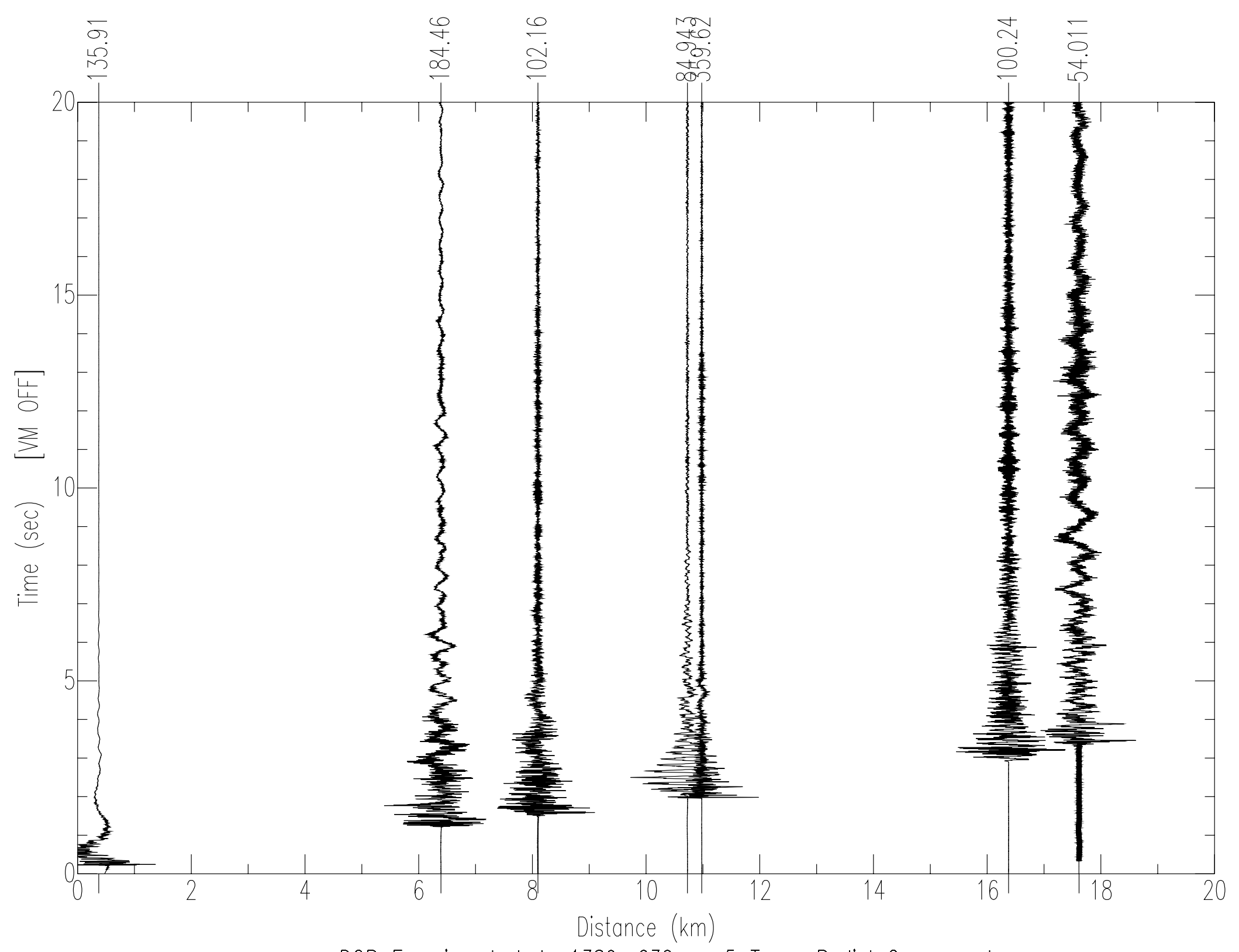

DOB Experiment, hole 1389, 630 m, 5 Ton, Radial Component 


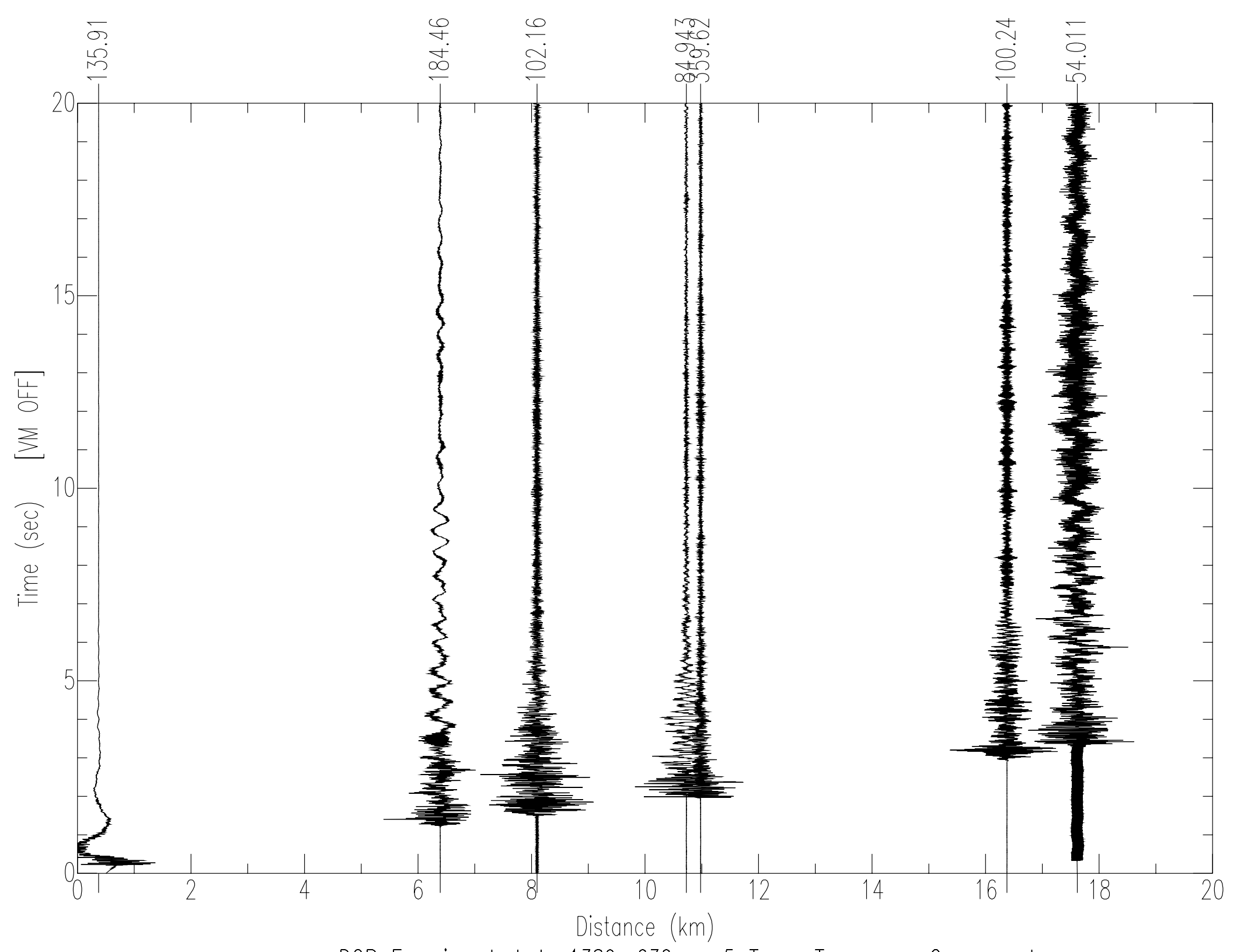

DOB Experiment, hole 1389, $630 \mathrm{~m}, 5$ Ton, Transverse Component 


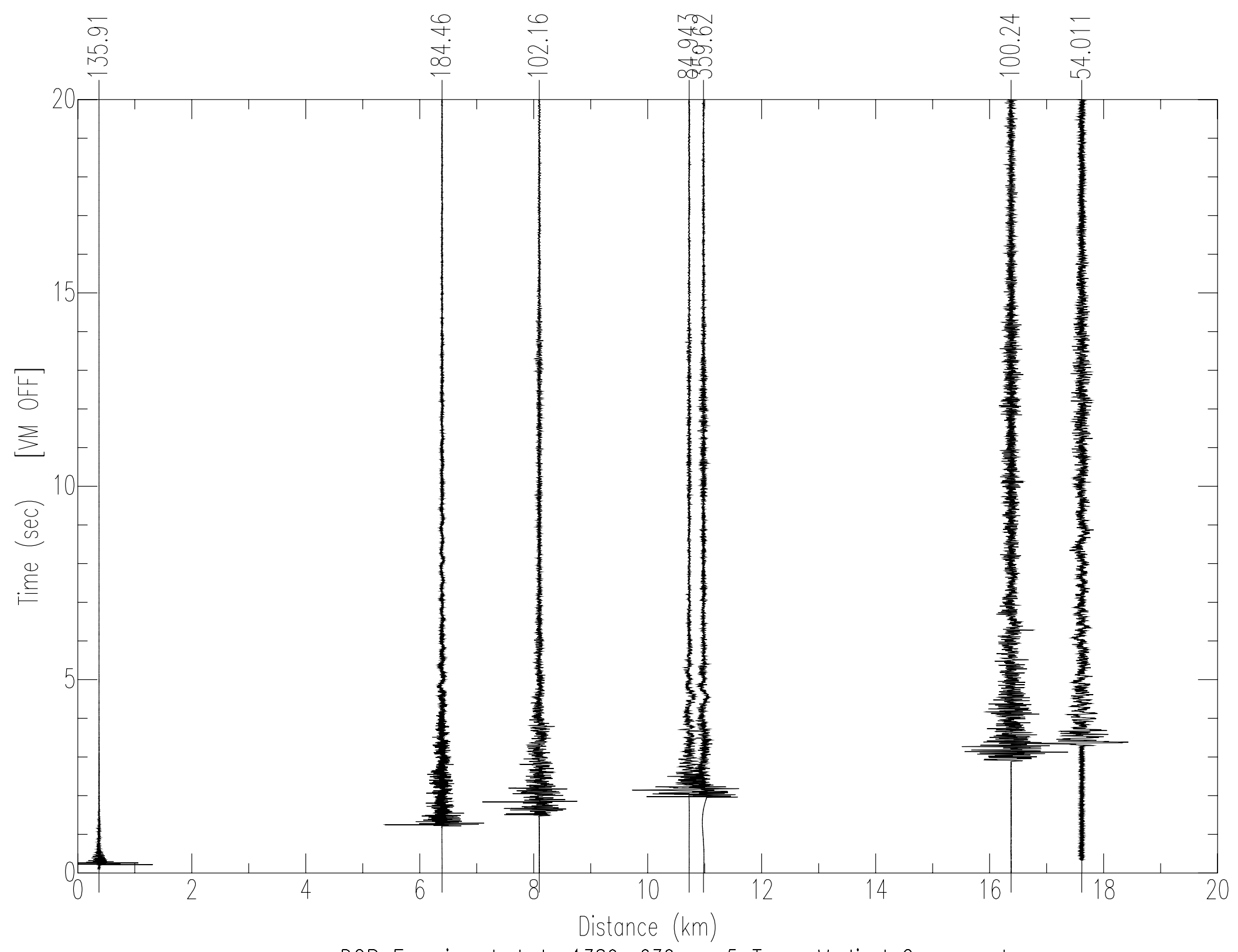

DOB Experiment, hole 1389, 630 m, 5 Ton, Vertical Component 
Appendix B

2.5 second record section plots for vertical, radial and transverse components of 5 ton, 25 ton and Green's function shots recorded at Shagan River in 1997. A normal moveout shift has been applied to each seismogram using a P-wave velocity of $5.6 \mathrm{~km} / \mathrm{s}$. Zero times correspond to the shot origin times. Origin times for the Green's function shots have been estimated using traveltimes of 25 ton shots. Shot to station azimuth is given at the end of each trace. Hole ID, depth, yield and component of motion are listed at the bottom of each shot. 


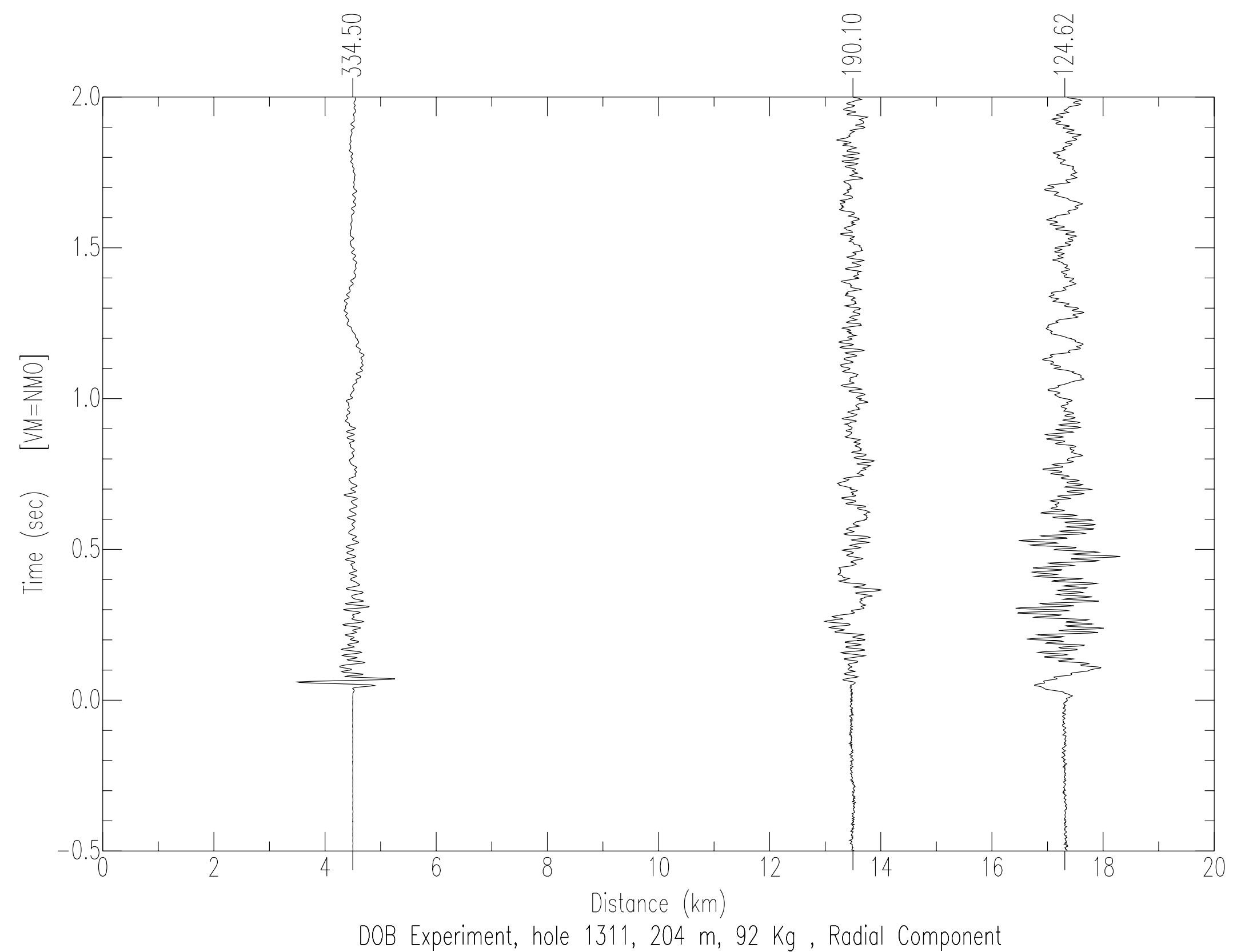




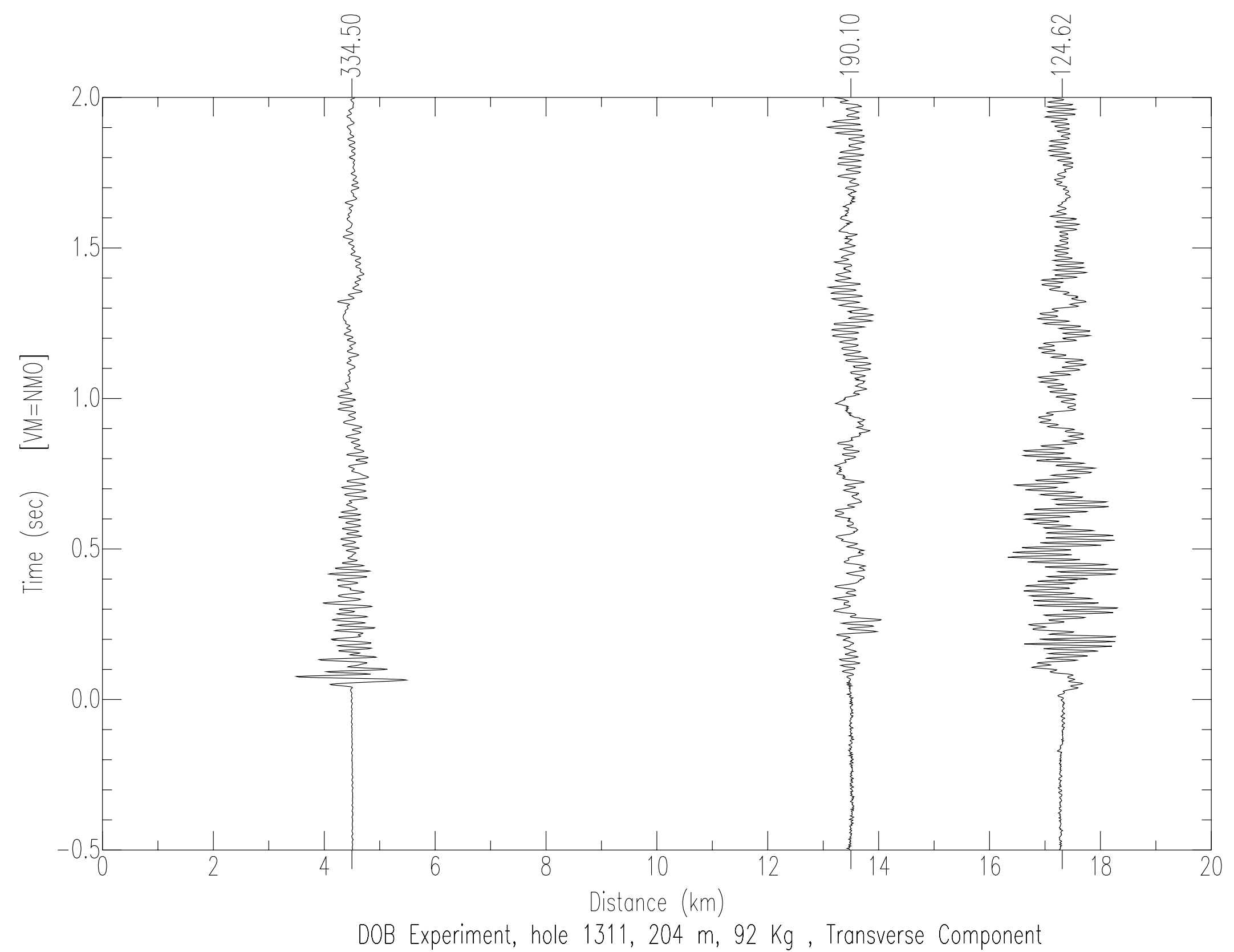




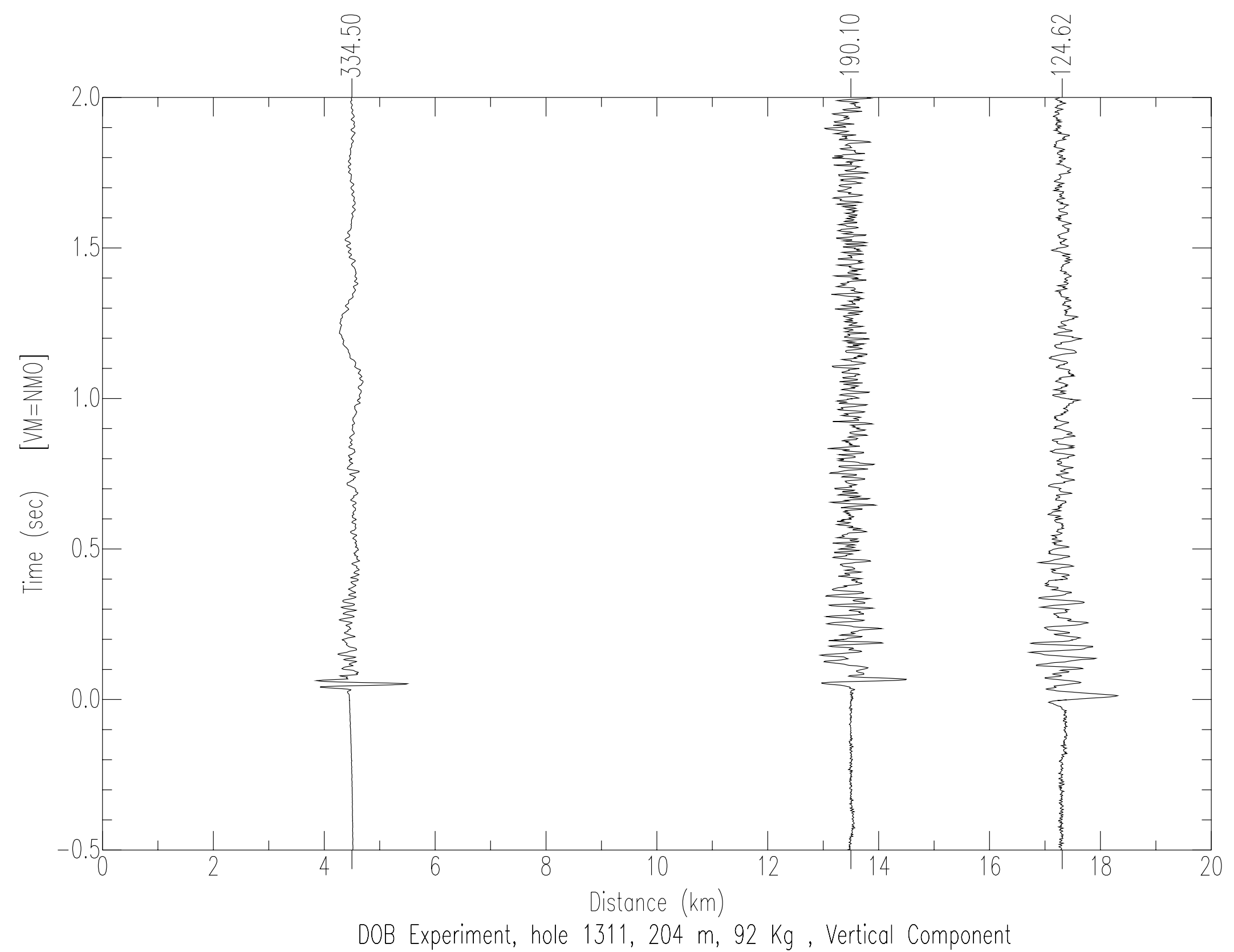




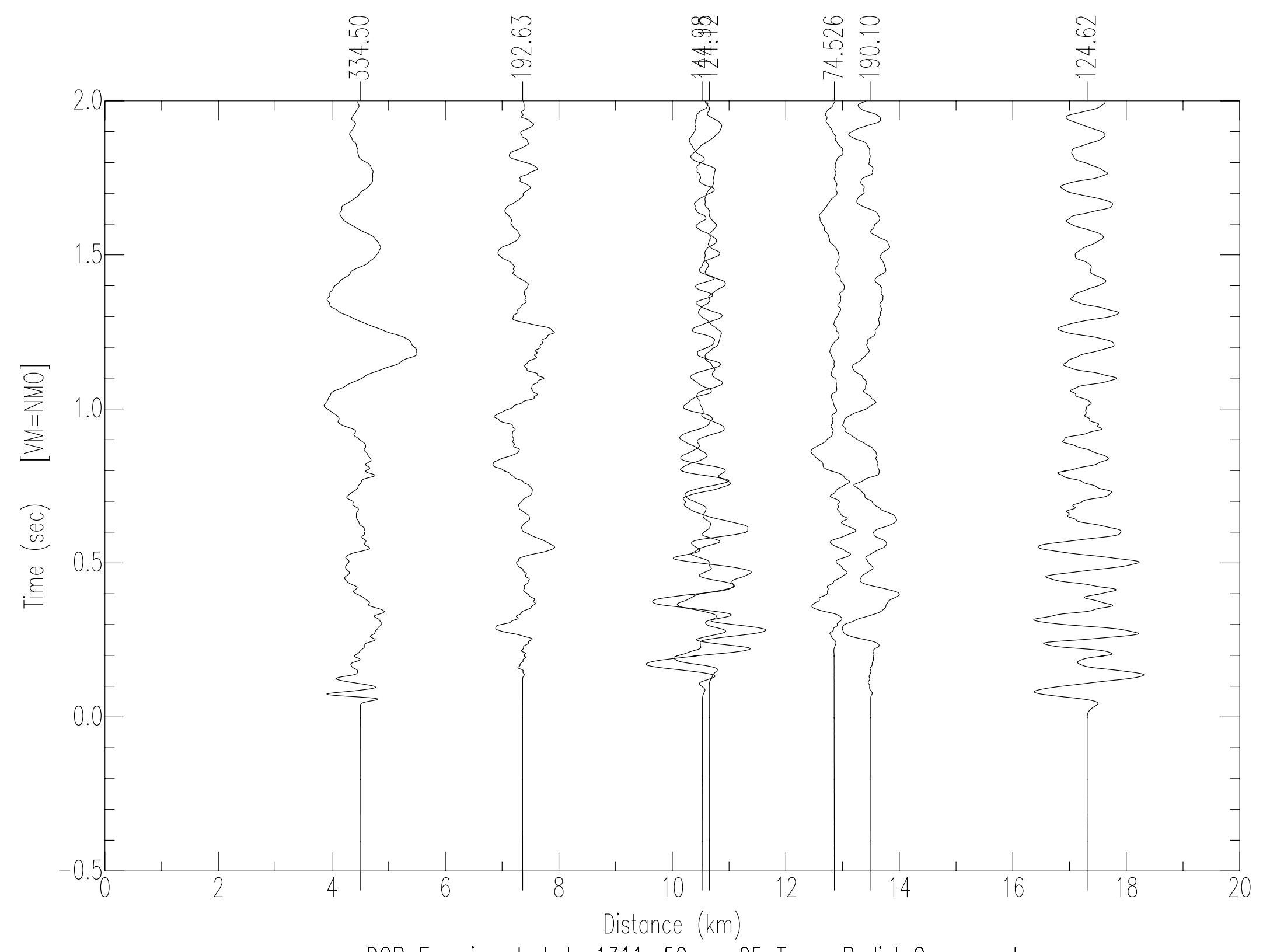

DOB Experiment, hole 1311, 50 m, 25 Ton, Radial Component 


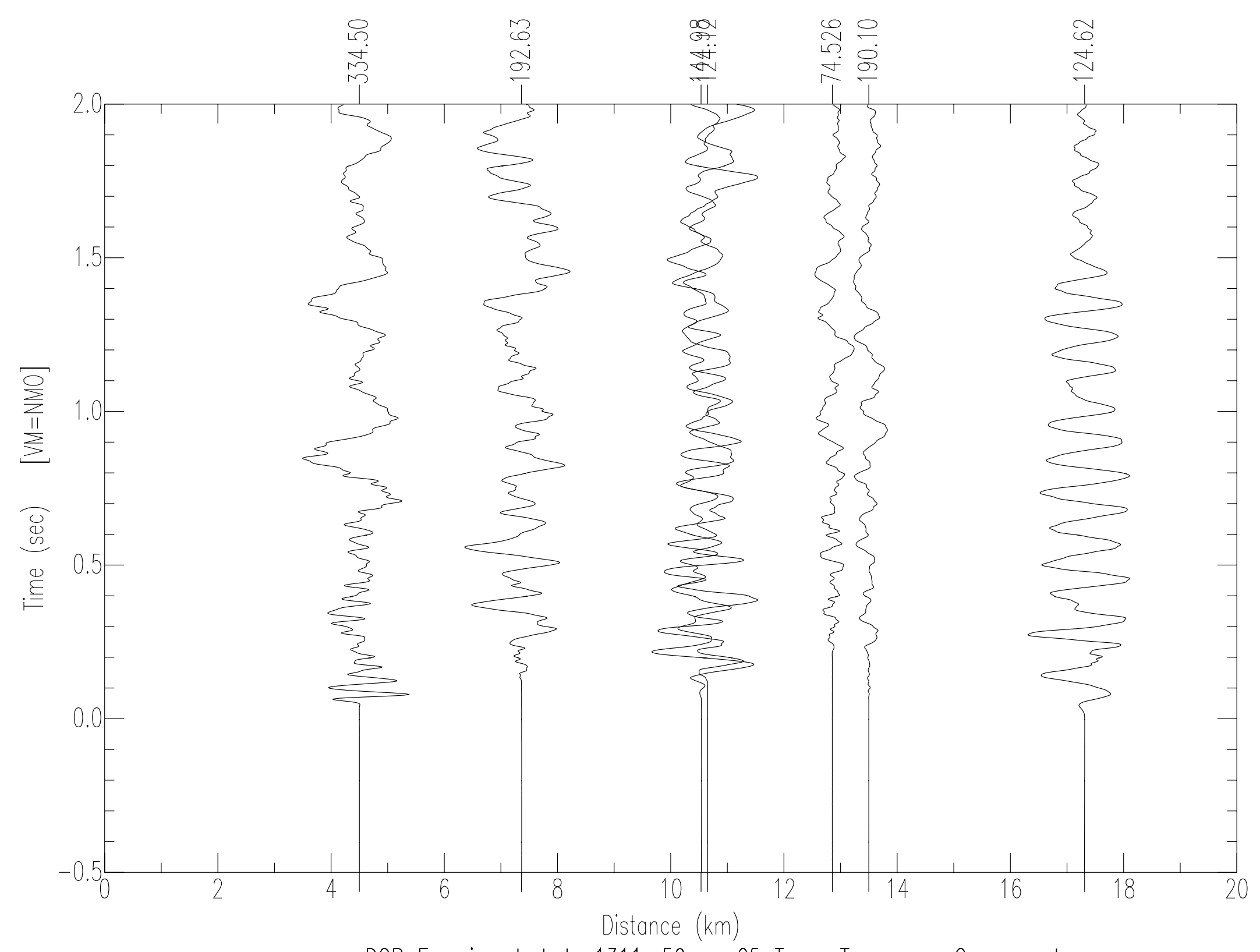

DOB Experiment, hole 1311, 50 m, 25 Ton , Transverse Component 


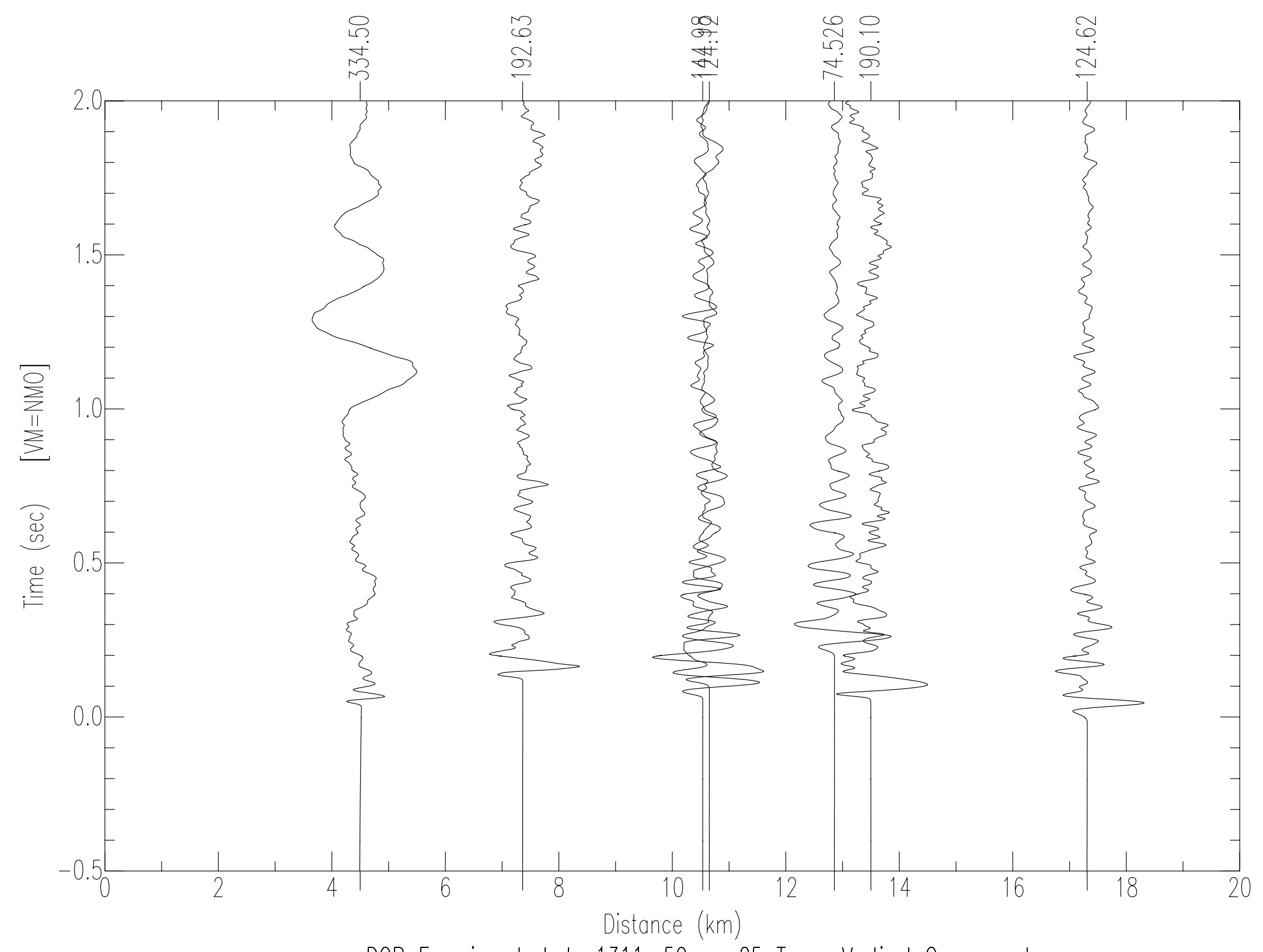

DOB Experiment, hole 1311, 50 m, 25 Ton, Vertical Component 


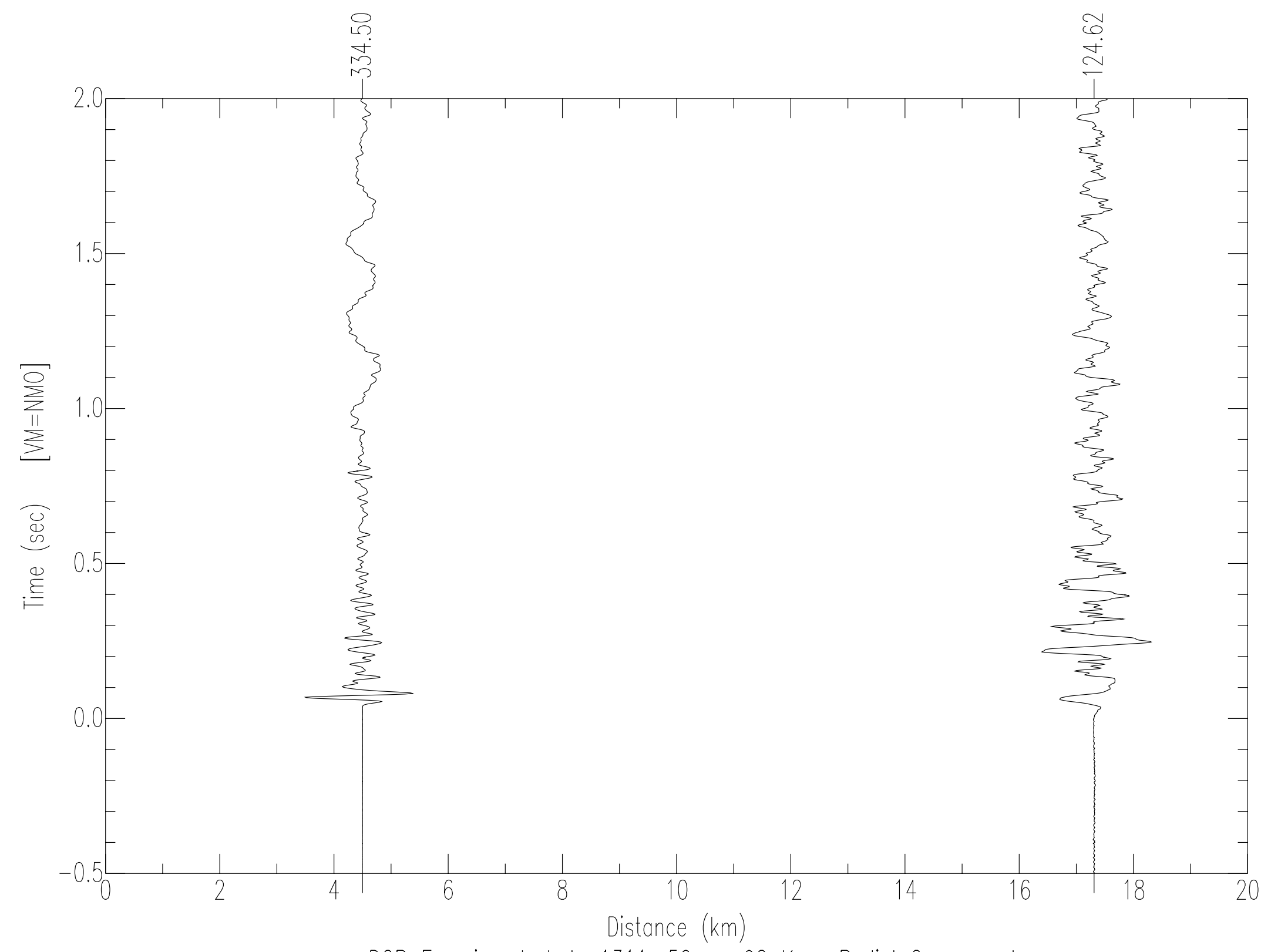

DOB Experiment, hole 1311, $50 \mathrm{~m}, 92 \mathrm{Kg}$, Radial Component 


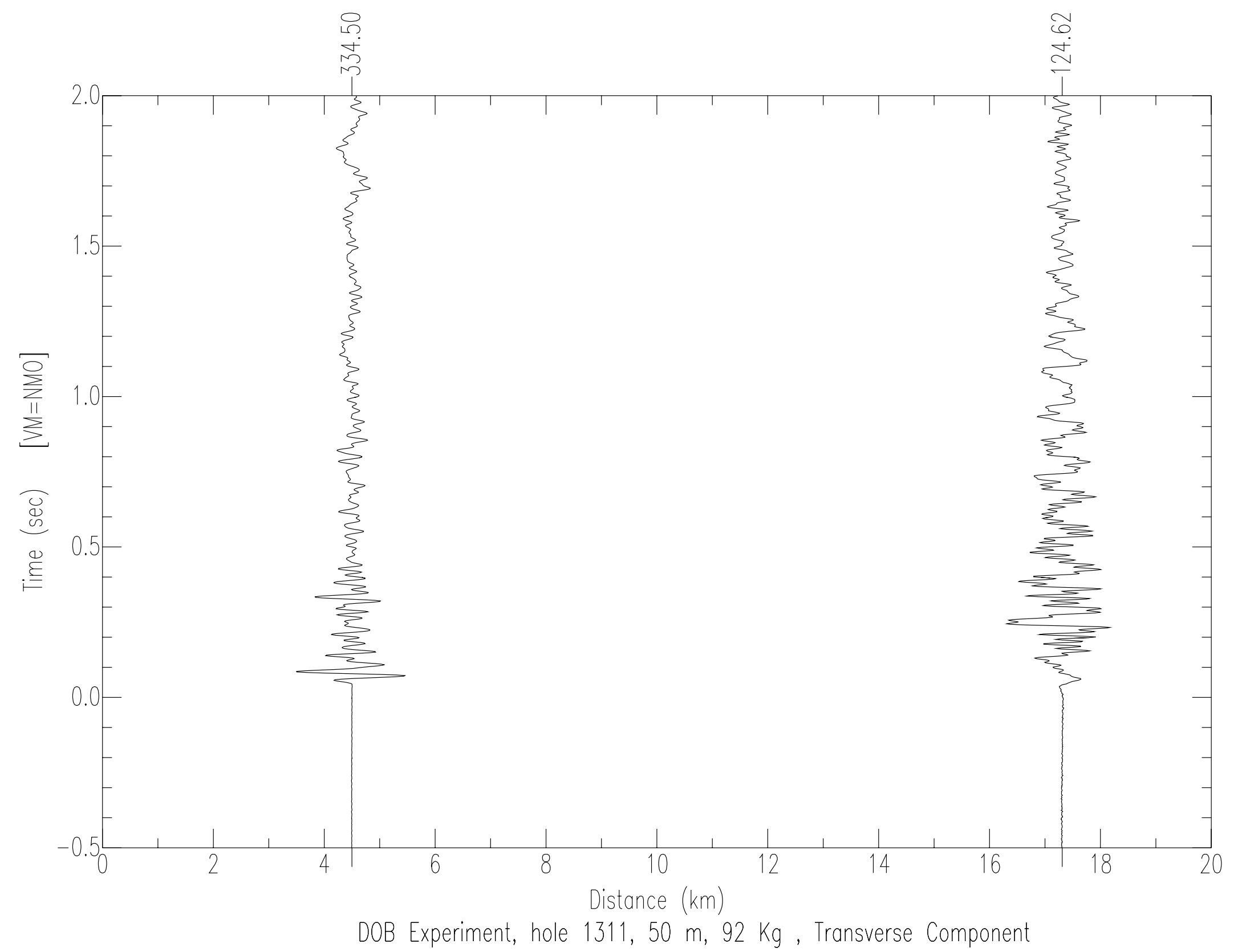




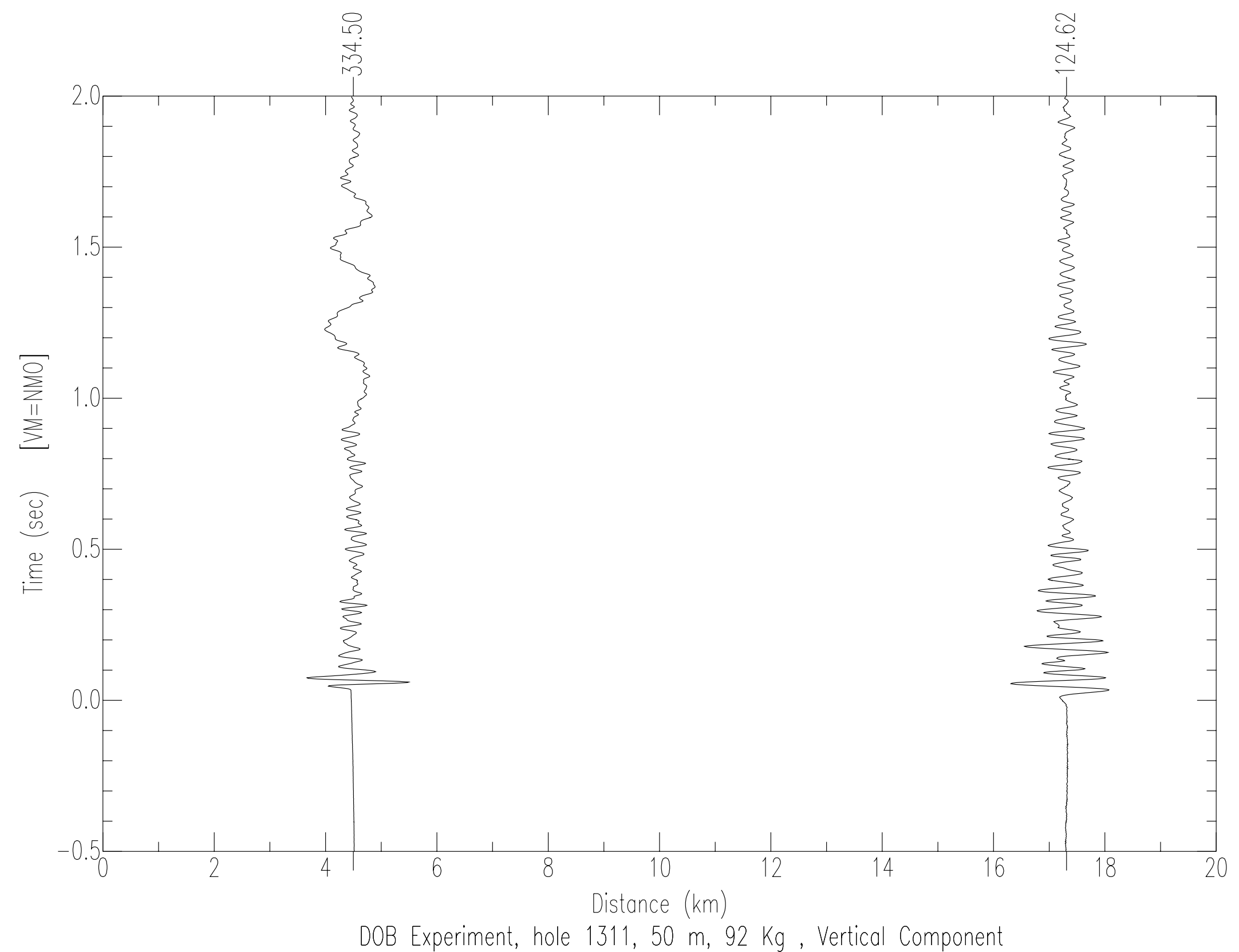




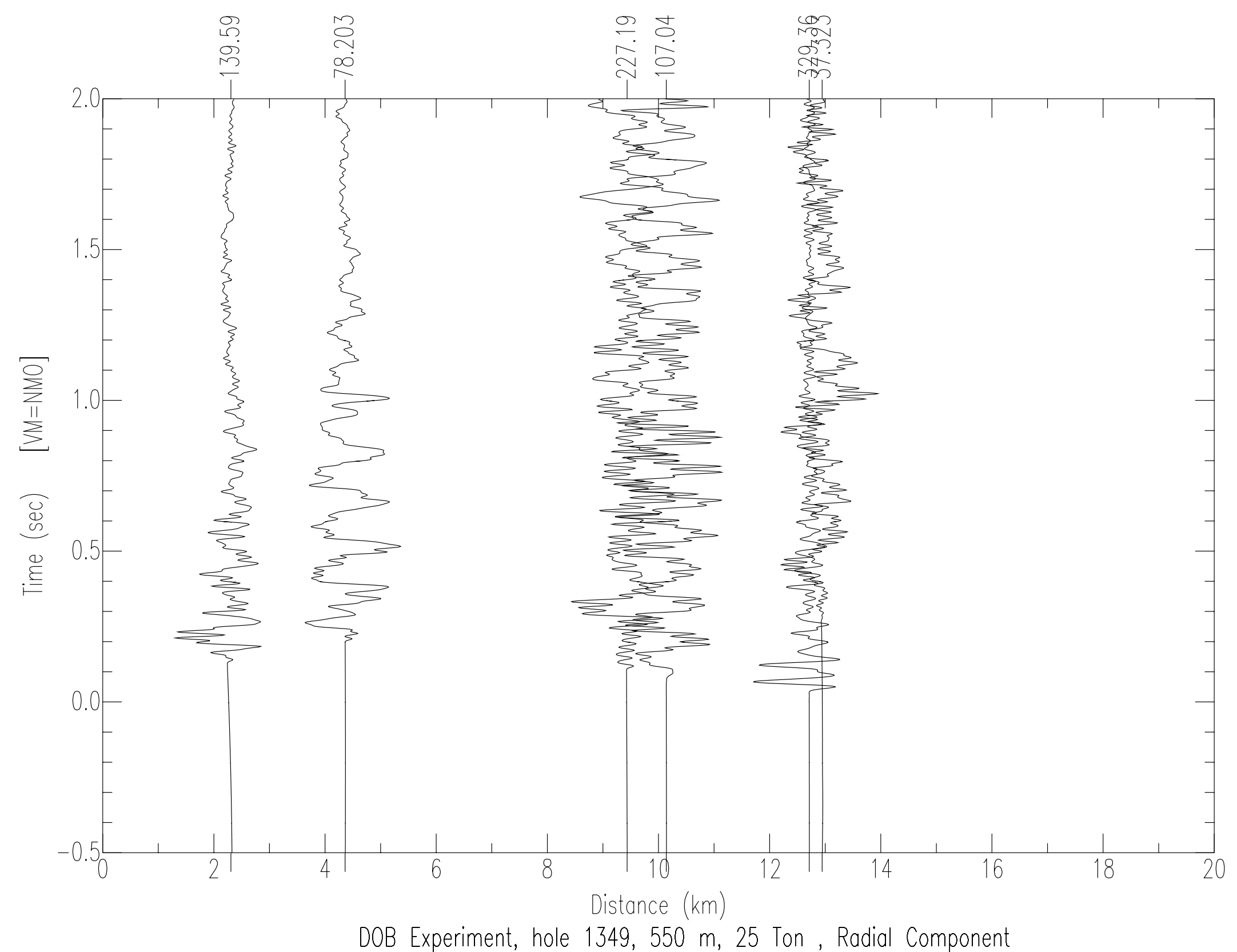




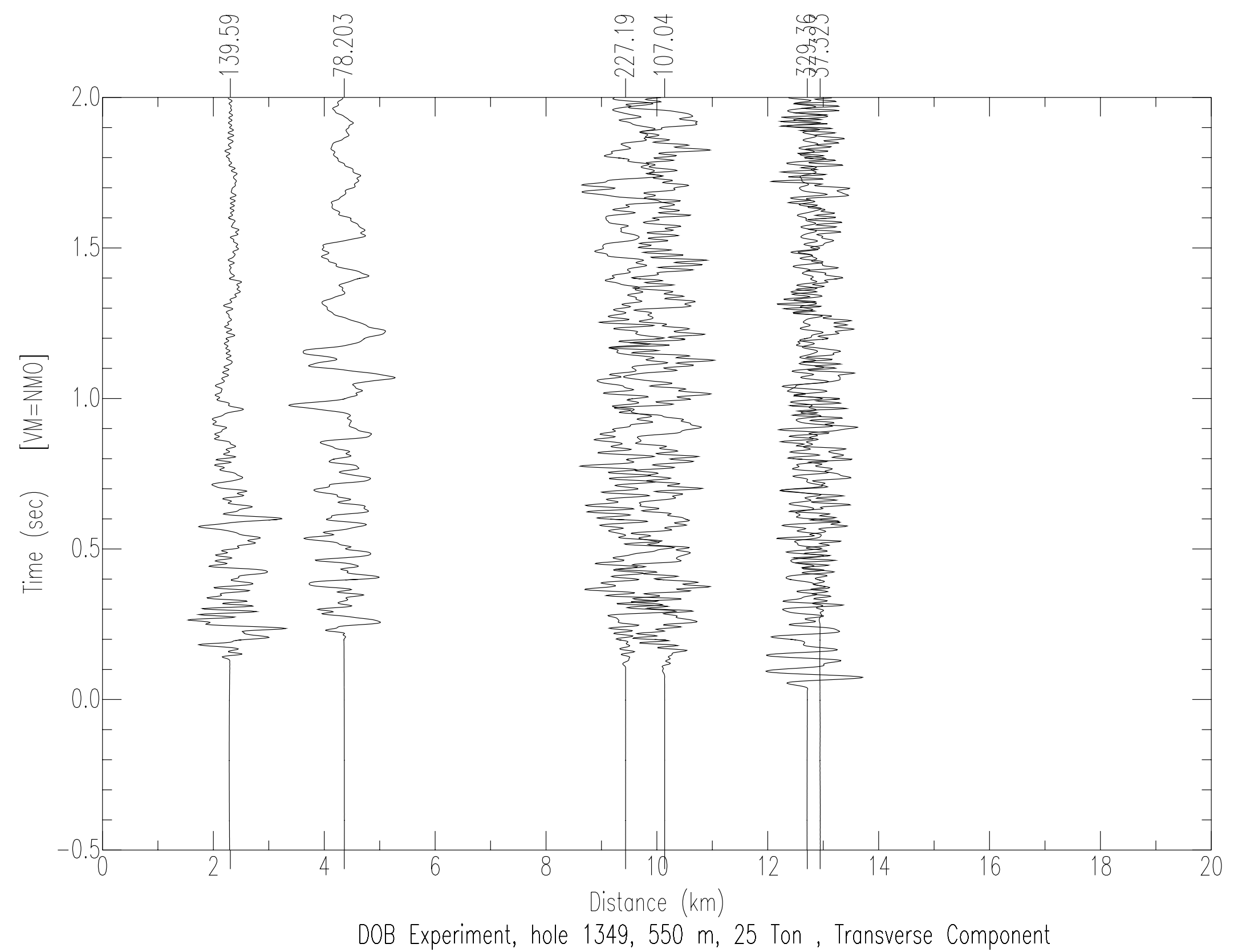




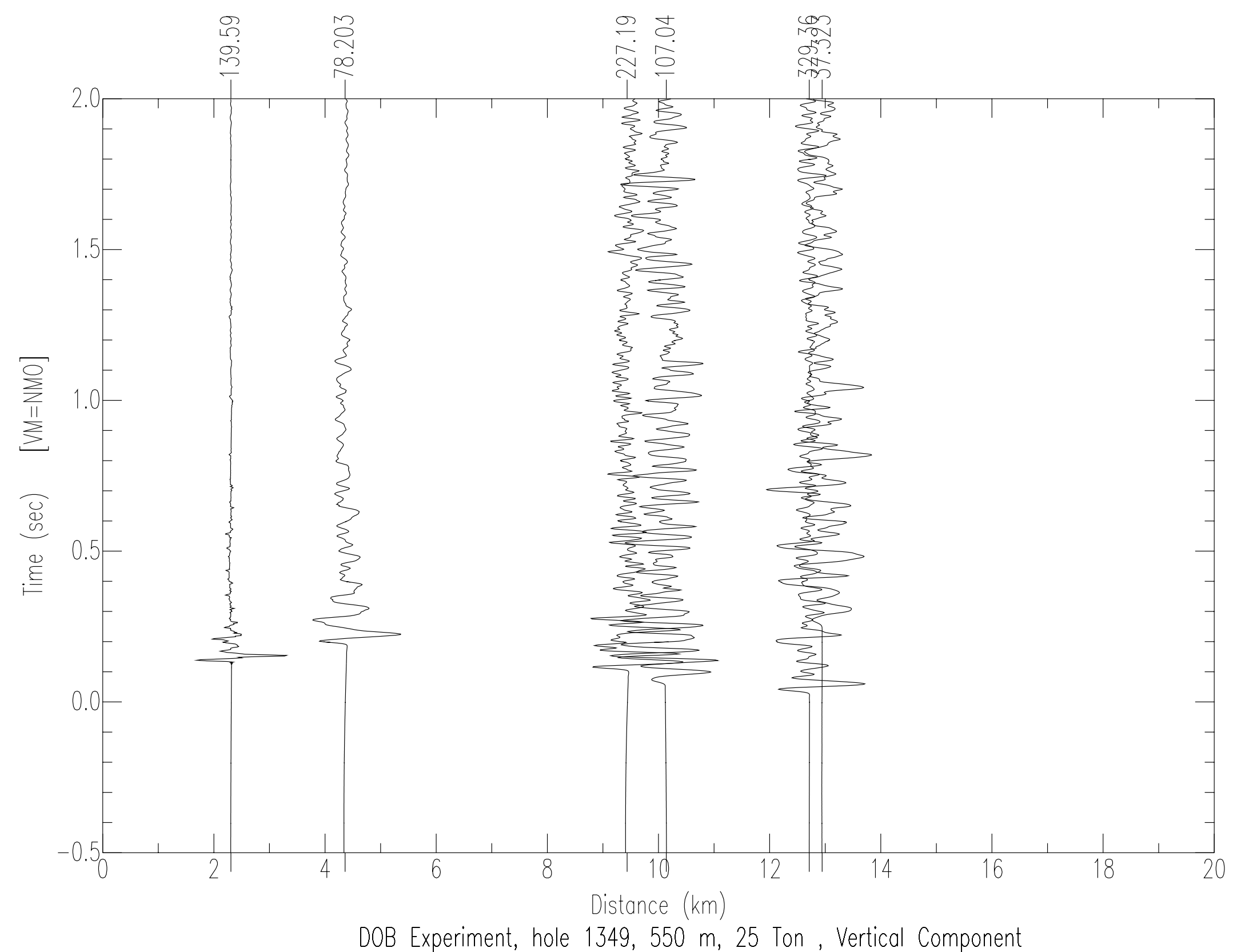




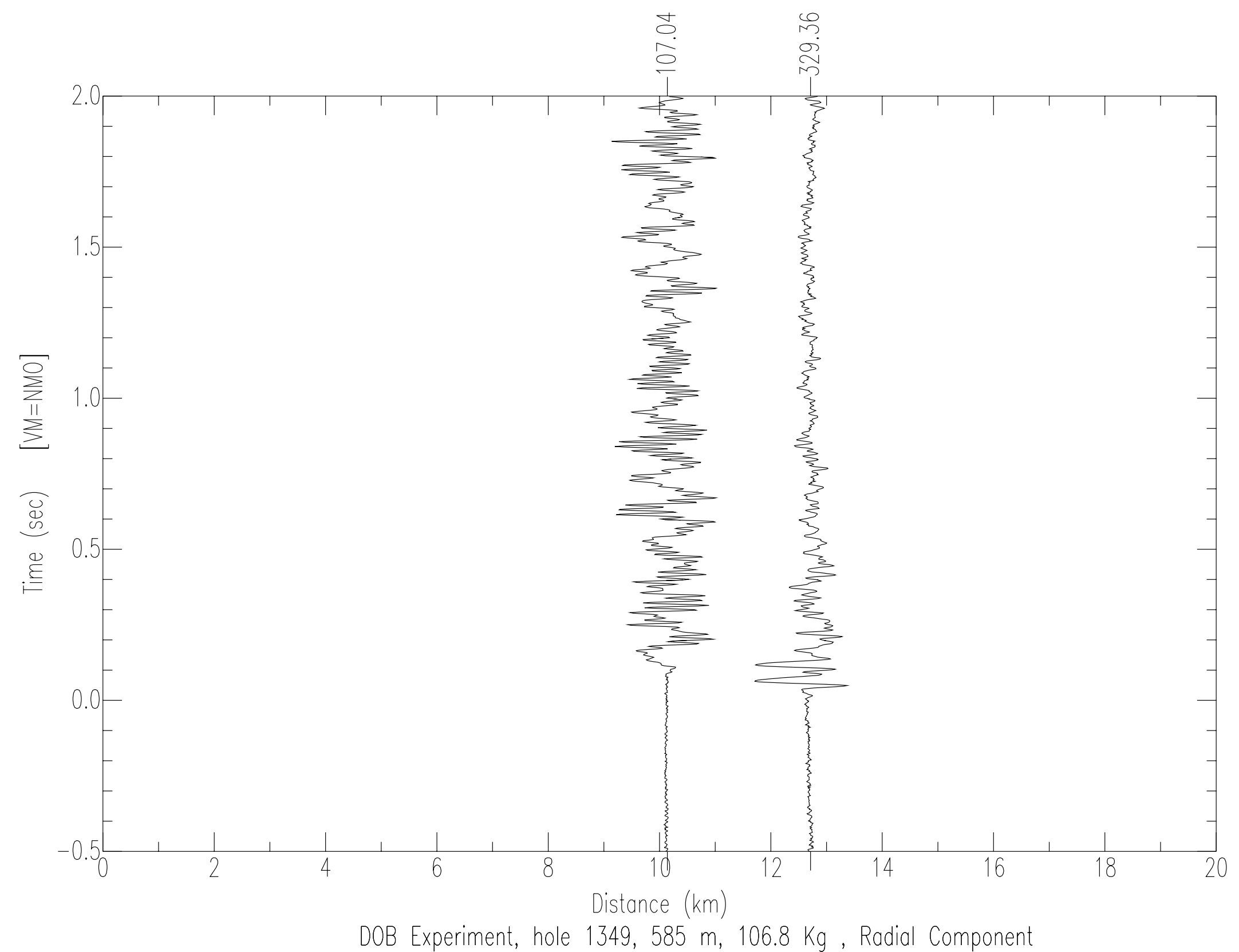




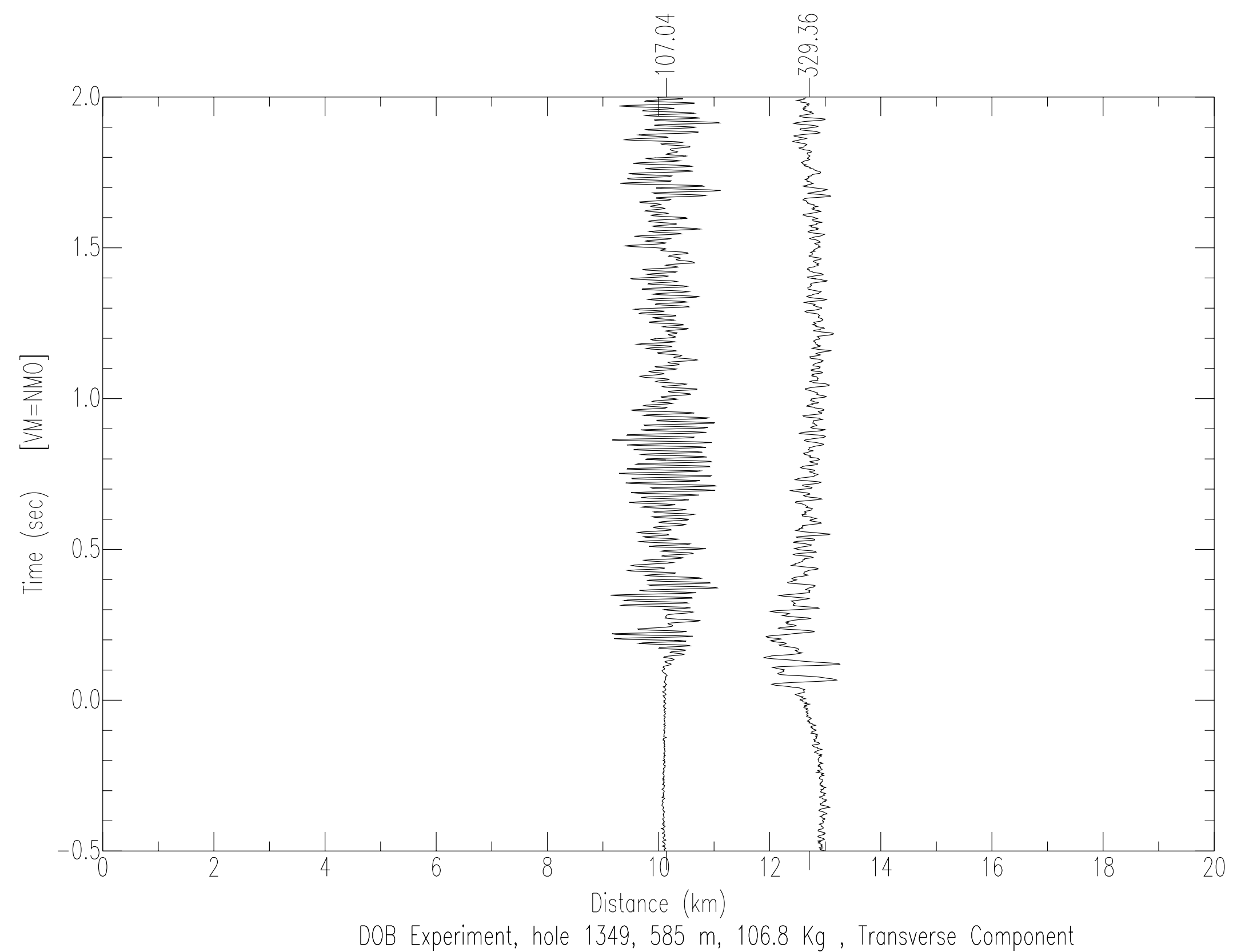




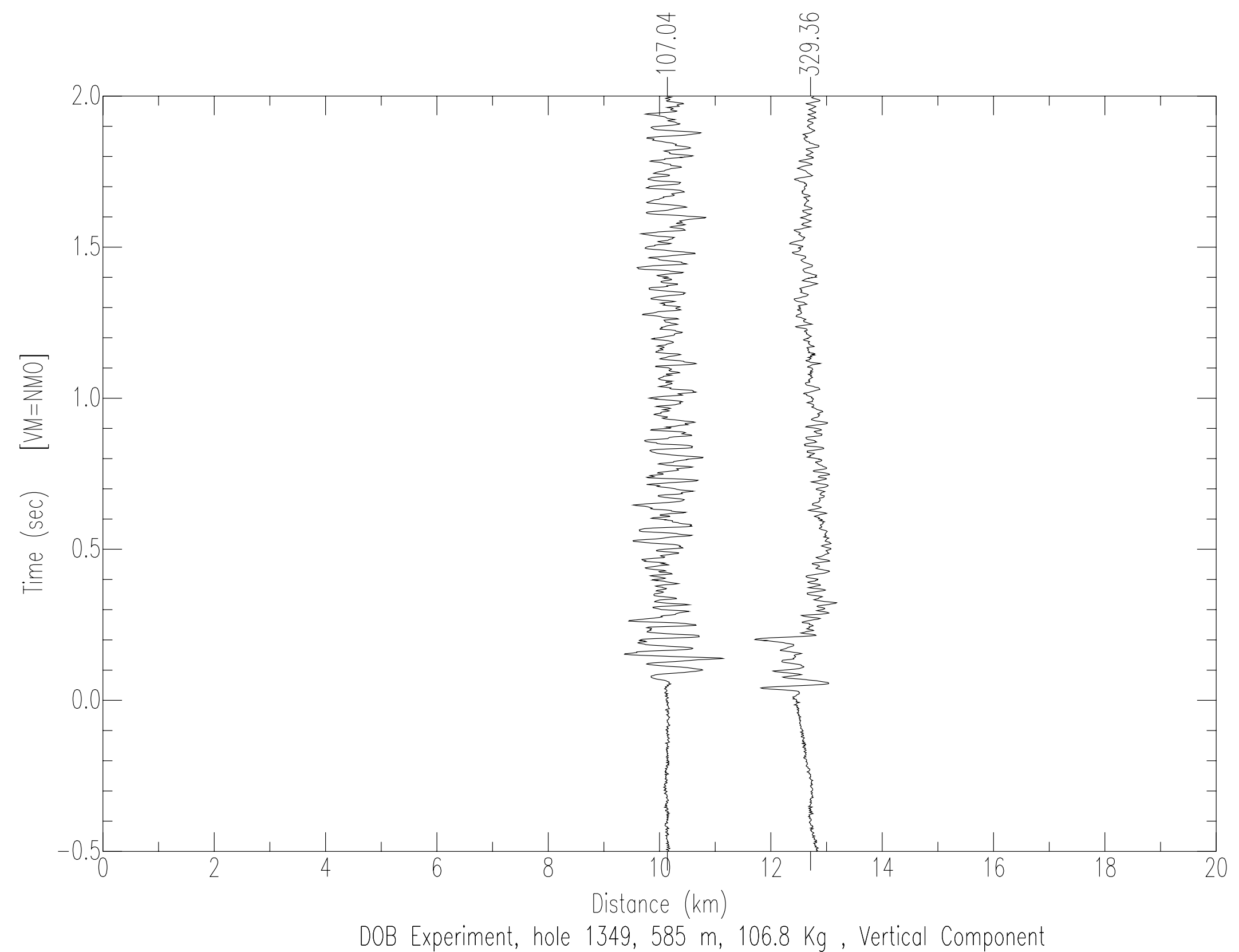




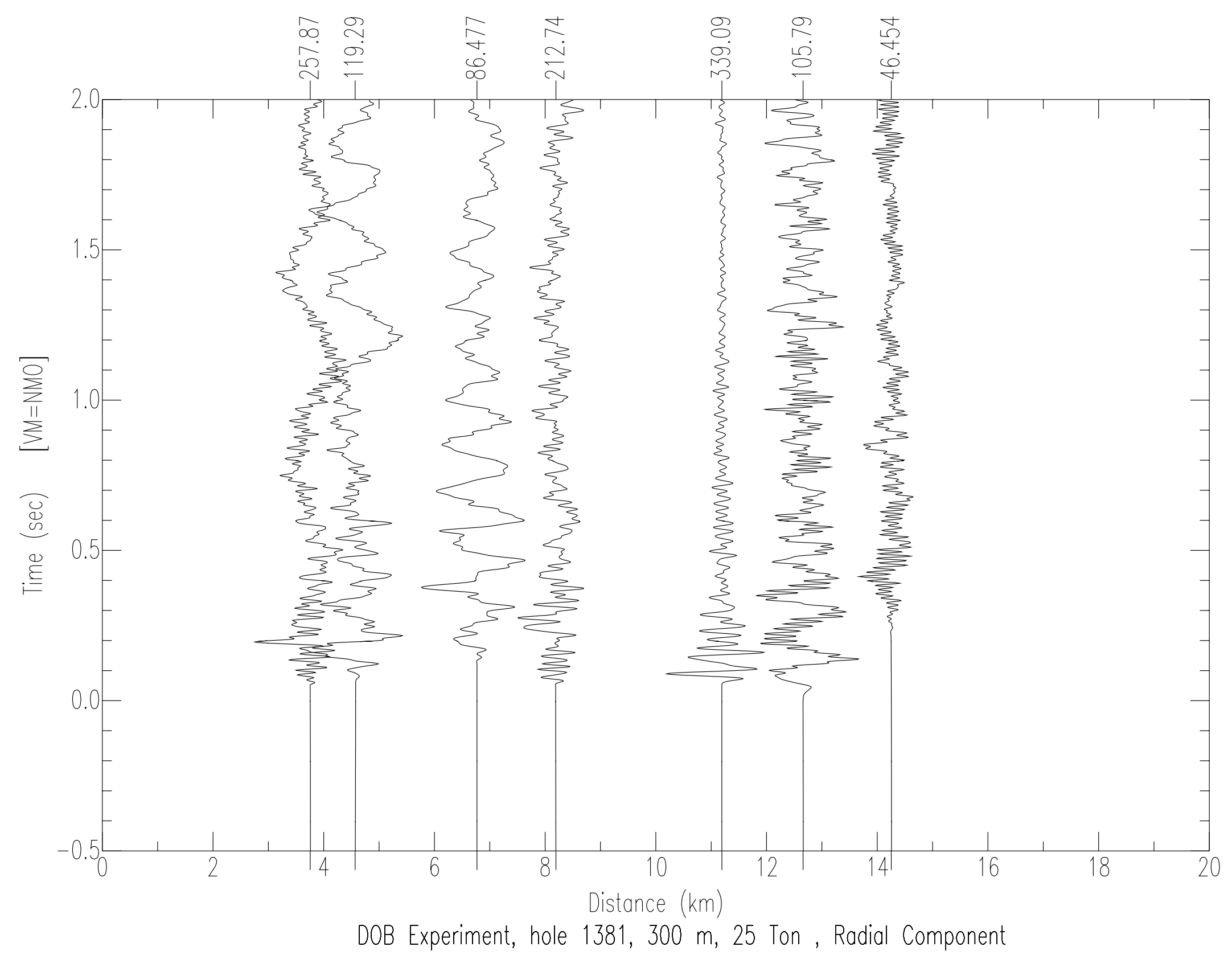




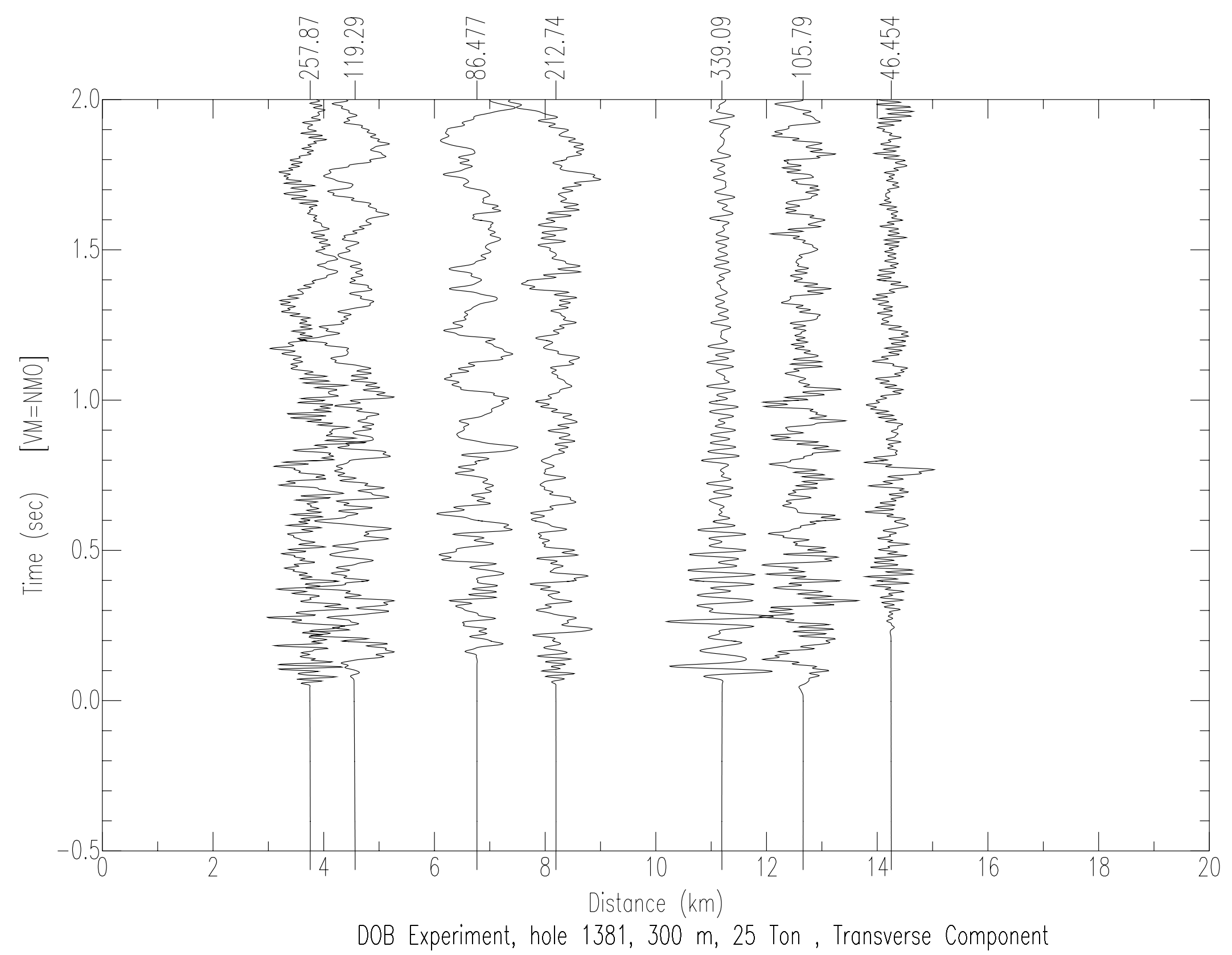




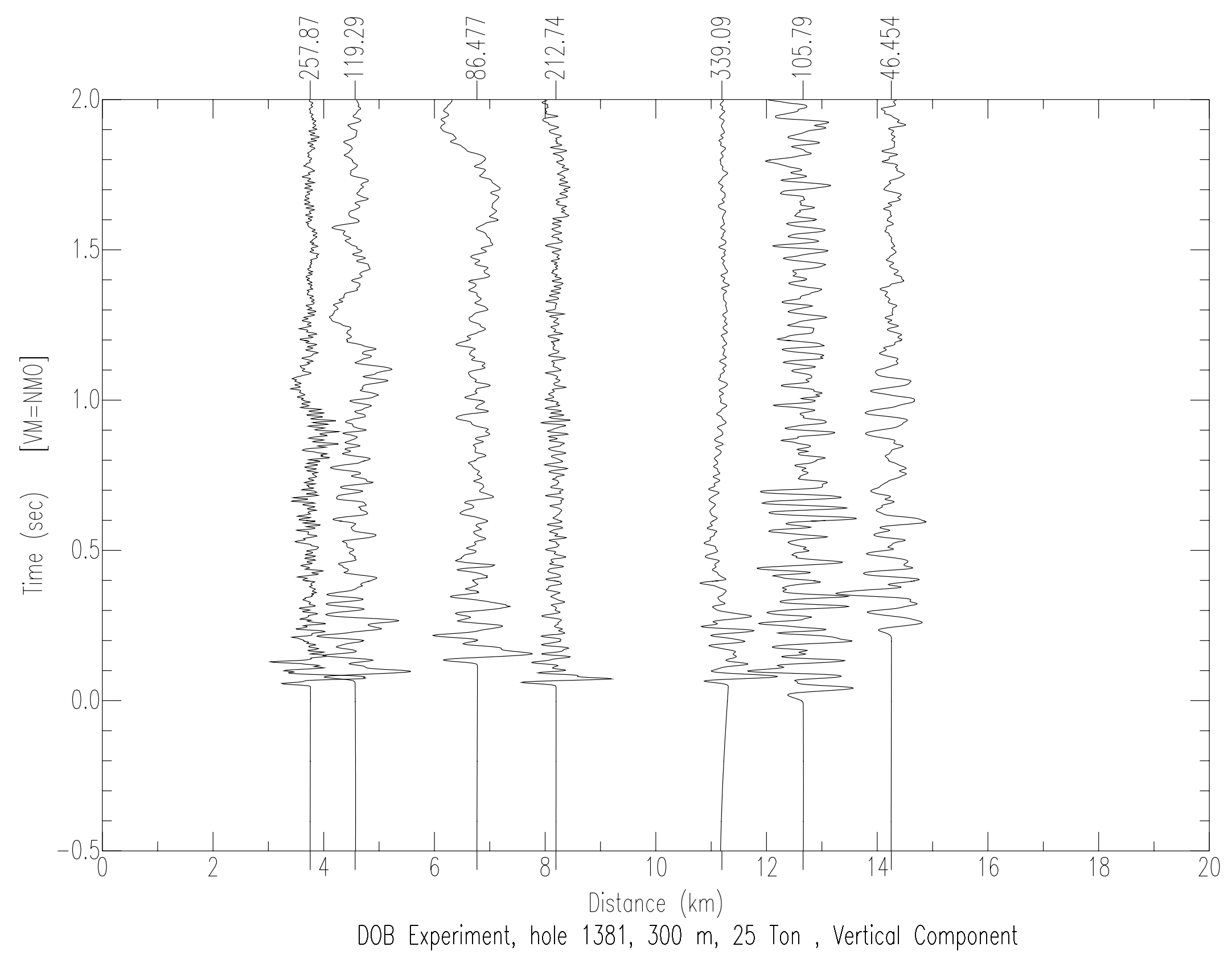




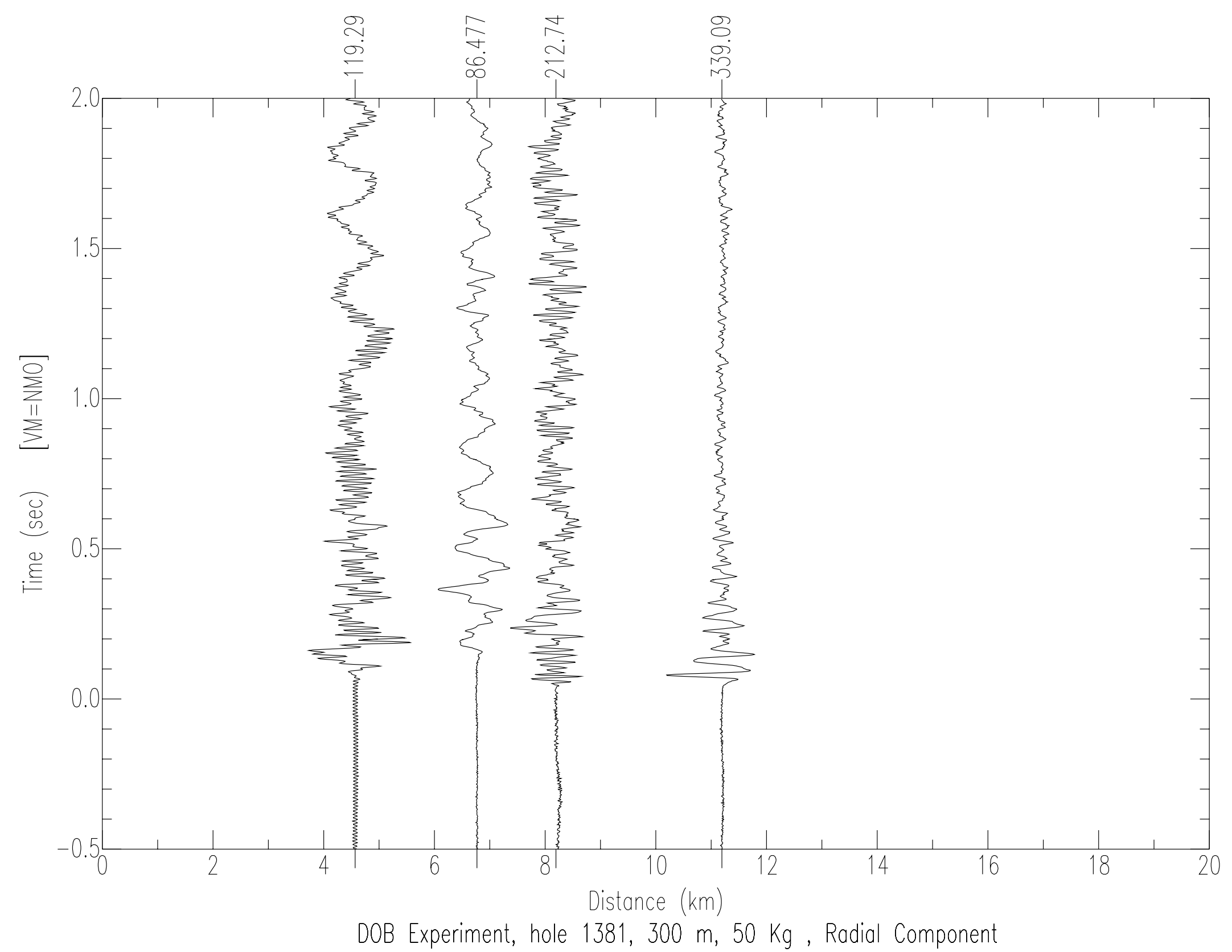




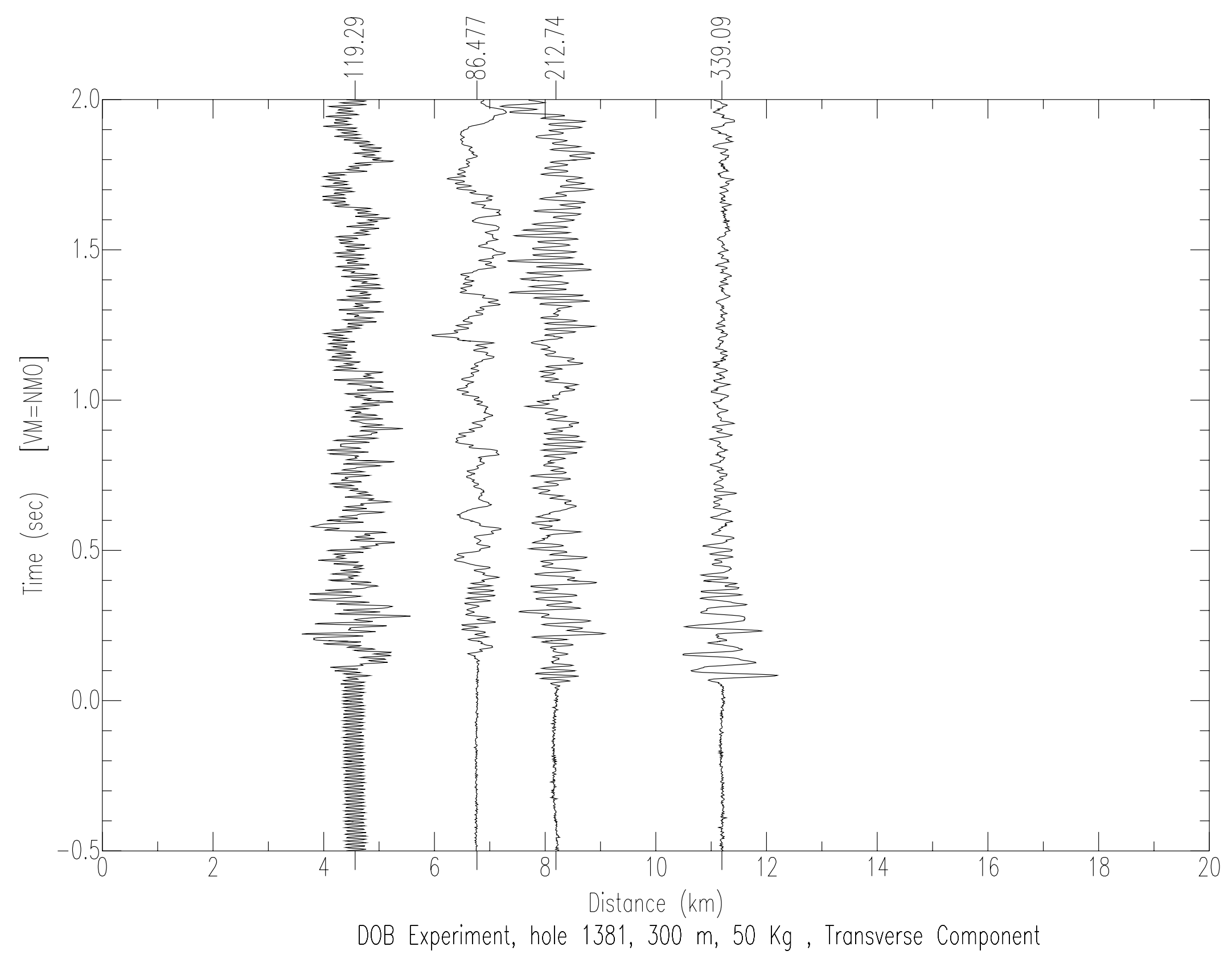




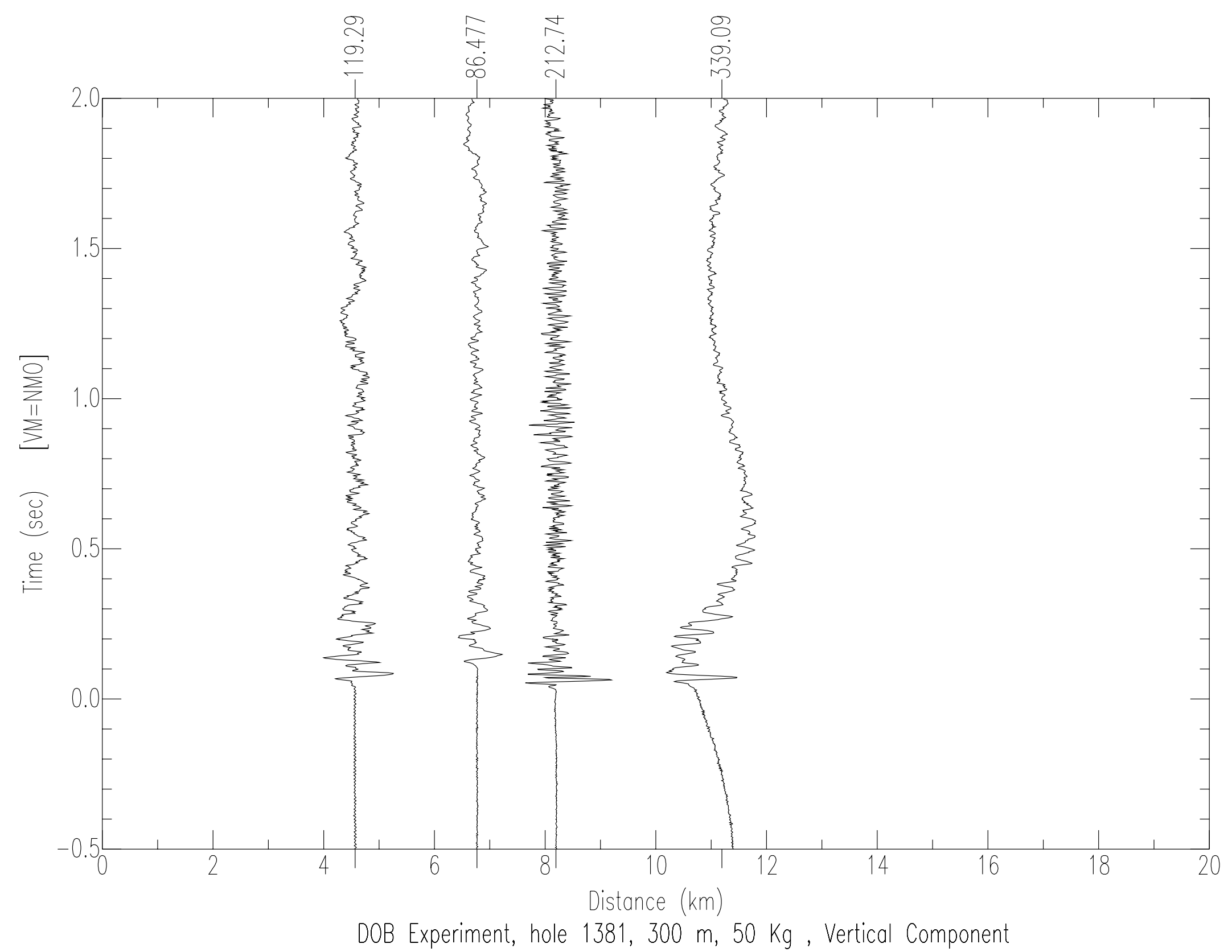




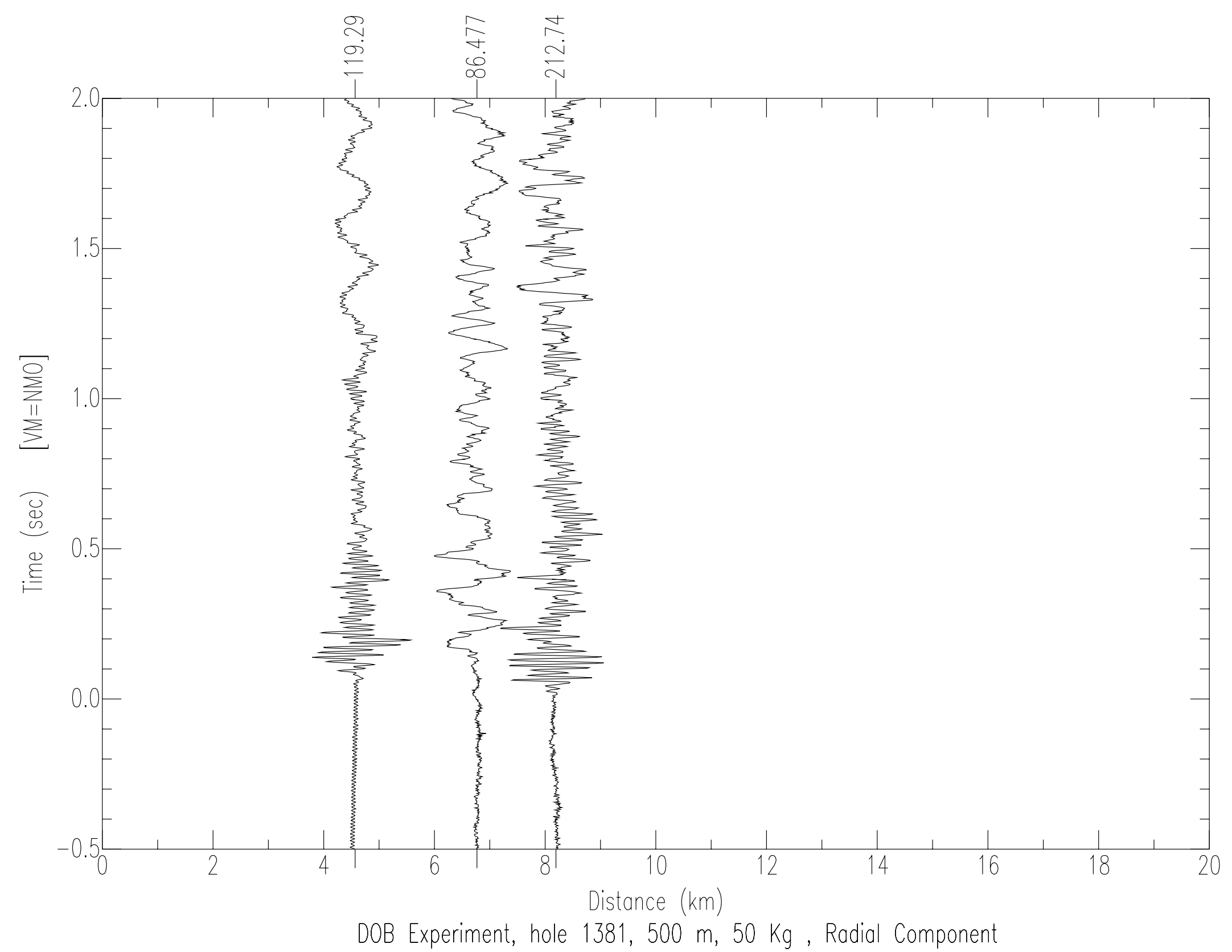




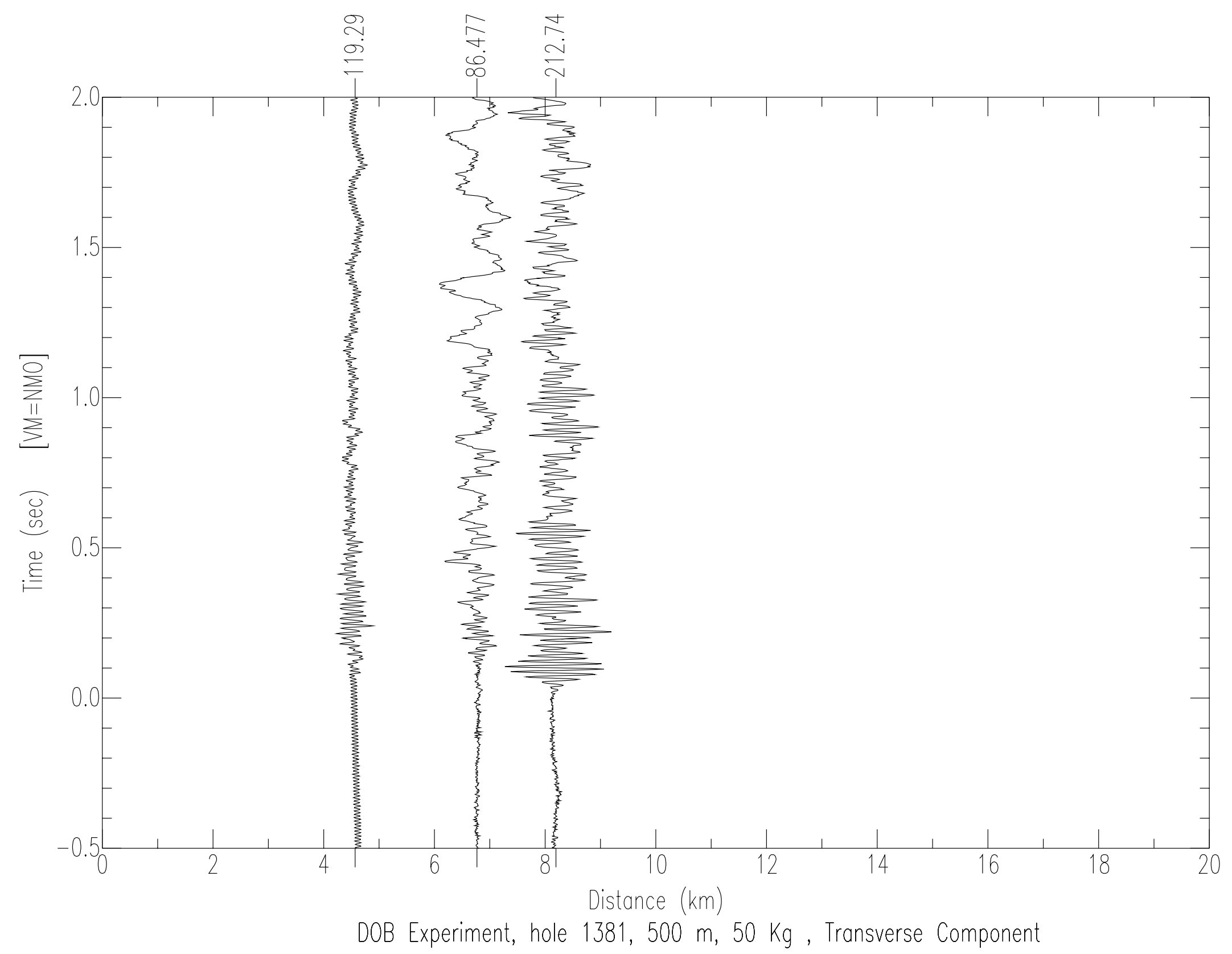




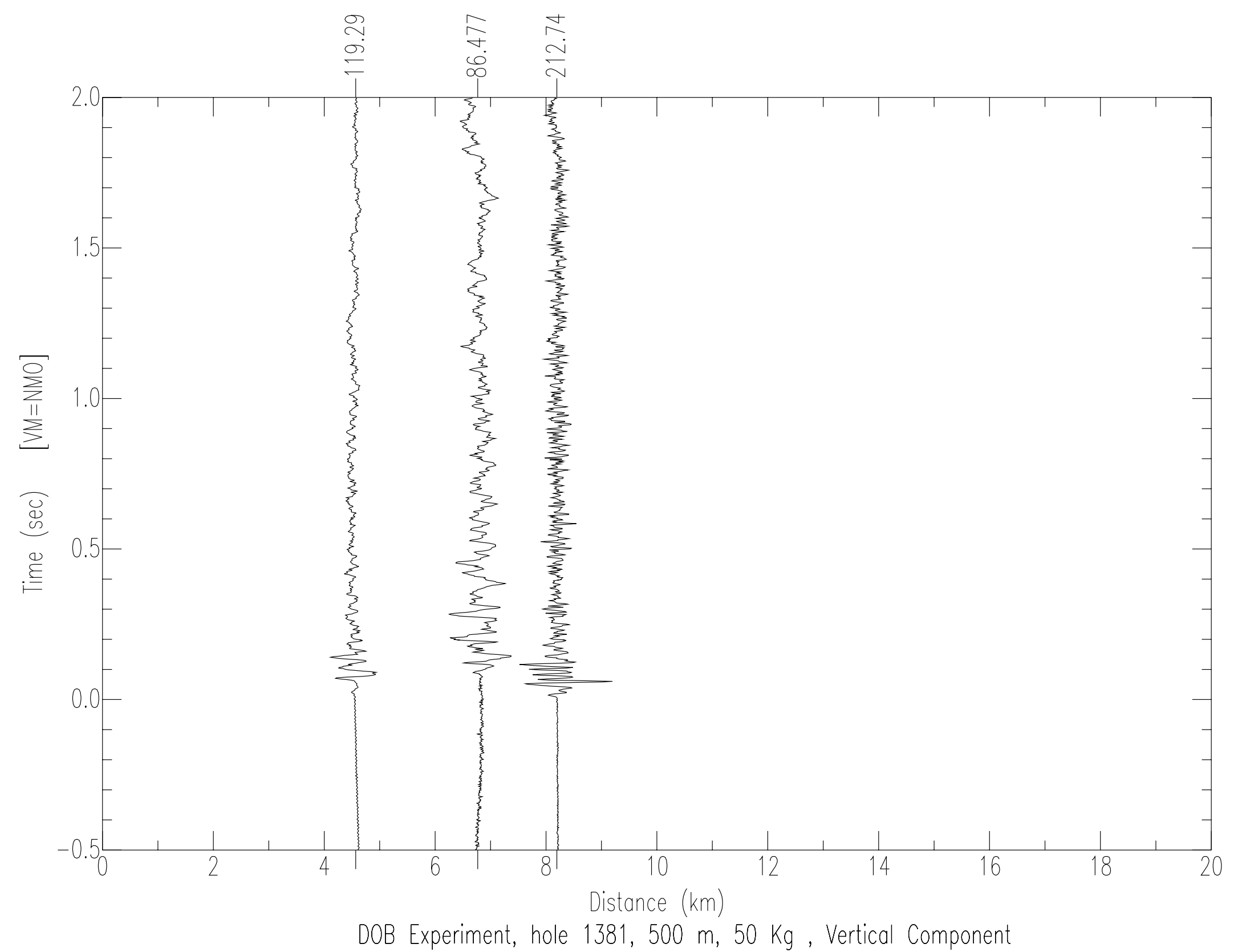




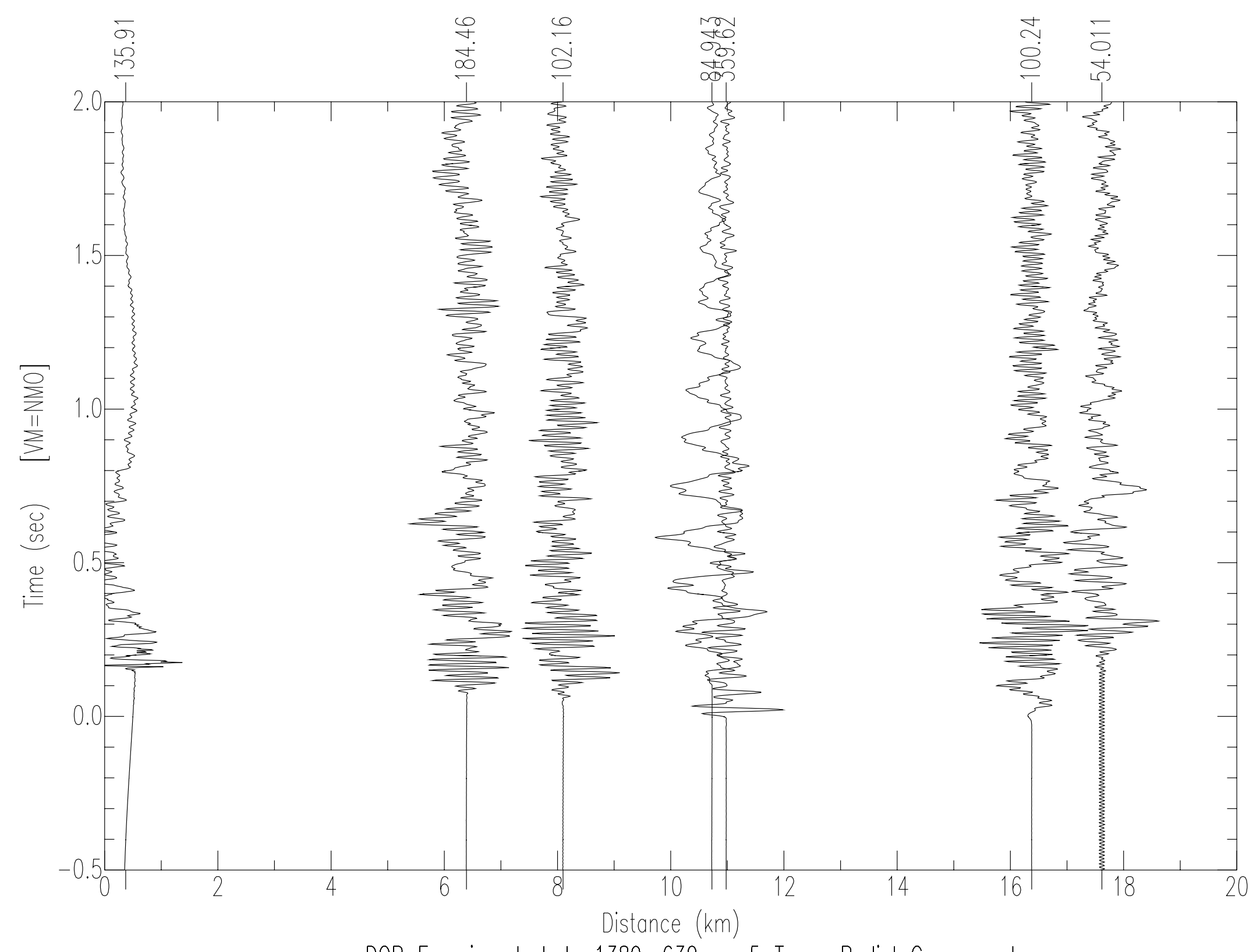

DOB Experiment, hole 1389, 630 m, 5 Ton, Radial Component 


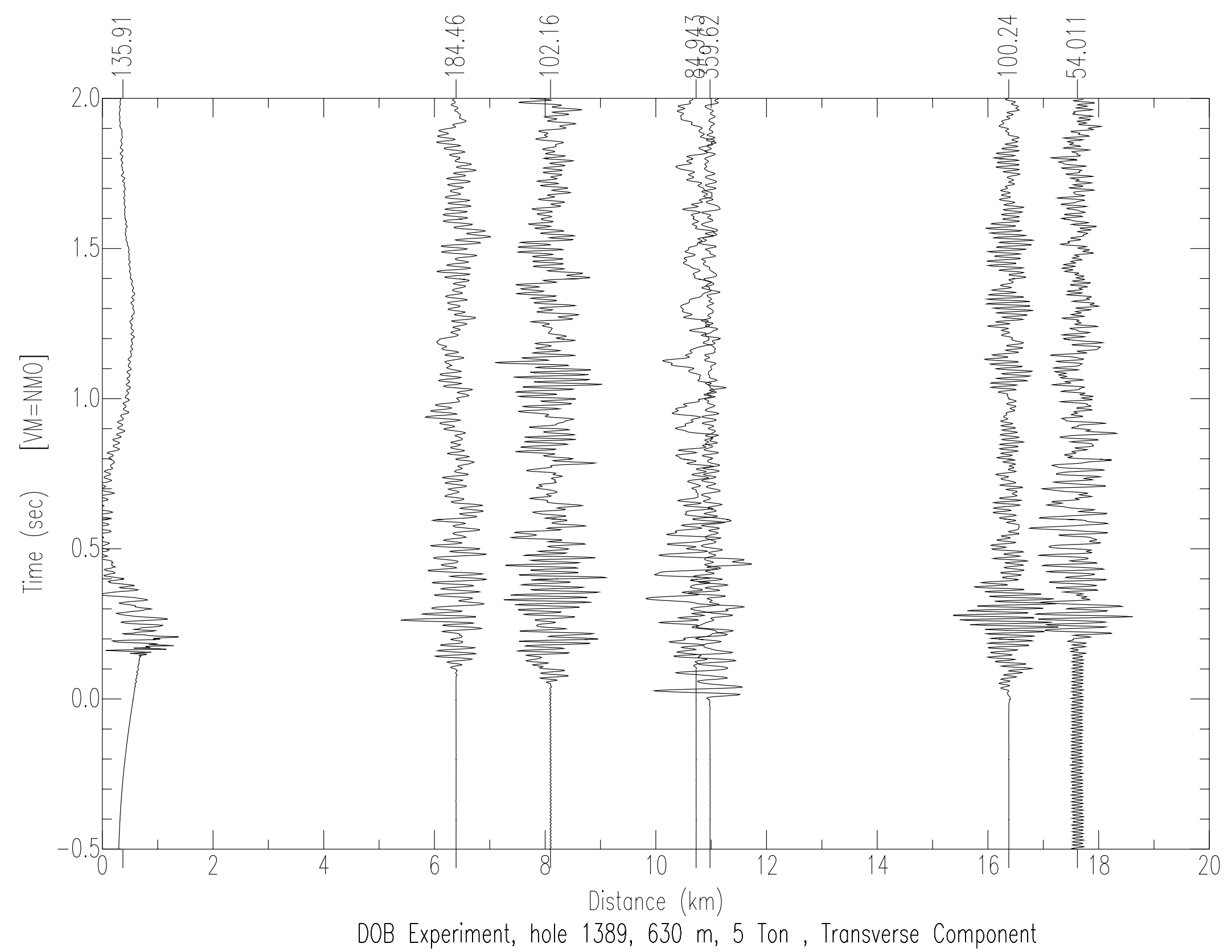




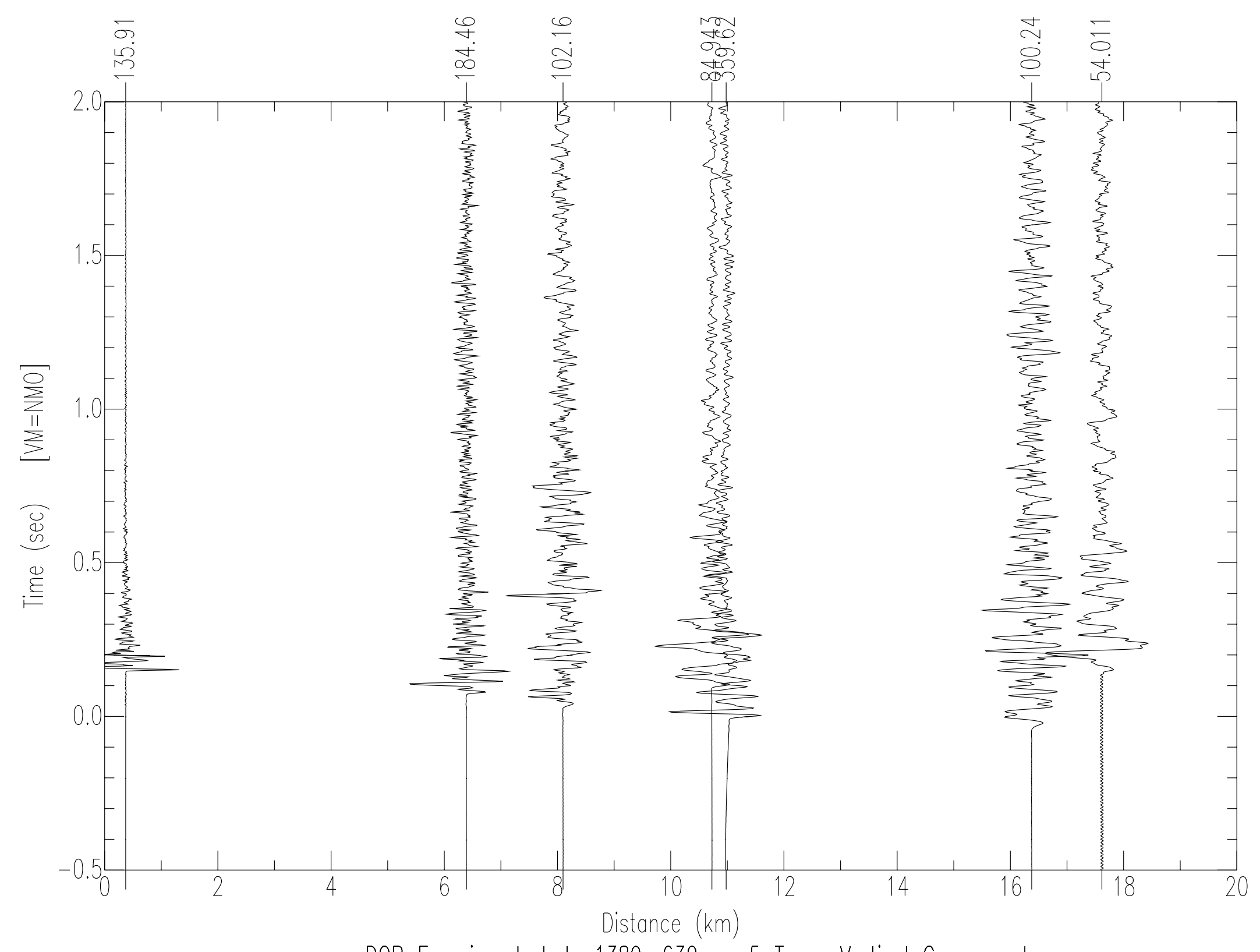

DOB Experiment, hole 1389, 630 m, 5 Ton, Vertical Component 


\section{Appendix $\mathrm{C}$}

Ground motion velocity spectra $(\mathrm{cm} / \mathrm{s}-\mathrm{s})$ versus frequency $(\mathrm{Hz})$ for 0.5 seconds of the P-wave for all vertical, radial and transverse recordings made at Shagan River in 1997. Noise spectra (0.5 seconds preceding $\mathrm{P}$ arrival) are included (light gray). Spectra are gathered by shot and all are plotted to the same scale. Shot hole, depth, yield and component of motion are indicated at the top of each plot. The Nyquist frequency is $250 \mathrm{~Hz}$. 
shot 1311, 204m, 92k, r component, all stations

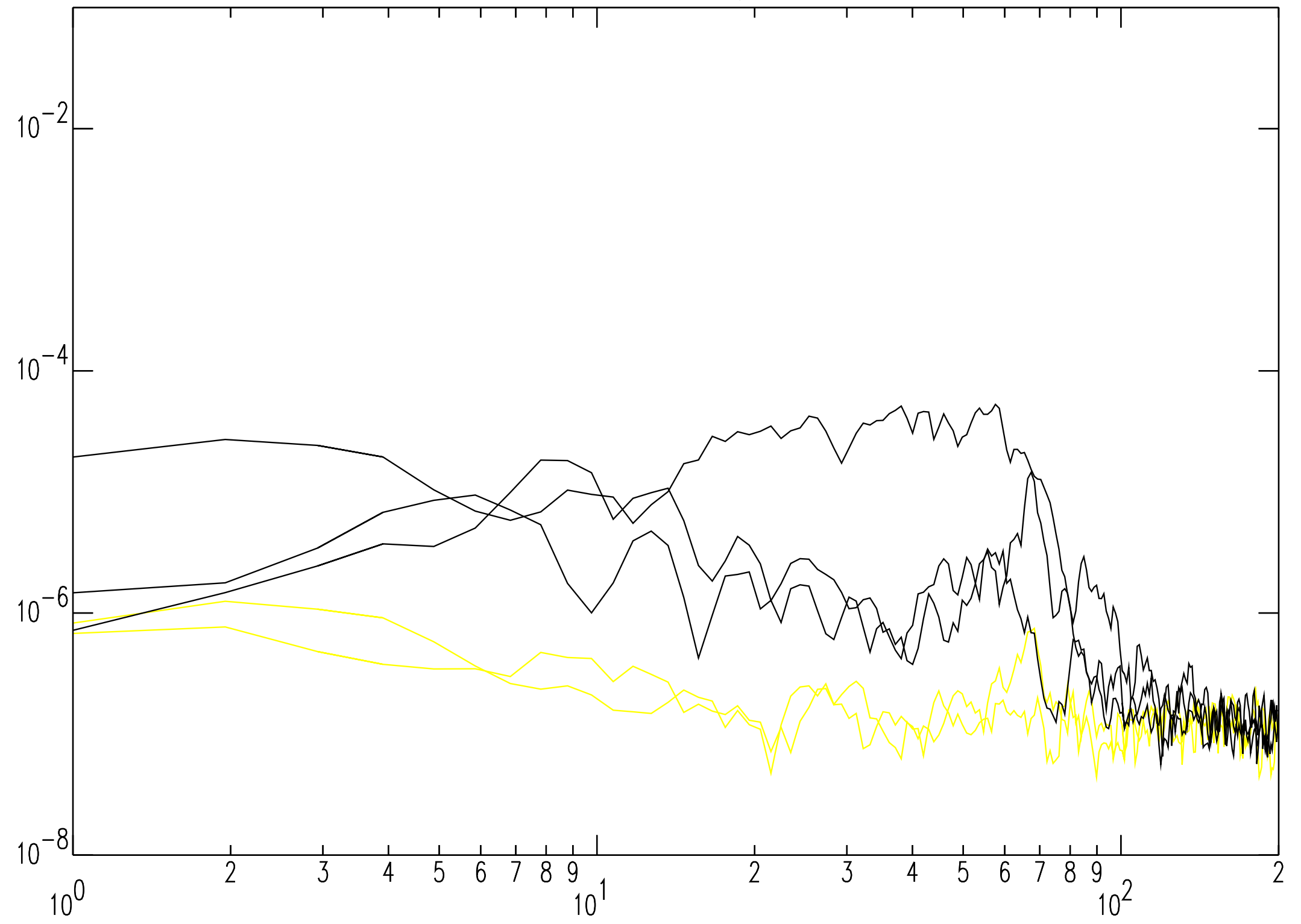


shot 1311, 204m, 92k, t component, all stations

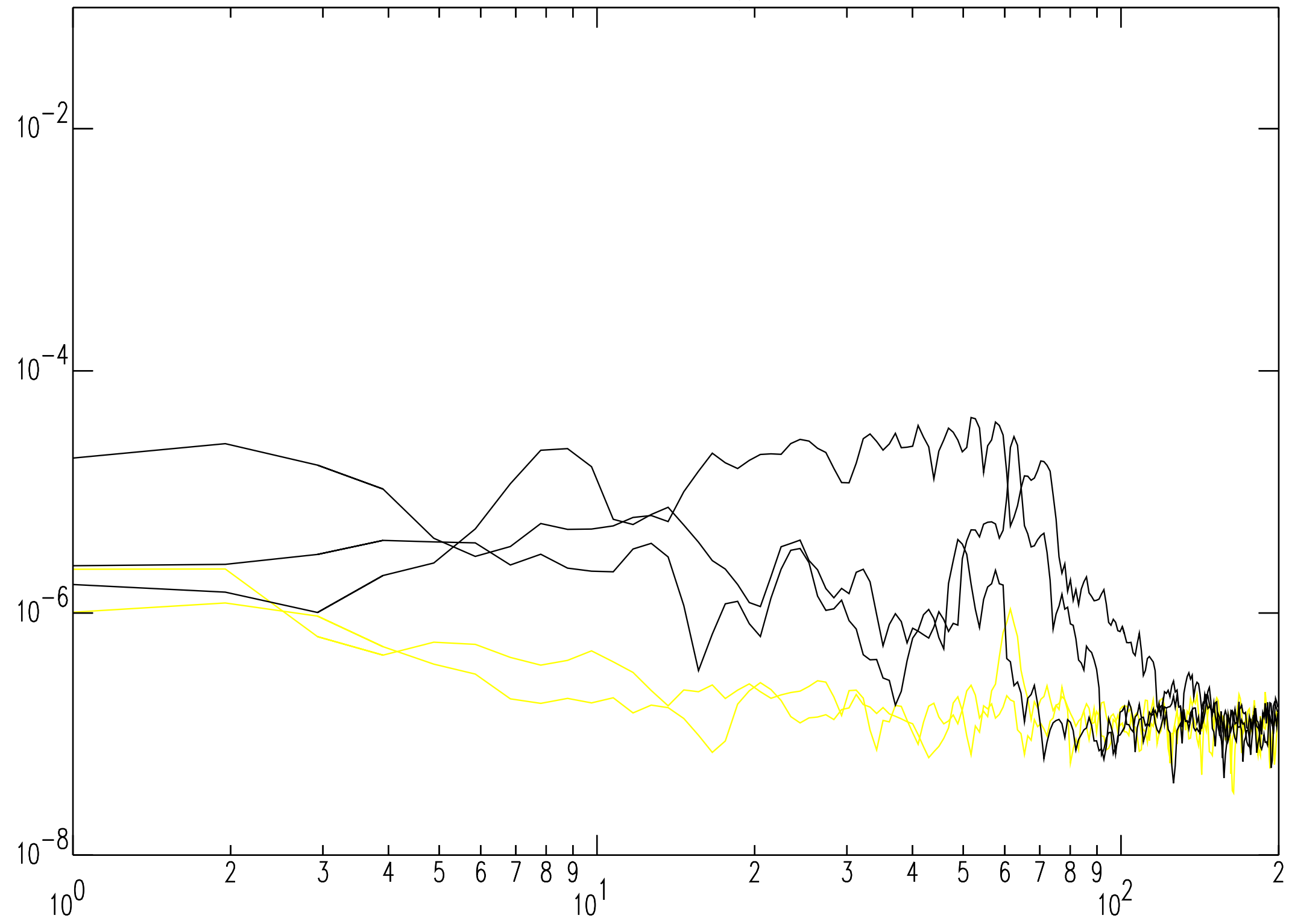


shot 1311, 204m, 92k, z component, all stations

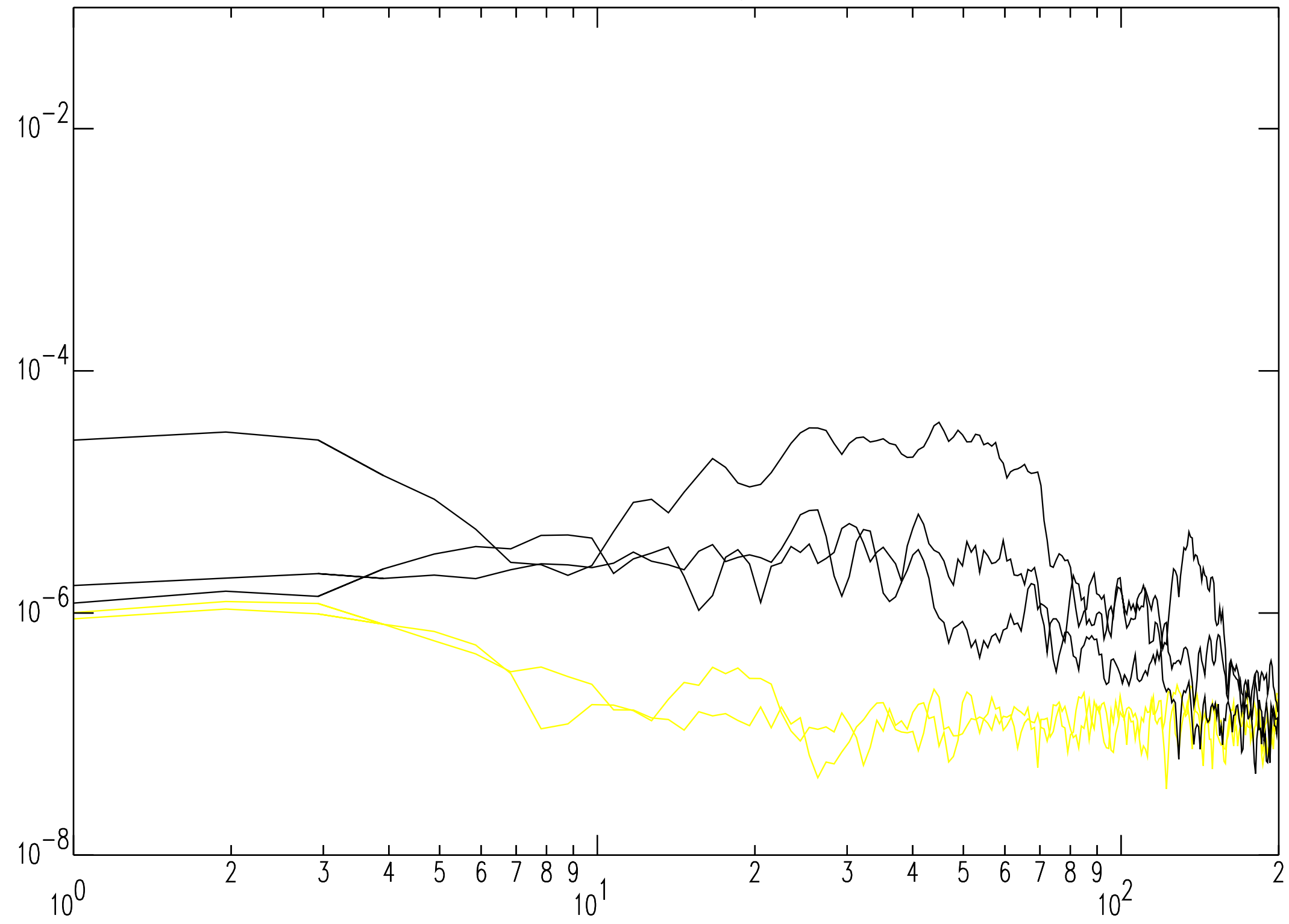


shot $1311,50 \mathrm{~m}, 25 \mathrm{t}, \mathrm{r}$ component, all stations

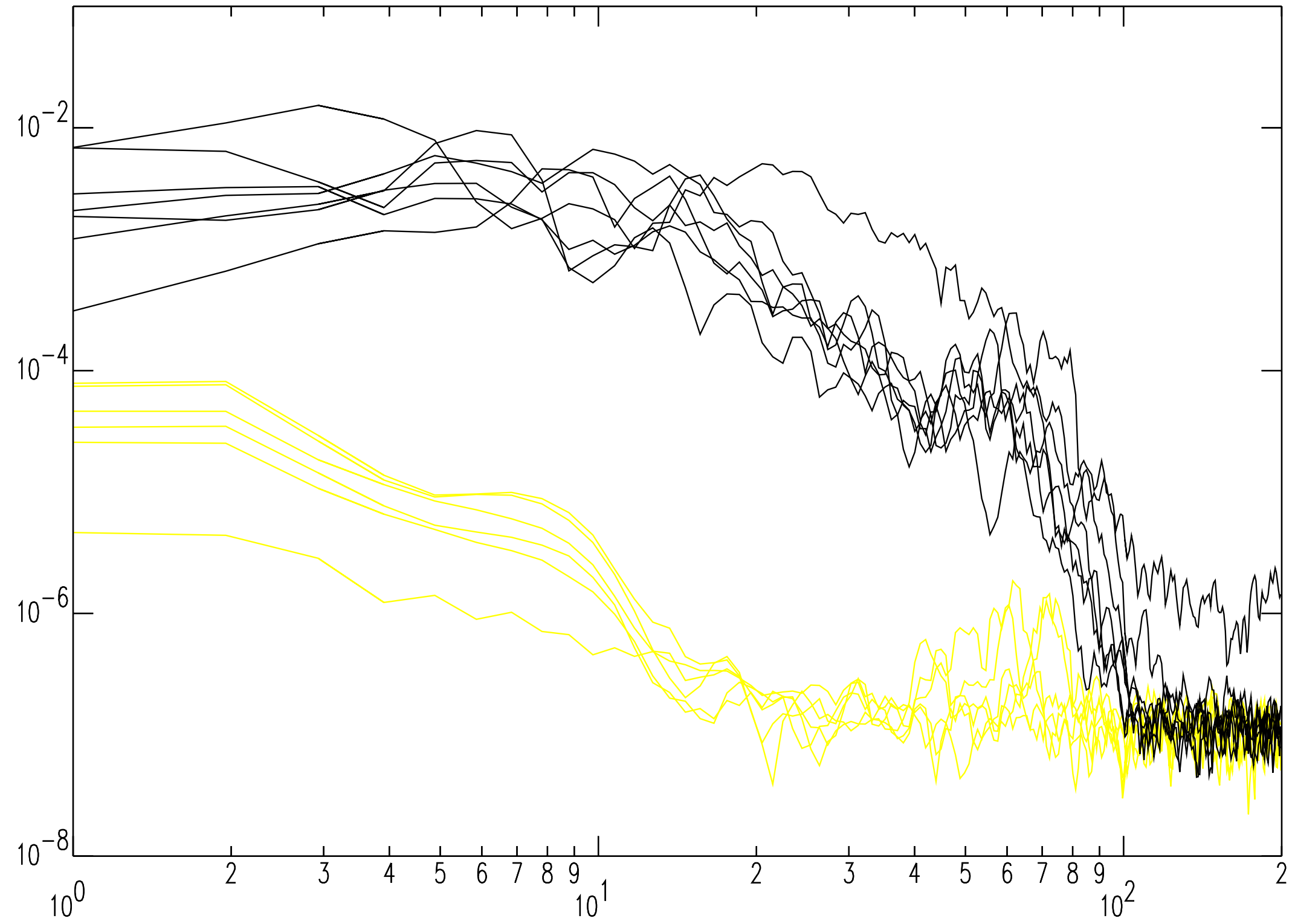


shot $1311,50 \mathrm{~m}, 25 \mathrm{t}$, t component, all stations

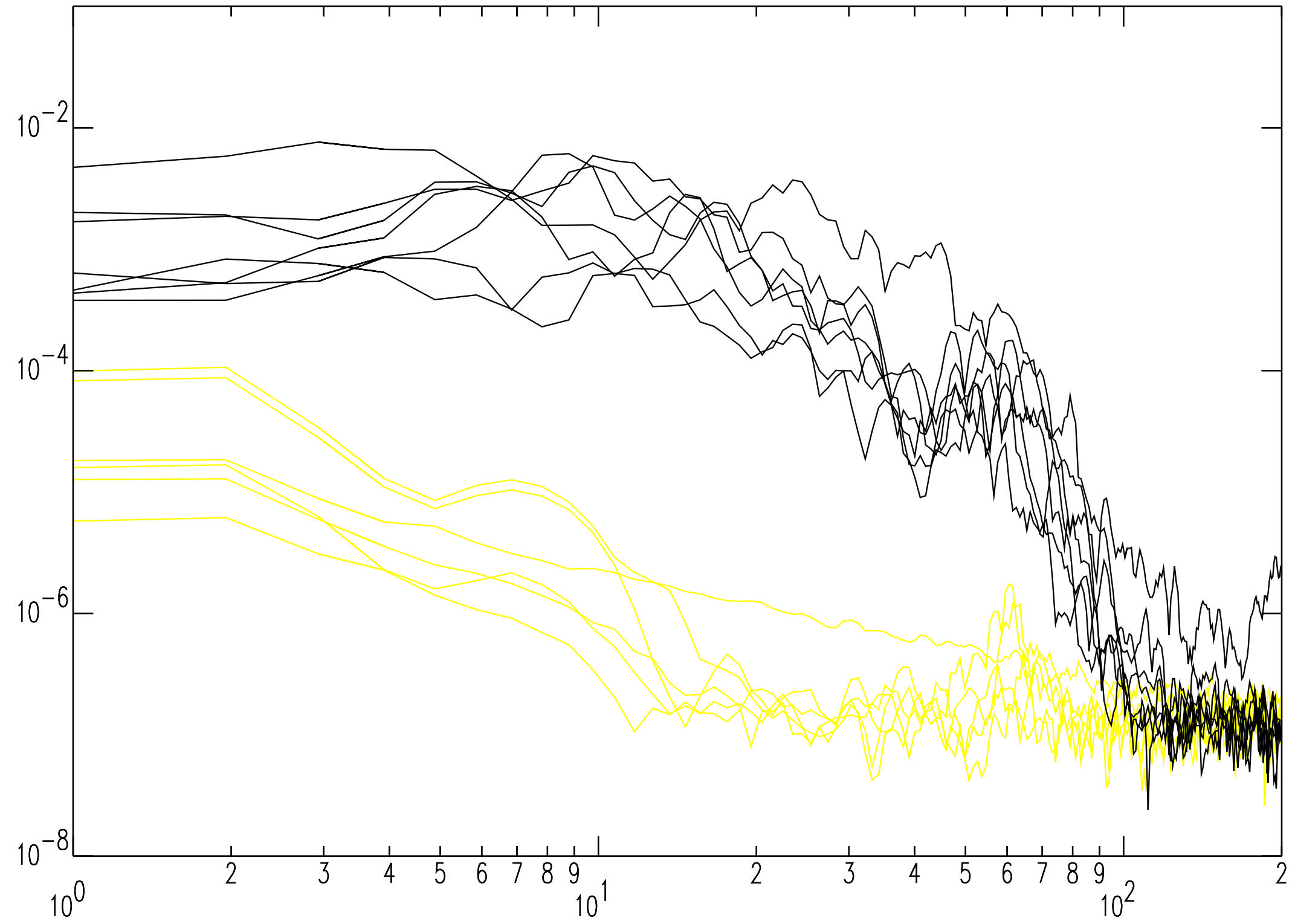


shot 1311, 50m, 25t, z component, all stations

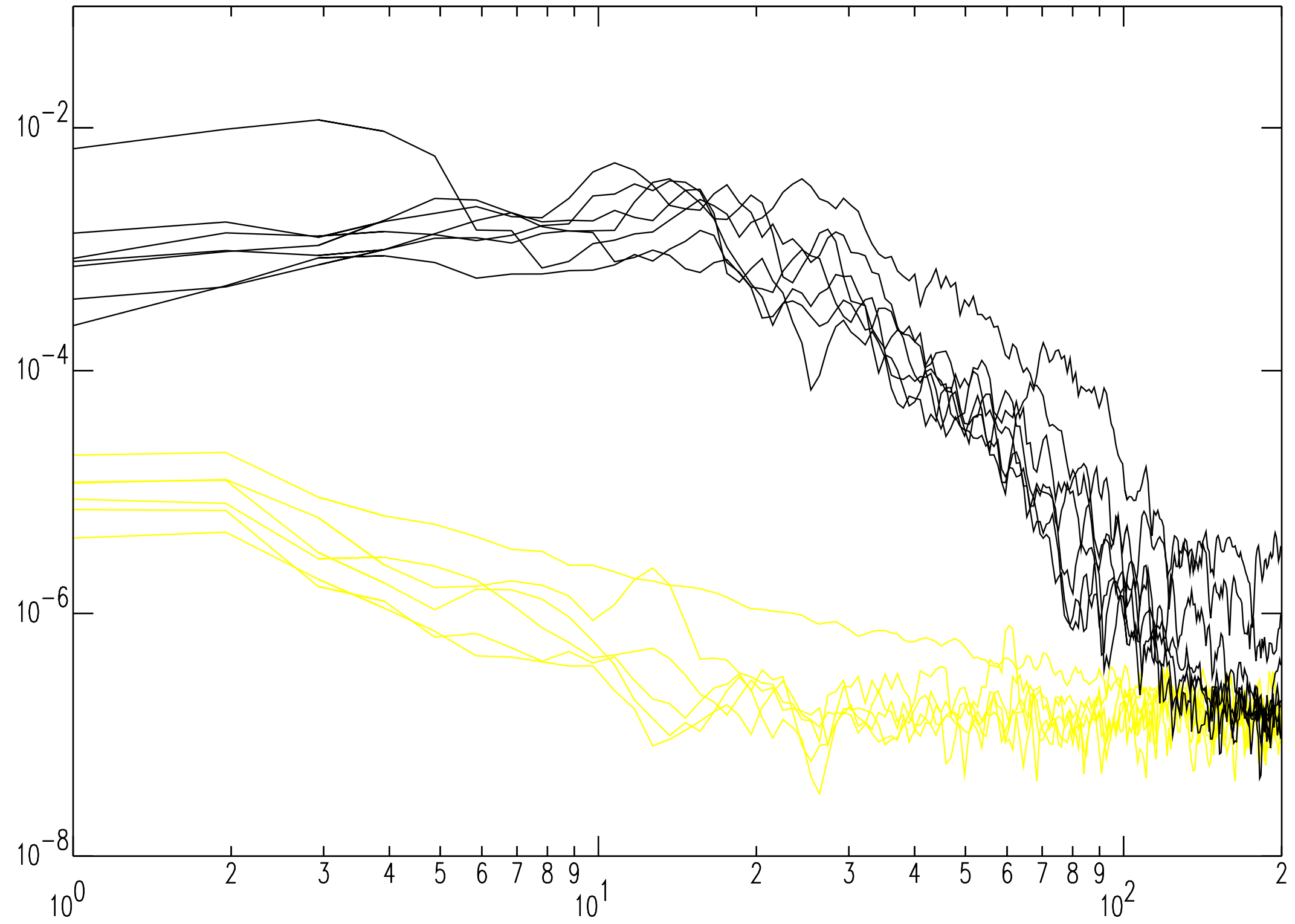


shot 1311, 50m, 92k, $r$ component, all stations

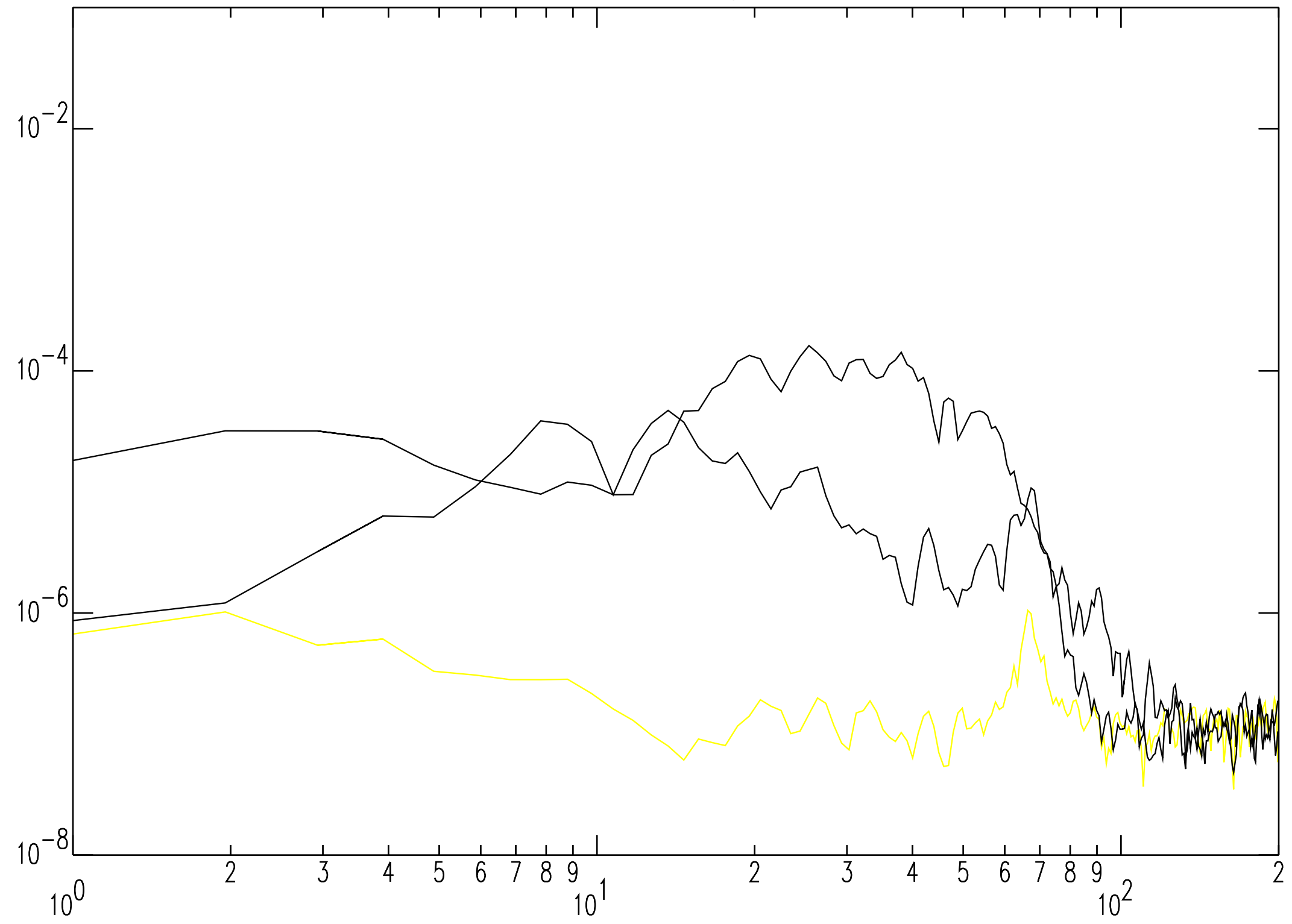


shot $1311,50 \mathrm{~m}, 92 \mathrm{k}$, t component, all stations

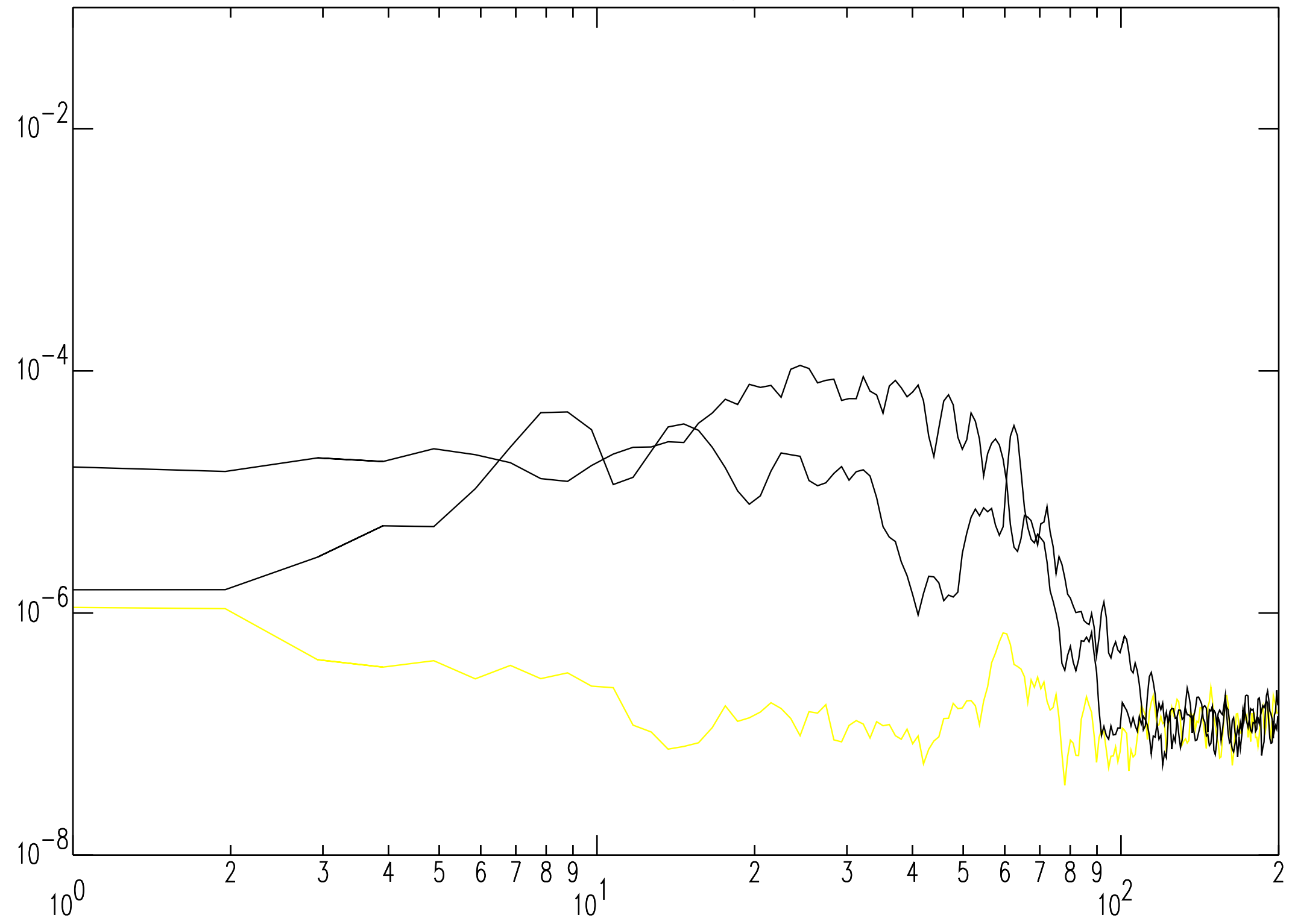


shot 1311, 50m, 92k, z component, all stations

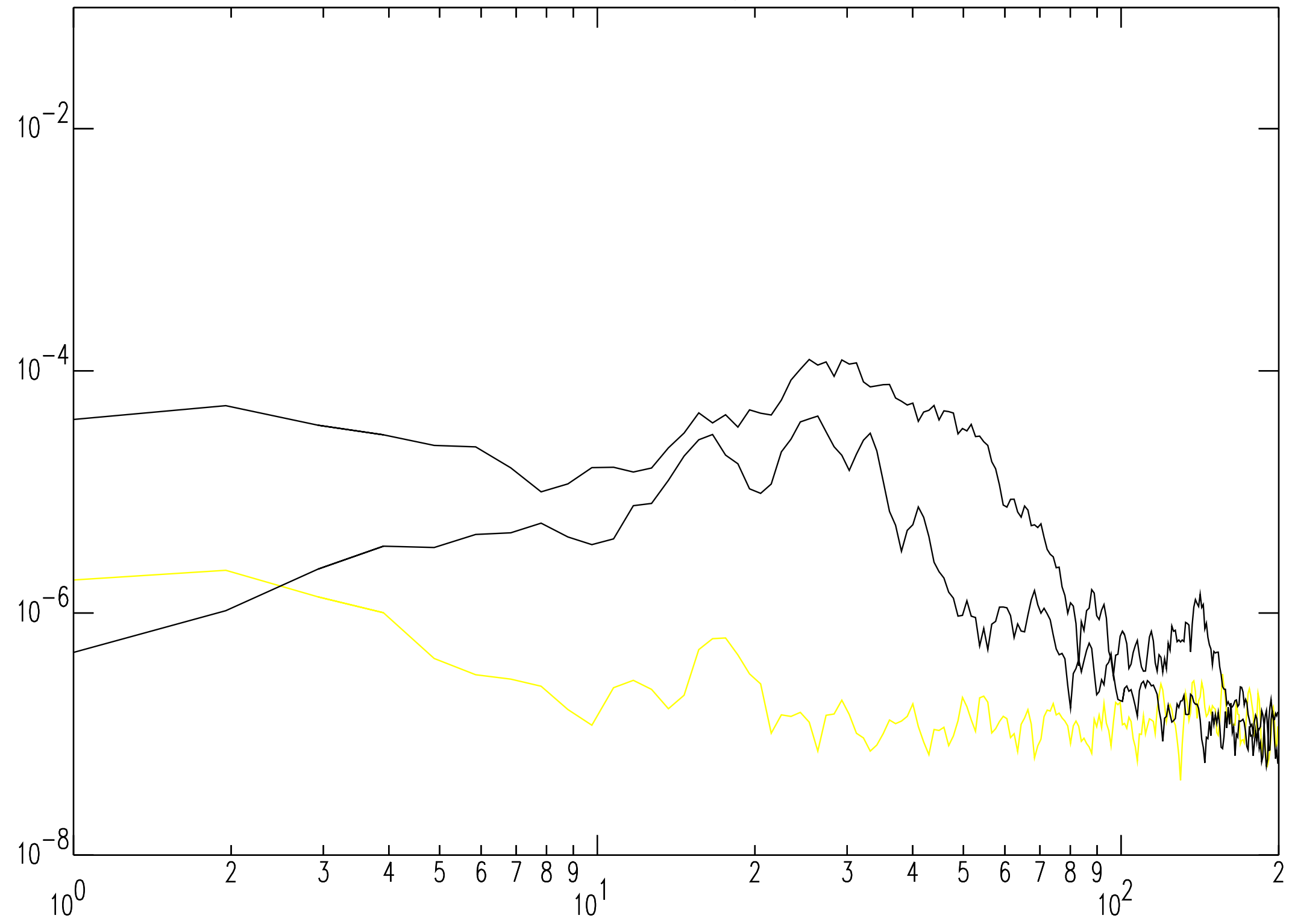


shot 1349, 550m, 25t, $r$ component, all stations

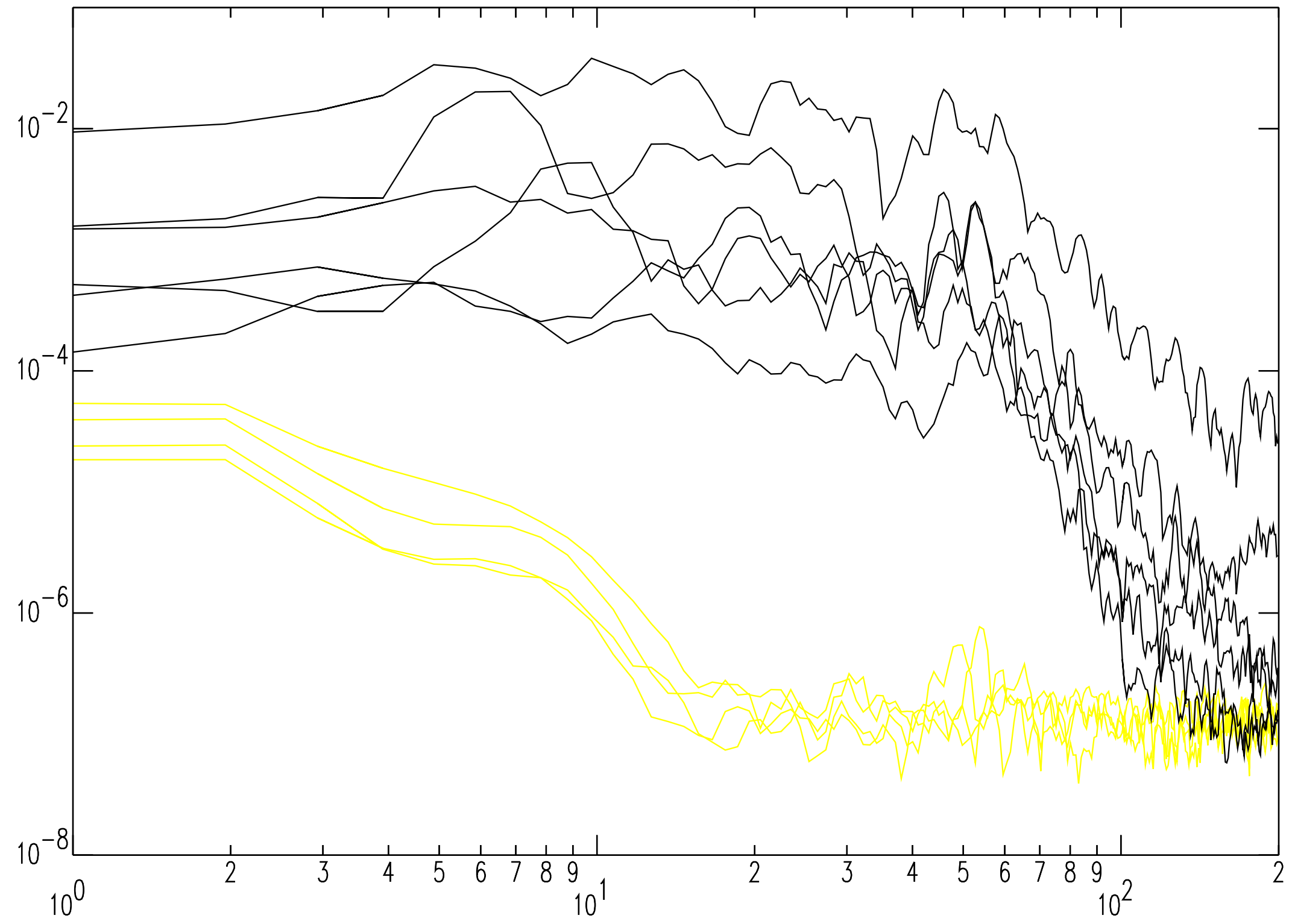


shot $1349,550 \mathrm{~m}, 25 \mathrm{t}, \mathrm{t}$ component, all stations

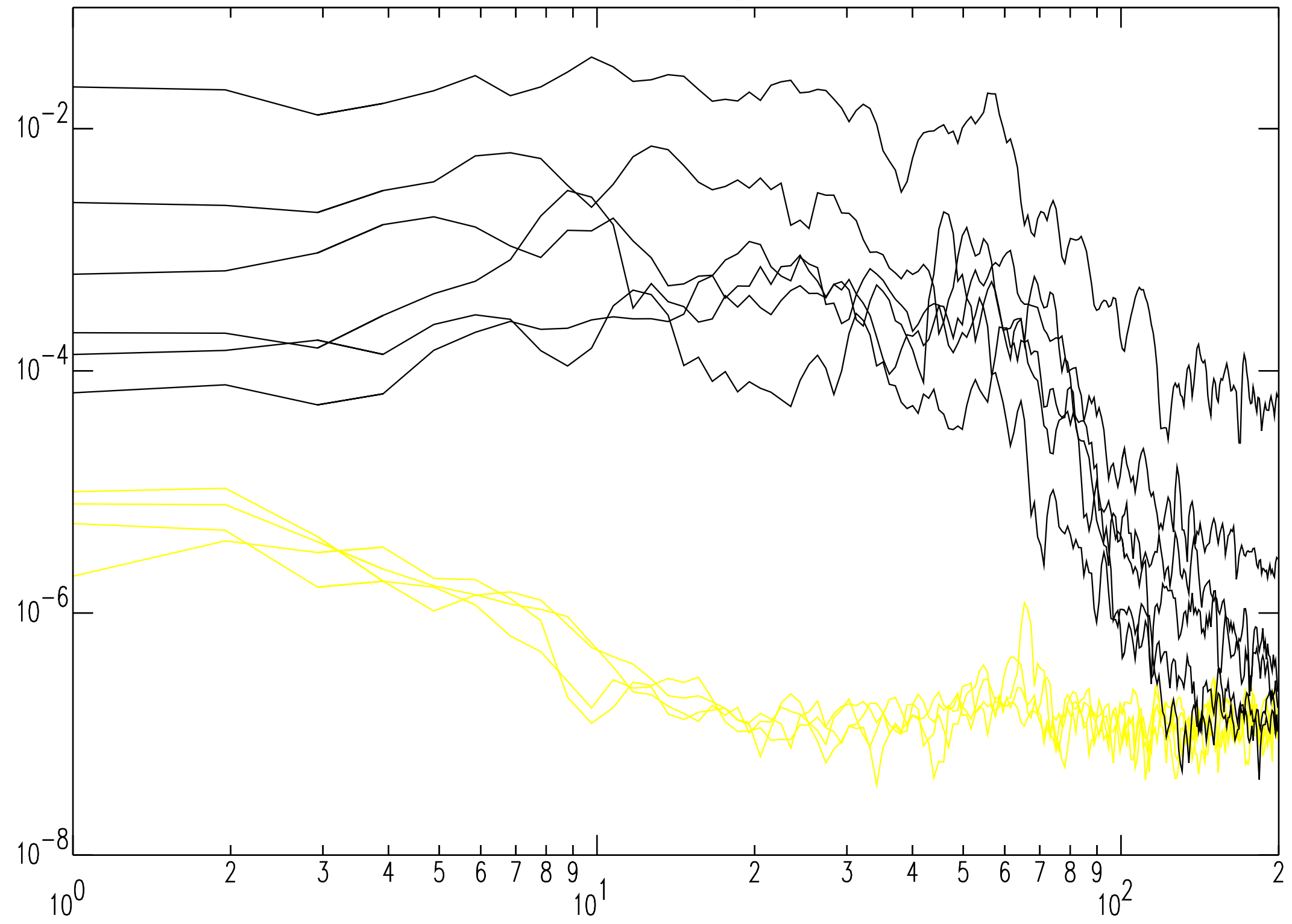


shot 1349, 550m, 25t, z component, all stations

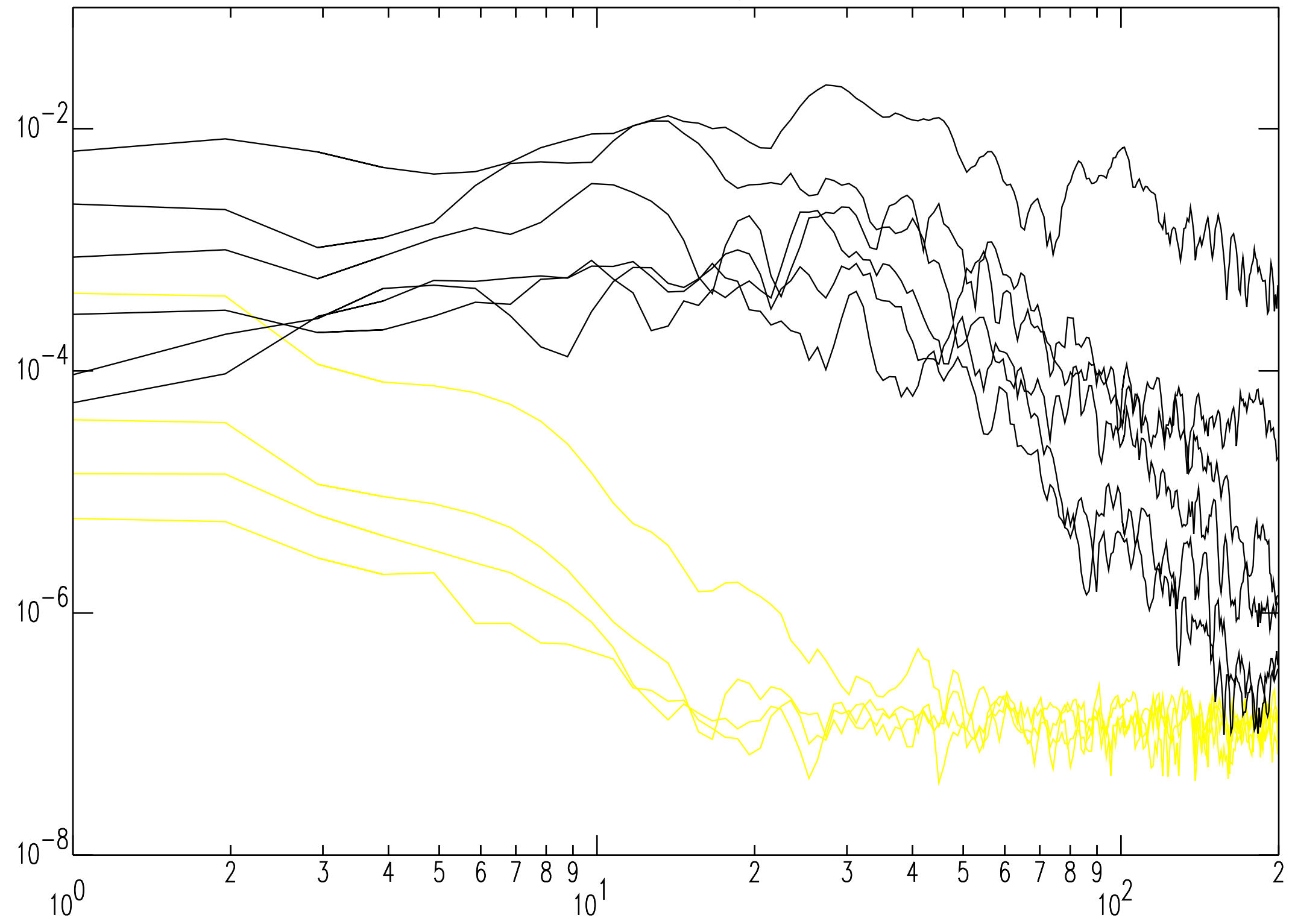


shot 1349, 585m, 106.8k, r component, all stations

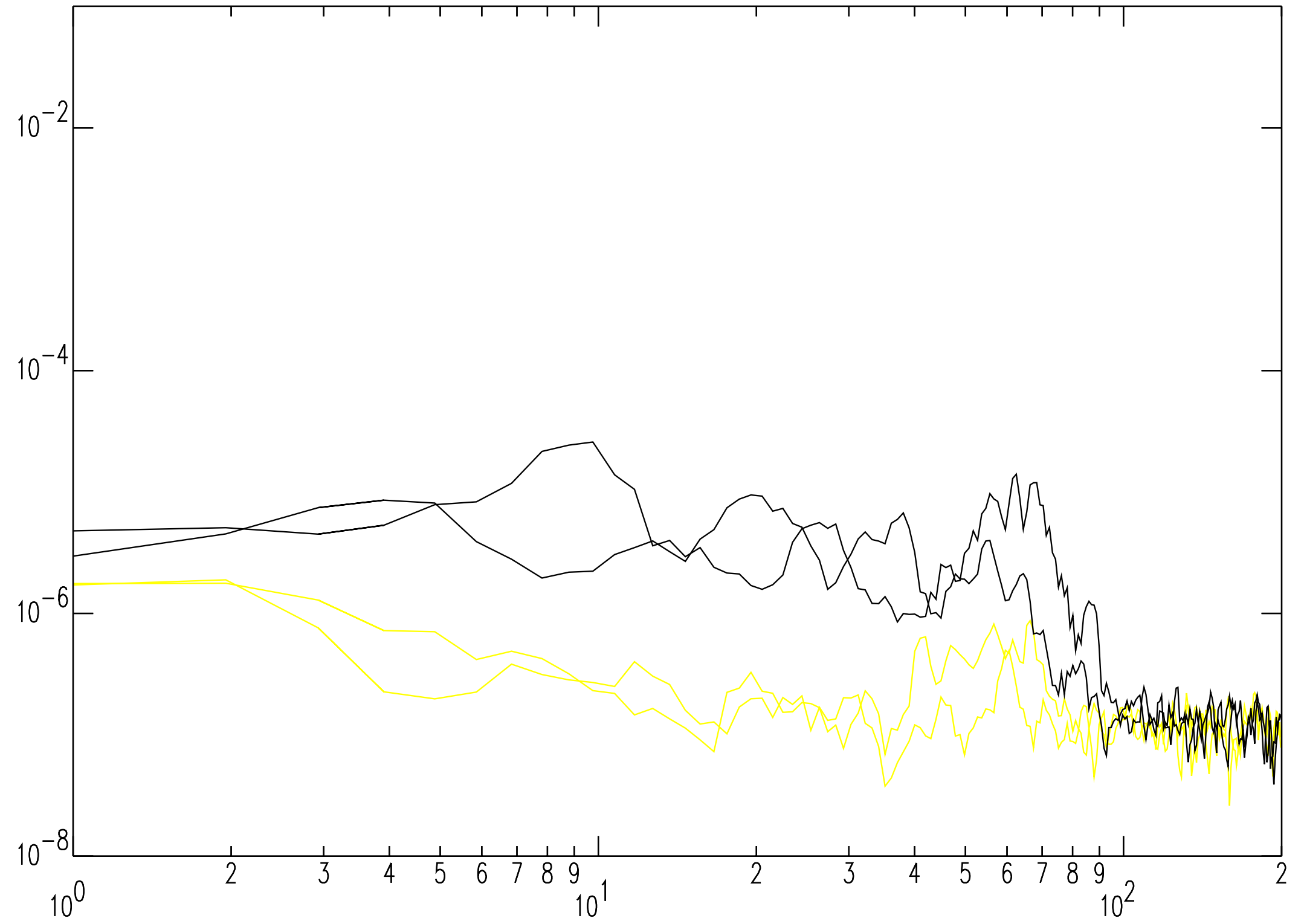


shot 1349, 585m, 106.8k, t component, all stations

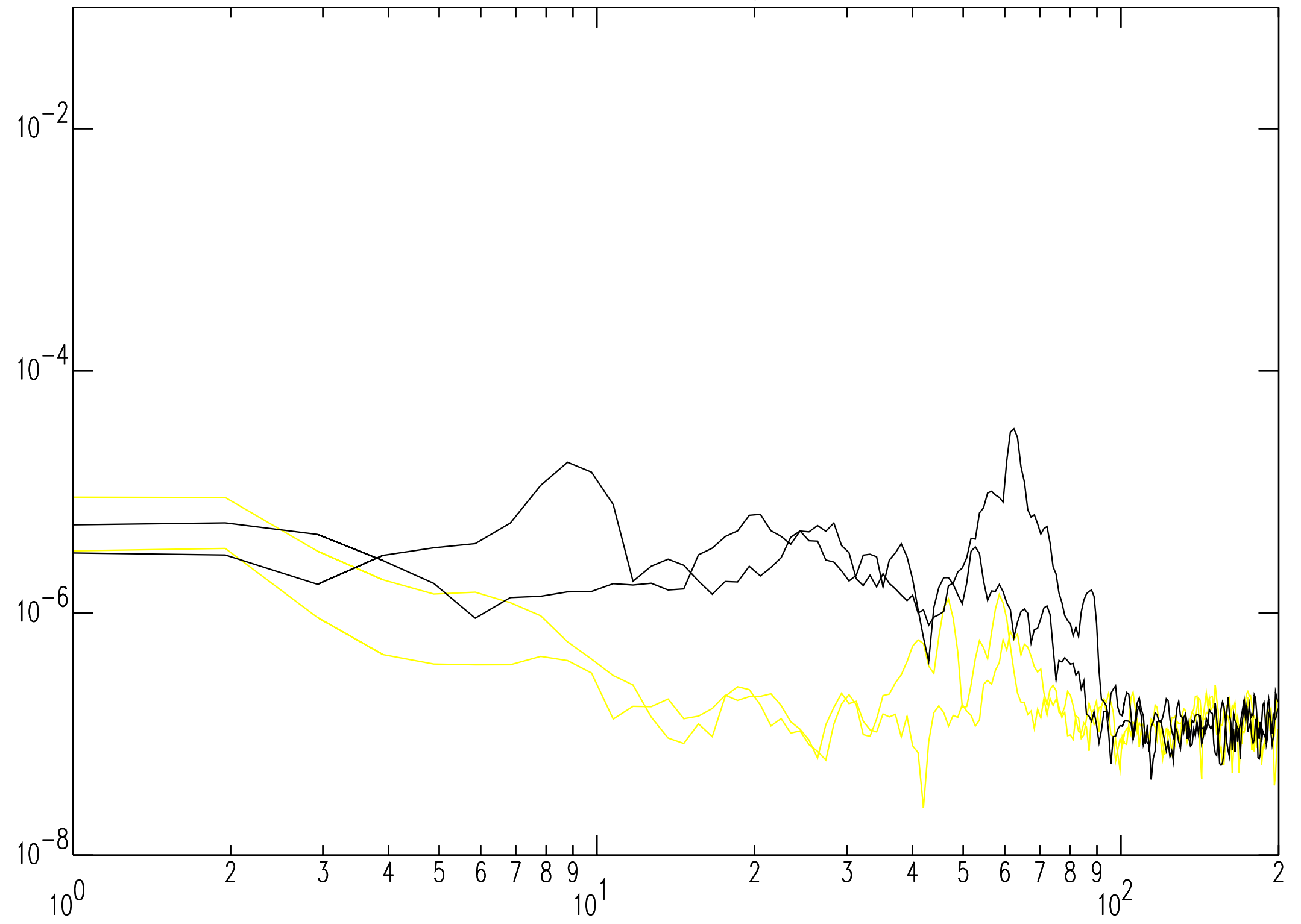


shot 1349, 585m, 106.8k, z component, all stations

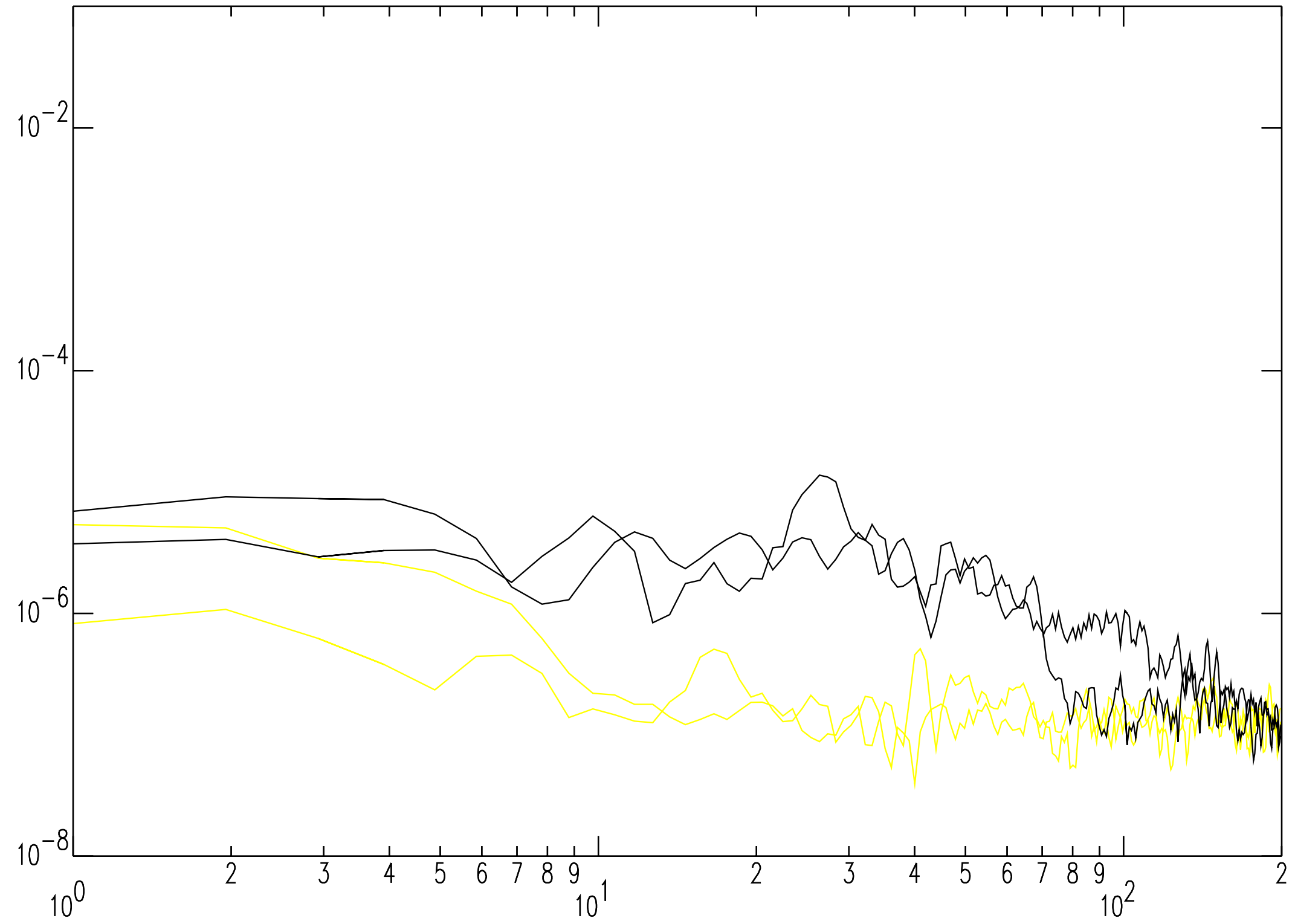


shot $1381,300 \mathrm{~m}, 25 \mathrm{t}, \mathrm{r}$ component, all stations

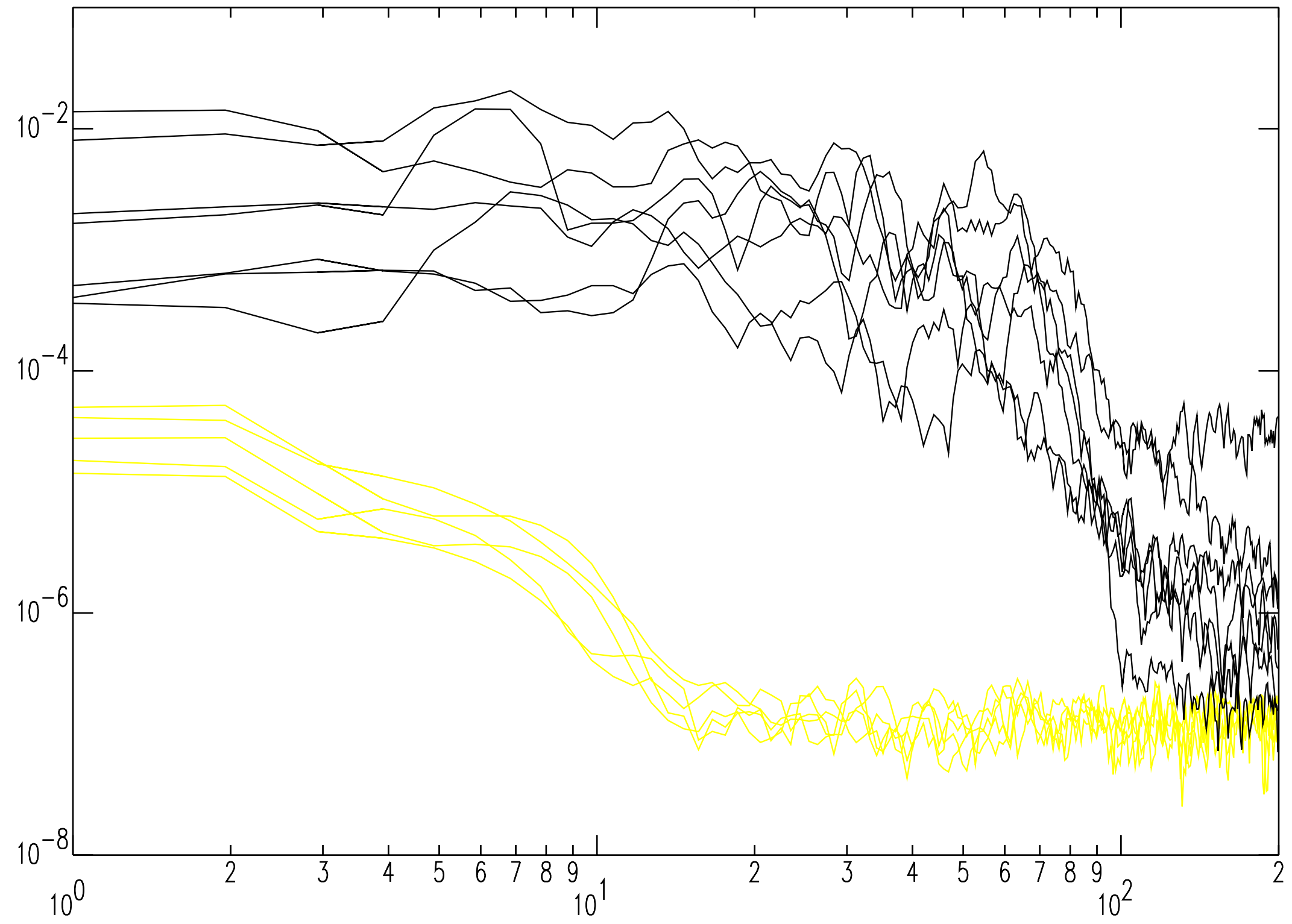


shot $1381,300 \mathrm{~m}, 25 \mathrm{t}, \mathrm{t}$ component, all stations

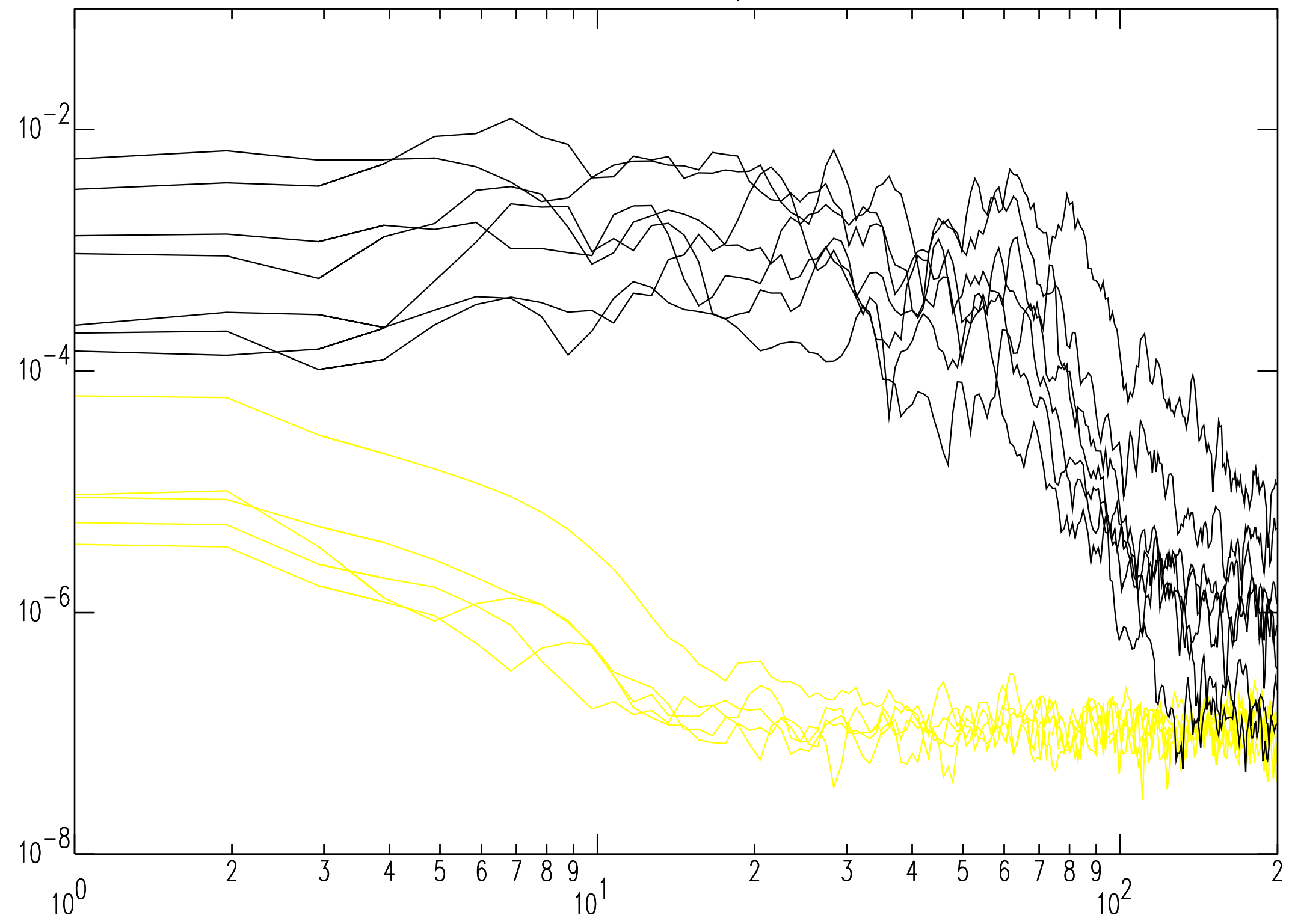


shot 1381, 300m, 25t, z component, all stations

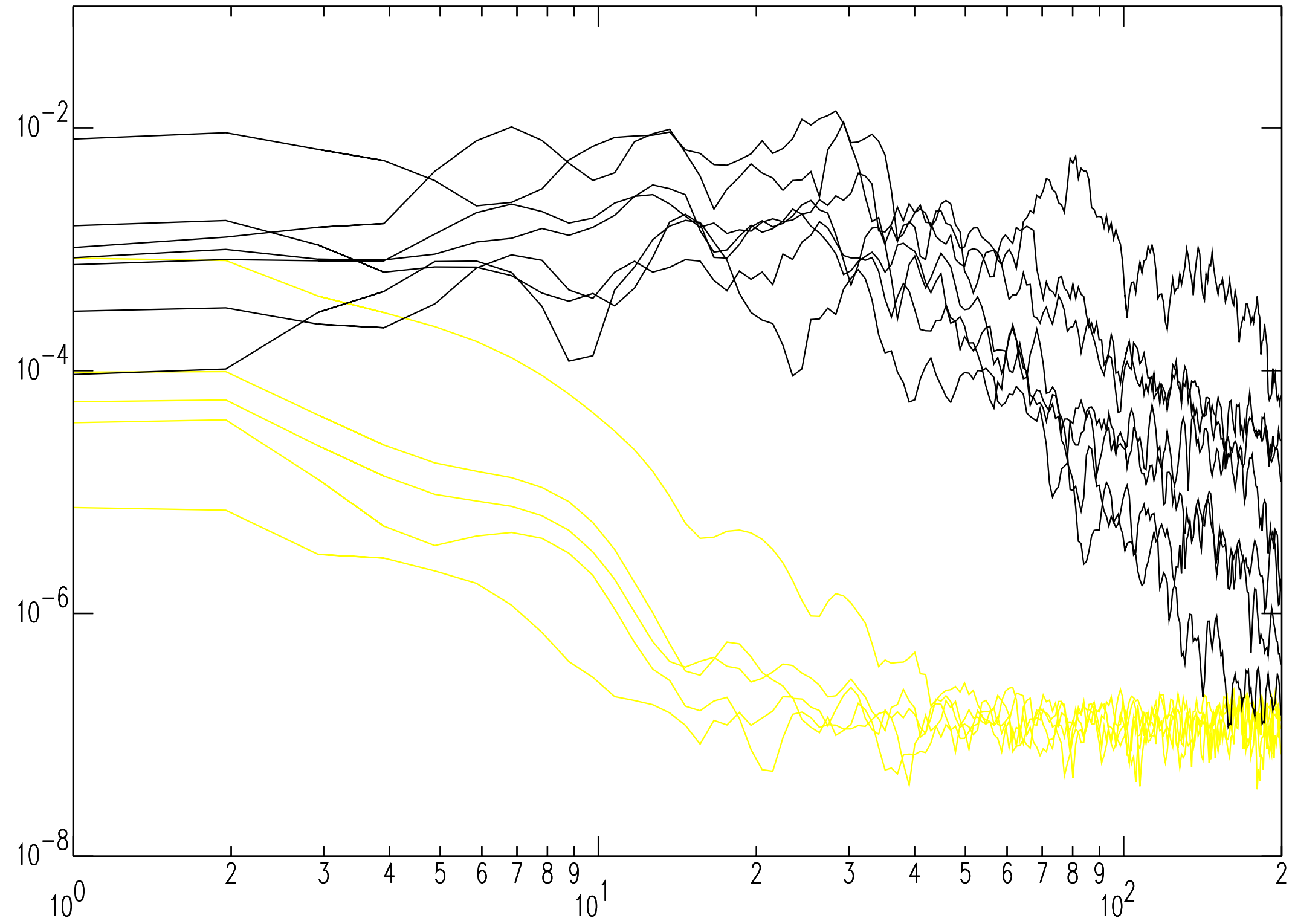


shot $1381,300 \mathrm{~m}, 50 \mathrm{k}, \mathrm{r}$ component, all stations

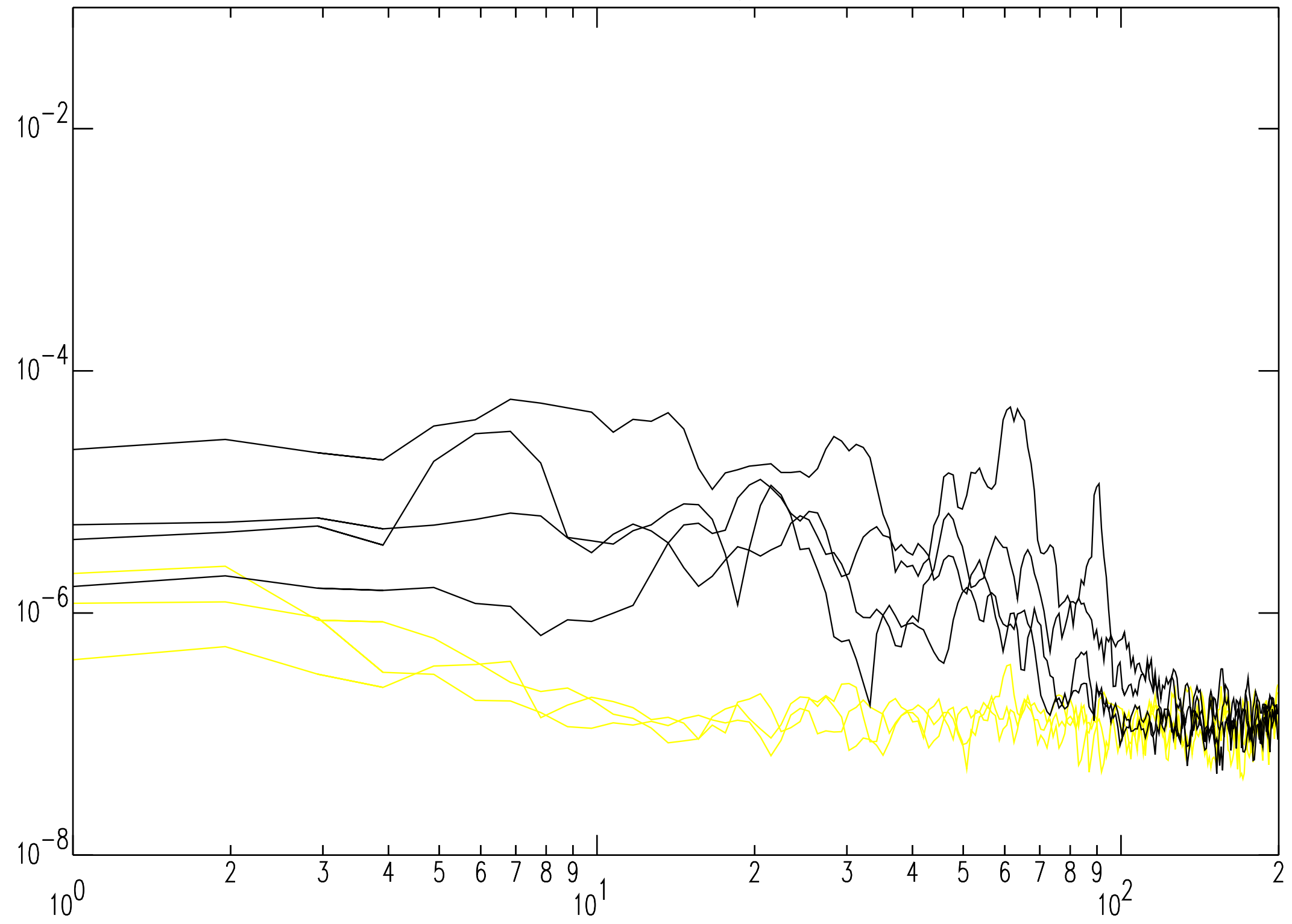


shot 1381, 300m, 50k, t component, all stations

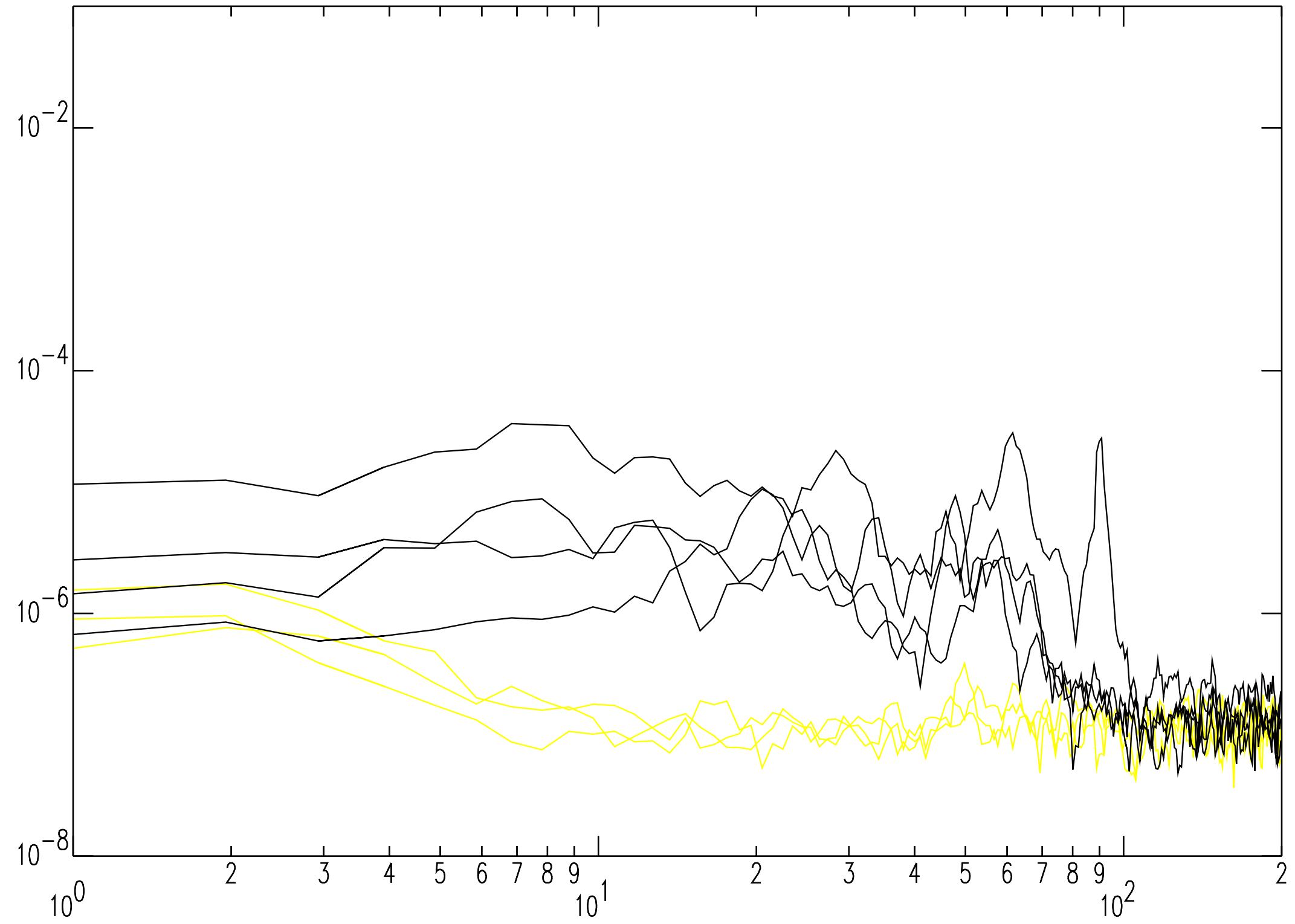


shot $1381,300 \mathrm{~m}, 50 \mathrm{k}, \mathrm{z}$ component, all stations

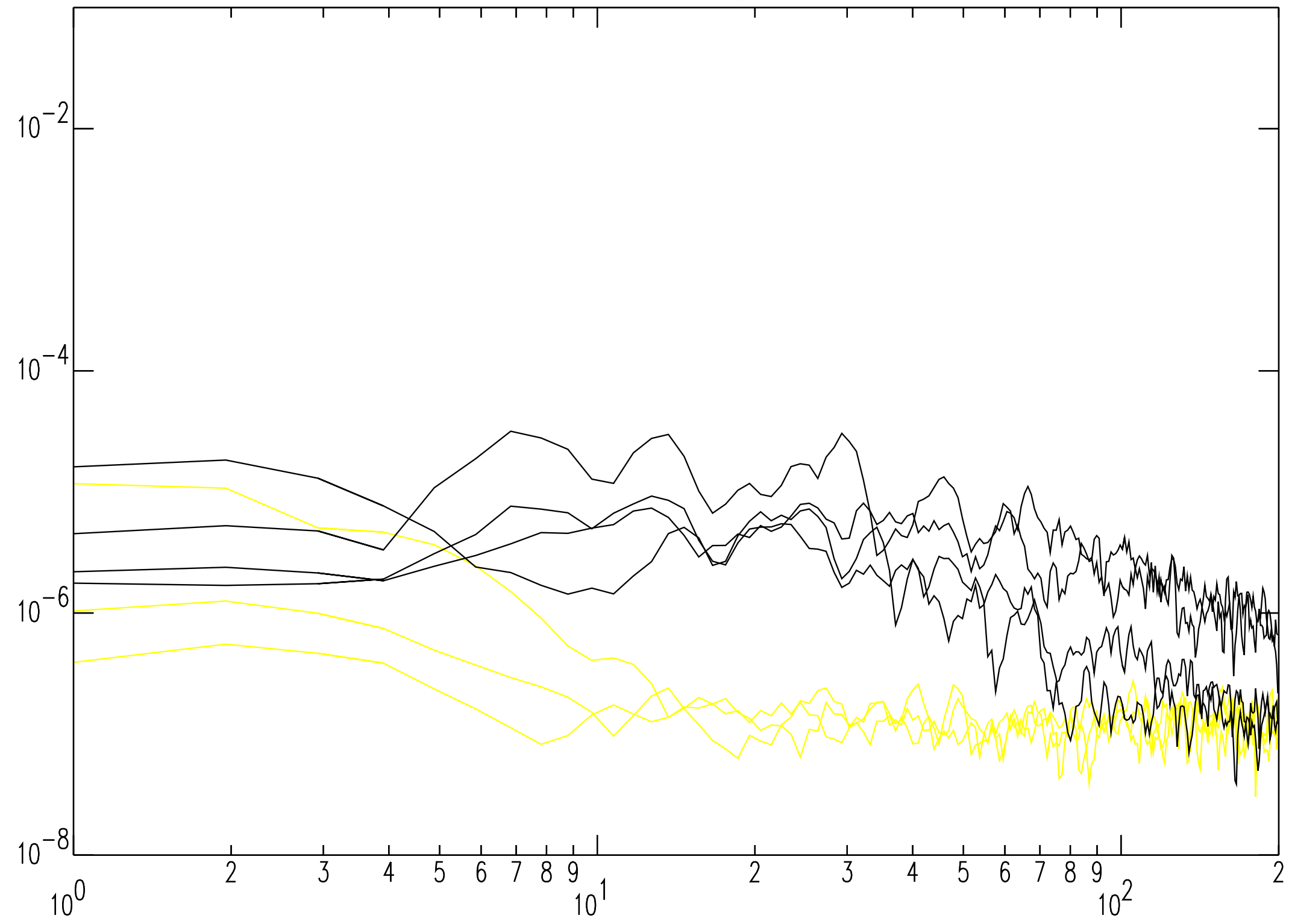


shot $1381,500 \mathrm{~m}, 50 \mathrm{k}, \mathrm{r}$ component, all stations

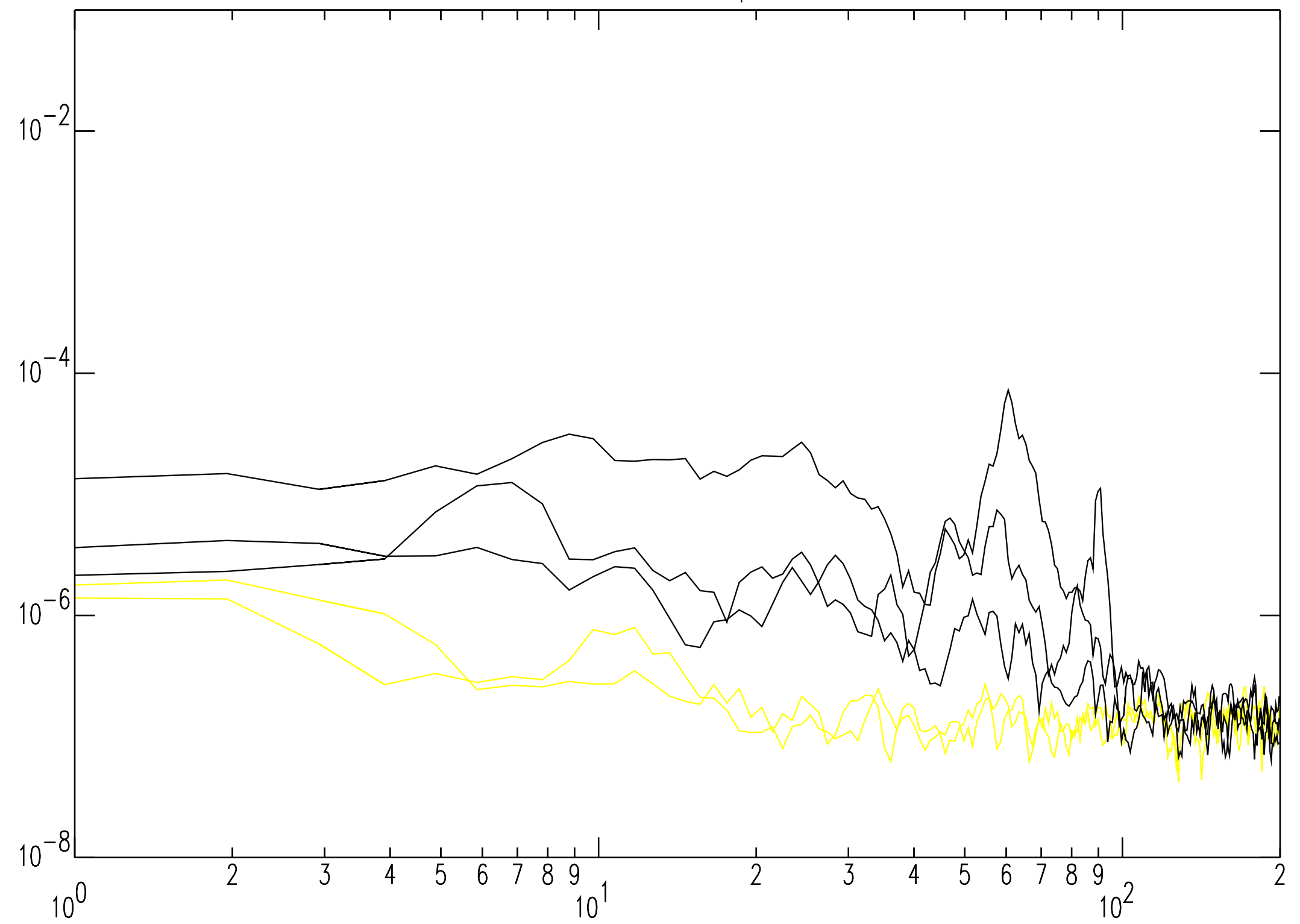


shot $1381,500 \mathrm{~m}, 50 \mathrm{k}$, t component, all stations

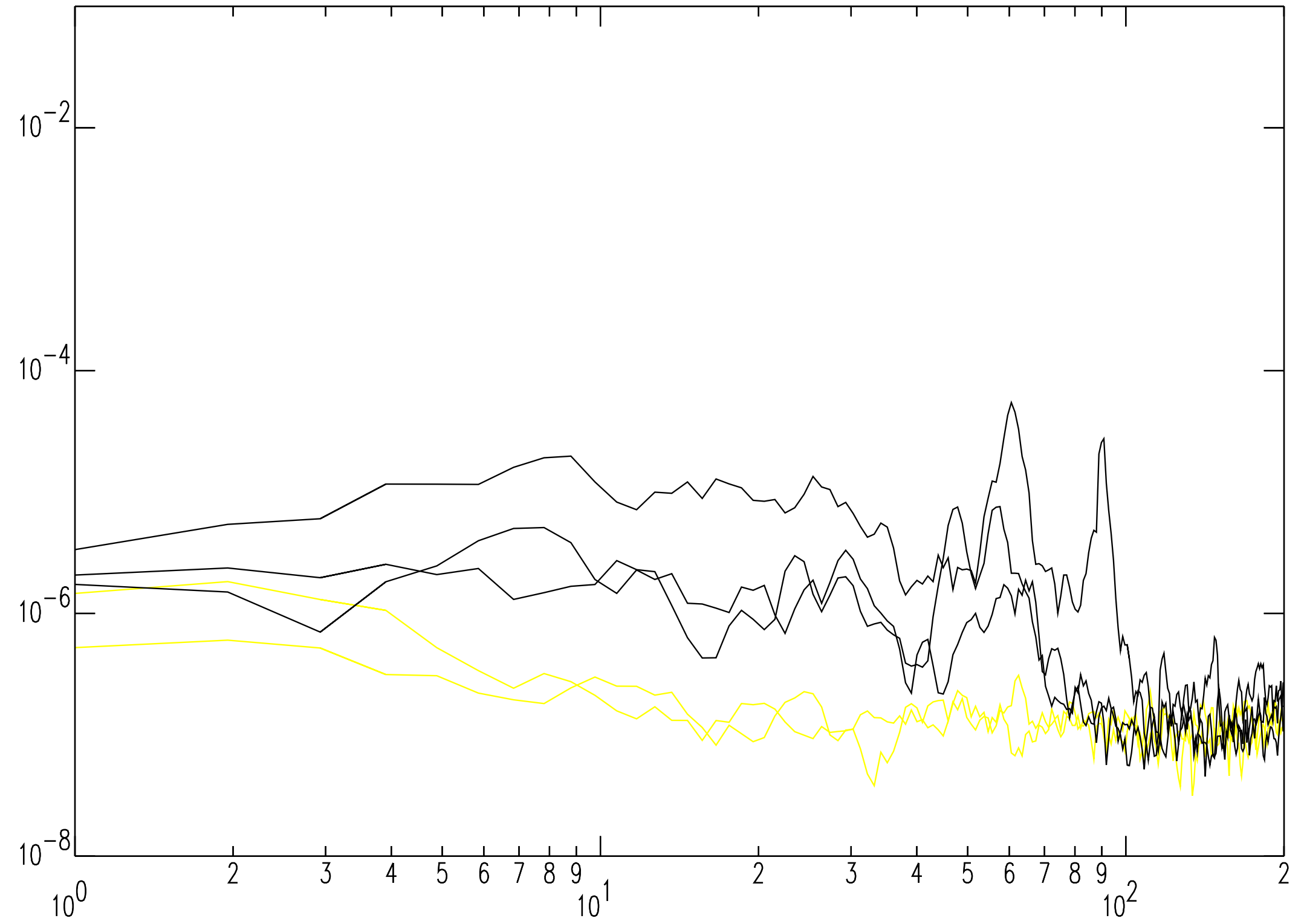


shot $1381,500 \mathrm{~m}, 50 \mathrm{k}, \mathrm{z}$ component, all stations

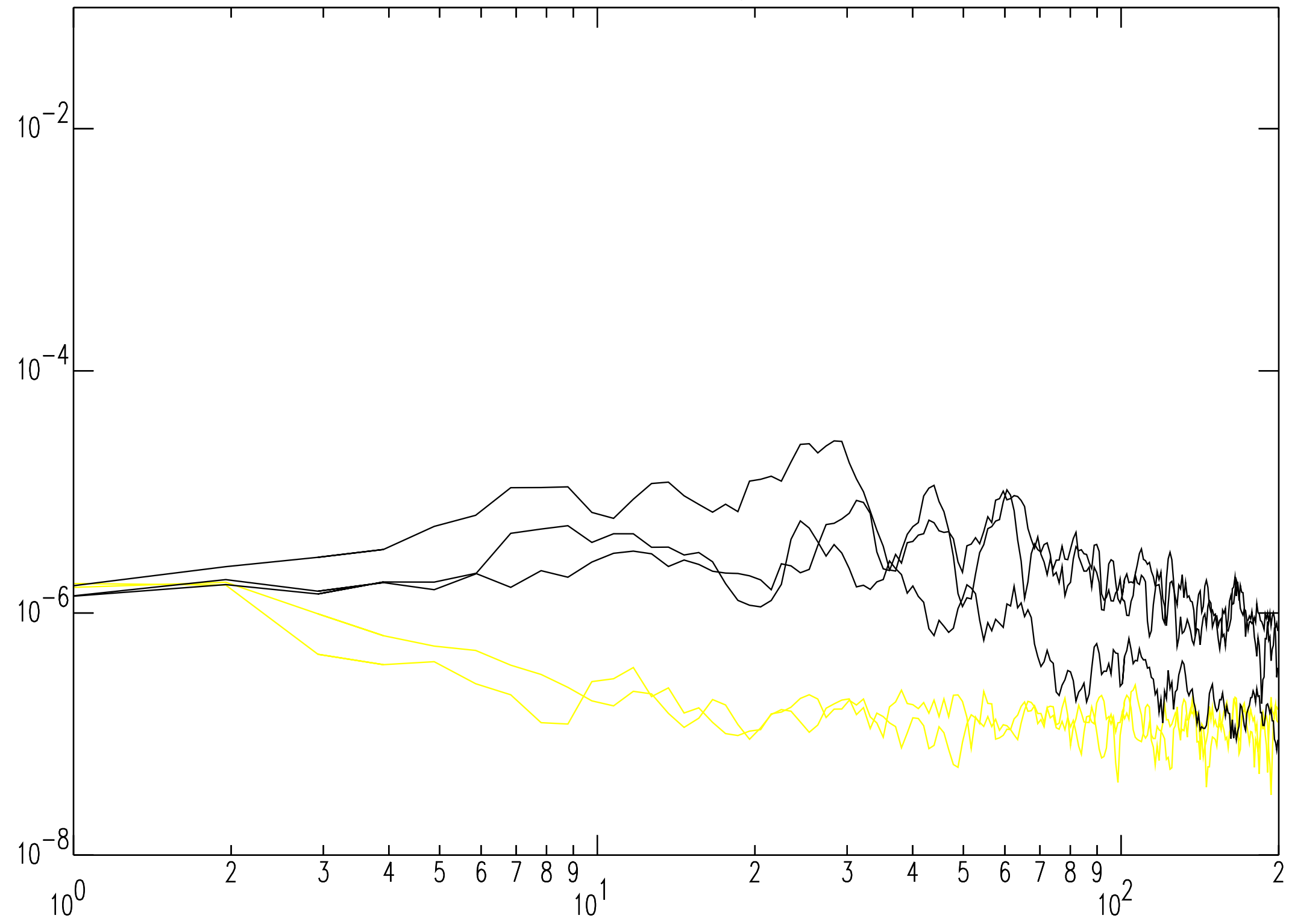


shot $1389,630 \mathrm{~m}, 5 \mathrm{t}, \mathrm{r}$ component, all stations

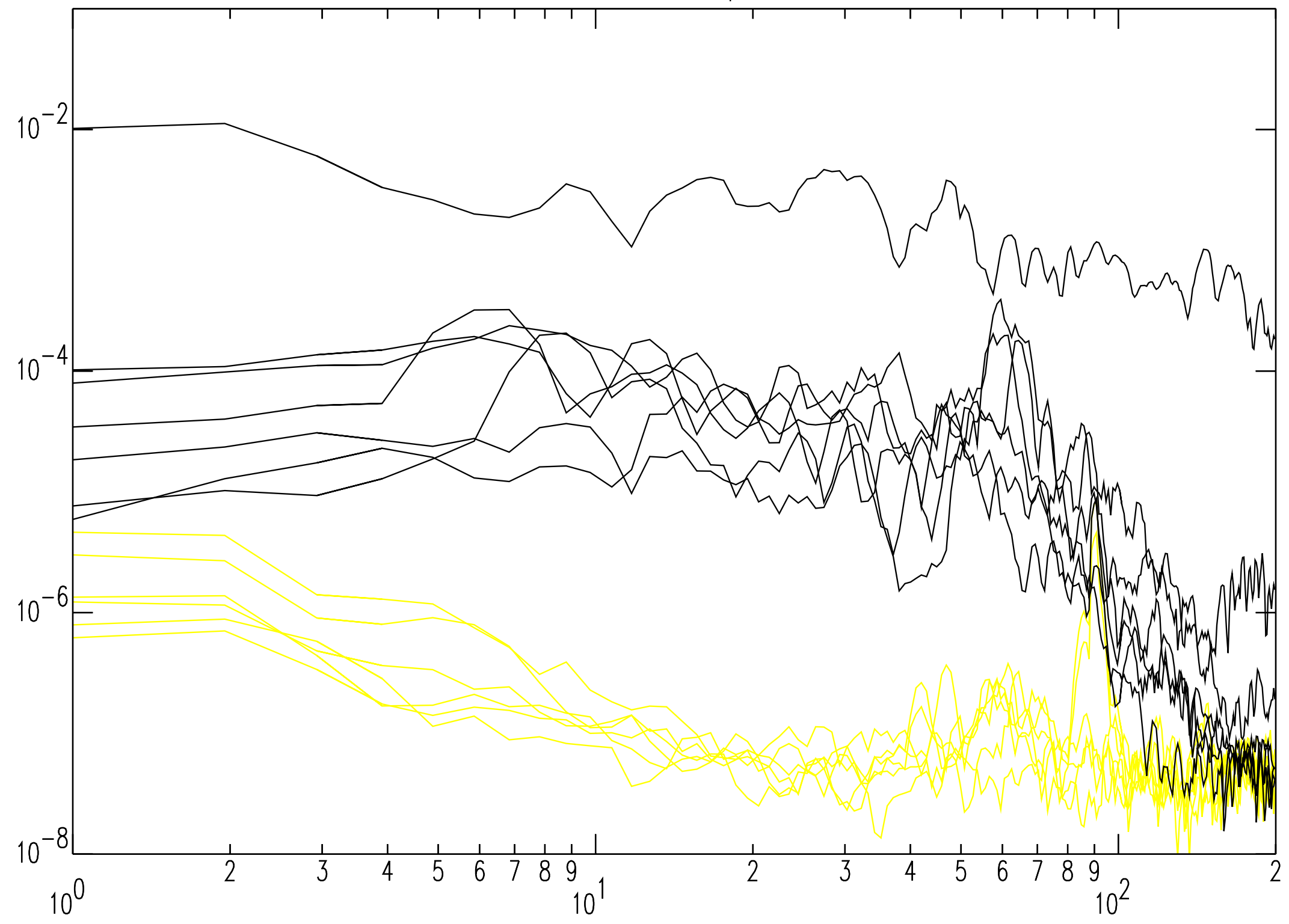


shot $1389,630 \mathrm{~m}, 5 \mathrm{t}$, t component, all stations

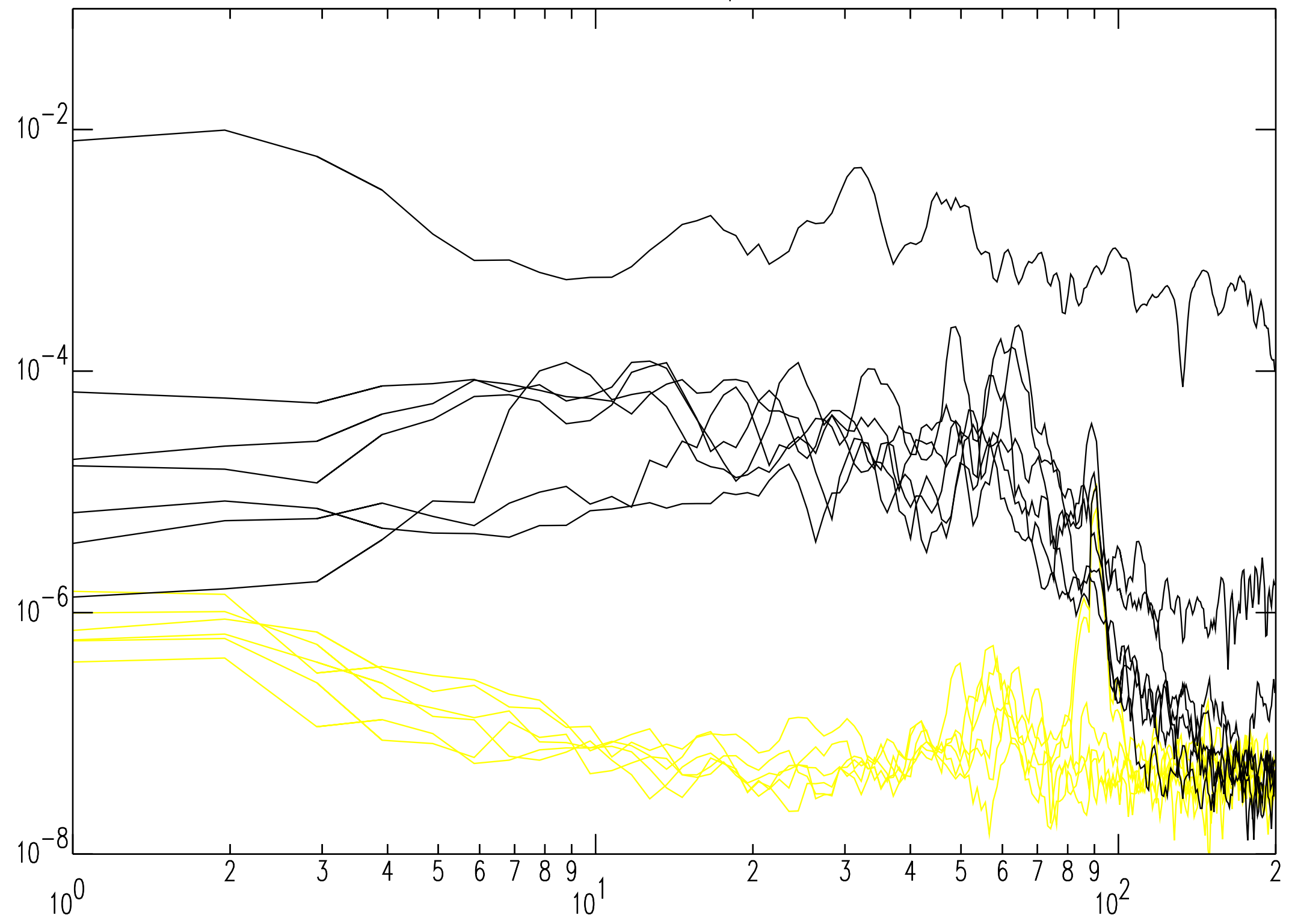


shot 1389, 630m, 5t, z component, all stations

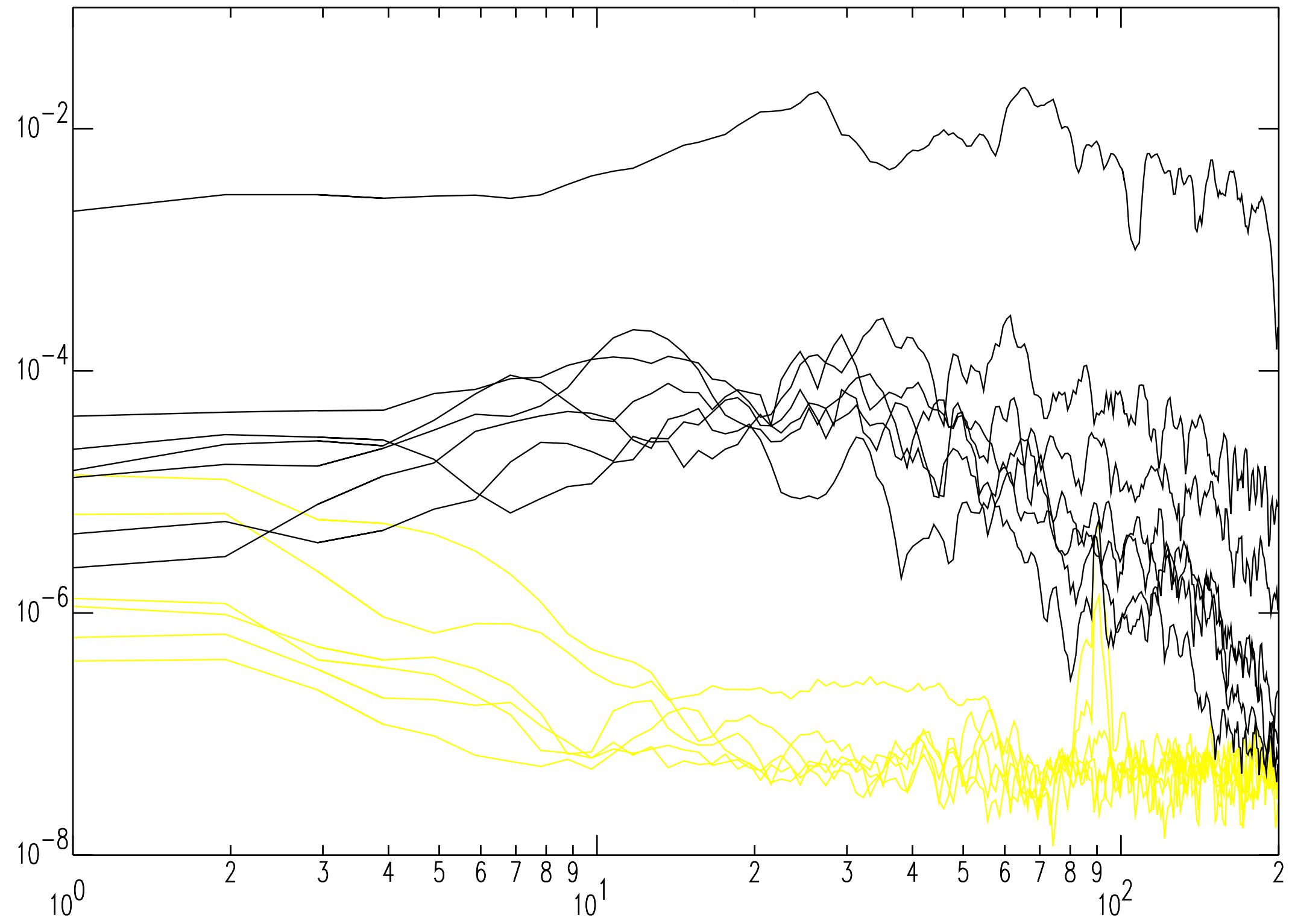




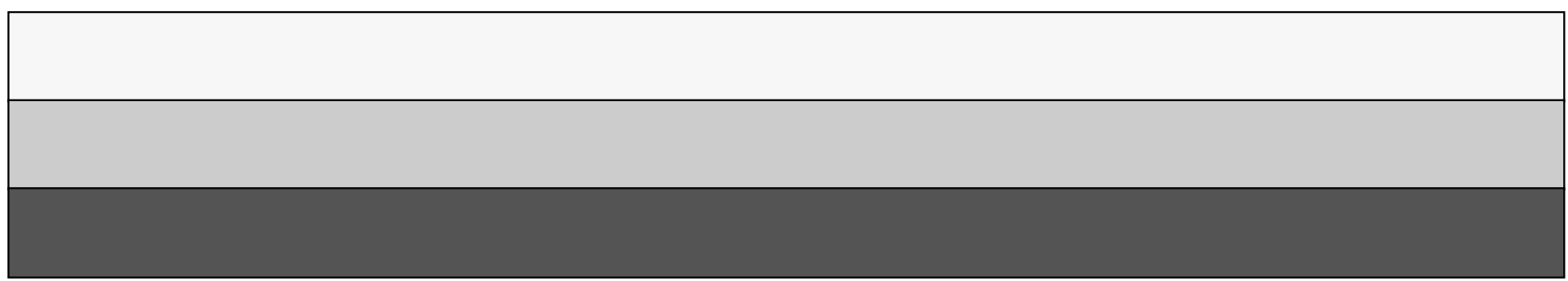

